\title{
L'industrie sur quartzite du site de Bidau à Garlin (Pyrénées-Atlantiques, France) : Acheuléen versus Moustérien?
}

The quartzite industry from the Bidau site at Garlin (Pyrénées-Atlantiques, France): Acheulean versus Mousterian?

Alexis Taylor, Mathieu Rué, Sébastien Bernard-Guelle, Paul Fernandes, Aurélie Ajas et Lorène Chesnauxe

\section{CpenEdition Journals}

Édition électronique

URL : http://journals.openedition.org/paleo/5806

DOI : $10.4000 /$ paleo.5806

ISSN : 2101-0420

Éditeur

SAMRA

Édition imprimée

Date de publication : 1 septembre 2020

Pagination : $280-318$

ISSN : $1145-3370$

Référence électronique

Alexis Taylor, Mathieu Rué, Sébastien Bernard-Guelle, Paul Fernandes, Aurélie Ajas et Lorène Chesnauxe, "L'industrie sur quartzite du site de Bidau à Garlin (Pyrénées-Atlantiques, France) Acheuléen versus Moustérien? », PALEO [En ligne], 30-2 | 2020, mis en ligne le 30 septembre 2020, consulté le 26 novembre 2020. URL : http://journals.openedition.org/paleo/5806 ; DOI : https:// doi.org/10.4000/paleo.5806

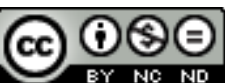

PALEO est mis à disposition selon les termes de la licence Creative Commons Attribution - Pas d'Utilisation Commerciale - Pas de Modification 4.0 International. 
L'INDUSTRIE SUR

QUARTZITE DU SITE

DE BIDAU À GARLIN

(PYRÉNÉES-ATLANTIQUES,

FRANCE):

ACHEULÉEN VERSUS

MOUSTÉRIEN?

Alexis Taylora,

Mathieu Ruéb,

Sébastien Bernard-Guellec,

Paul Fernandes,

Aurélie Ajasd,

Lorène Chesnauxe

a. Paléotime, 75 avenue J. S. Achard Picard, FR-38250 Villard-de-Lans; UMR 7055, Préhistoire et Technologie, Nanterre - alexis.taylor@paleotime.fr

b. Paléotime, 75 avenue J. S. Achard Picard, FR-38250 Villard-de-Lans; UMR 5140, Archéologie des Sociétés Méditerranéennes, Montpellier -

mathieu.rue@paleotime.fr

c. Paléotime, 75 avenue J. S. Achard Picard, FR-38250 Villard-de-Lans; UMR

7269, LAMPEA, Aix-en-Provence - sebastien.bernard-guelle@paleotime.fr

d. Paléotime, 75 avenue J. S. Achard Picard, FR-38250 Villard-de-Lans; UMR

5199, PACEA, FR-33615 Pessac - paul.fernandes@paleotime.fr et

aurelie.ajas@paleotime.fr

e. TRACES, UMR 5608 Université Toulouse Jean Jaurès, Maison de la Recherche, 5 allées Antonio Machado, FR-31058 Toulouse cedex 9 -

chesnauxlorene@yahoo.fr
Le site de Bidau à Garlin (64) a fait l'objet d'une fouille préventive sur $2700 \mathrm{~m}^{2}$ dans le cadre d'un aménagement d'une zone d'activité économique en marge d'un diffuseur autoroutier de l'A65. Le mobilier découvert s'inscrit dans une séquence pédosédimentaire semblable à celles décrites lors des opérations préventives sur le tracé de l'A65 notamment (sites de Bénazit, Duclos, Romentères, Septsos...). À Garlin, la position stratigraphique de la nappe d'objets pose question et relance la problématique de l'attribution chronologique des séries dites acheuléennes. La nappe de mobilier s'insère en effet en grande majorité dans l'horizon BT1 développé aux dépens des limons loessiques datés du Pléistocène supérieur, aux environs de 0,80 $\mathrm{m}$ de profondeur et ce jusqu'à parfois 1,4 $\mathrm{m}$, sans organisation sédimentaire interne, selon une pente générale d'environ $1 \%$. La pédostratigraphie et les datations OSL permettent de situer la période de formation de cet épandage lithique entre le MIS5 et le MIS3. Le mobilier recueilli est quasi-exclusivement confectionné sur galets de quartzite. Il est marqué par la prédominance des chaînes opératoires de débitage sur celles de façonnage qui sont attestées par quelques hachereaux, bifaces et galets aménagés. Le débitage est majoritairement de type Discoïde unifacial ou bifacial partiel. On note également la forte présence de nucléus débités frontalement sur enclume. L'outillage est rare, peu diversifié pour l'outillage retouché (denticulés, racloirs...), la part de l'outillage lourd et/ou façonné y est relativement importante (galets aménagés, grands éclats tranchants, bifaces, hachereaux...). Les témoins de débitage en silex sont extrêmement rares. La série présente donc des caractères technologiques et typologiques évoquant une phase récente de l'Acheuléen pyrénéo-garonnais. Toutefois, son insertion chronostratigraphique apparaît incompatible avec cette attribution chronoculturelle. En effet, au vu des résultats de l'étude taphonomique, il faut envisager que la série lithique se rattache à un technocomplexe moustérien daté du Pléistocène récent mais dont les principales caractéristiques peuvent relever d'un déterminisme pétrographique et/ou fonctionnel.

PALEO 30 | t. 2

JUILLET 2019

PAGES 280 À 318

MOTS-CLÉS Géoarchéologie, datation OSL, taphonomie lithique, Acheuléen, Moustérien, Pléistocène supérieur, quartzites. 
The quartzite industry from the Bidau site at Garlin (Pyrénées-Atlantiques, France): Acheulean versus Mousterian?

Archaeological survey excavations were made at Bidau (Garlin, 64, France), prior to the construction of an economic activity area located on the A65 motorway exit. Quartzite artifacts were discovered within a sedimentary sequence similar to those described on other A65 survey excavations (Bénazit, Duclos, Romentères, and Septsos sites among others...). At Garlin, the archaeological layer's stratigraphic position raises questions and revives discussions on so-called Acheulean artifacts' cultural attribution. Indeed, the artifacts are mostly comprised in the BT1 horizon developed on loessial silts dated to the Upper Pleistocene, about 0,8 to $1,4 \mathrm{~m}$ deep, without internal sedimentary organization, on a slight slope (around 1\%). Pedostratigraphy and OSL datations place this archaeological layer's formation between MIS5 and MIS3. The collected objects are mostly made from quartzite pebbles. Blank production sequences clearly dominate tool-shaping sequences documented by a small number of hachereaux, bifaces and pebble tools. Debitage is mostly from the Discoid type, unifacial or partially bifacial. Many cores have also been reduced using the anvil technique, following a frontal and unipolar progression. Tools are scarce, poorly diversified when retouched (denticulates, scrapers...), the part of heavy or shaped tools being important (pebble tools, big cutting flakes, bifaces, hachereaux...). Flint artifacts are extremely rare. The collection thus presents technological and typological features pointing towards a recent stage of the PyreneoGaronnais Acheulean culture. However, the archaeological layer's chronostratigraphic position cannot support this particular cultural attribution. Indeed, according to the results of the taphonomic study, an attribution to the Upper Pleistocene Mousterian complex should be considered, the collection's main features being related to a petrographic and/or functional determinism.

\section{INTRODUCTION}

L'objet de cet article est de présenter les principaux résultats issus de la fouille préventive du site de Bidau à Garlin (Taylor et al. 2017) et d'alimenter le débat sur l'attribution chronologique et culturelle des séries lithiques sur quartzite du Sud-Ouest de la France. En effet, en l'absence d'éléments diagnostics et sur la base des assemblages et des divers composantes typotechnologiques des séries lithiques, la caractérisation chronoculturelle des industries des périodes anciennes du Paléolithique pose fréquemment problème, surtout lorsque le contexte taphonomique n'est pas favorable ou complexe. C'est le cas des industries sur quartz et quartzite du piedmont pyrénéen, rattachées au Paléolithique moyen ancien ou à l'Acheuléen, que certains n'hésitent pas à qualifier de taphofaciès (Bertran et al. 2012). L'exercice est d'autant plus délicat sur les sites qui attestent d'une utilisation prépondérante des roches tenaces (quartzites et quartz). Comme déjà signalé pour les gisements garonnais (e.g. Jarry et Lelouvier 2014), les contraintes de ces matériaux (dureté, modules...), certes globalement de bonne qualité, peuvent entrainer des convergences techniques rendant parfois bien difficile l'interprétation chronoculturelle. Le site de Bidau s'insère pleinement dans cette problématique et apporte son lot de questionnements supplémentaires.

\section{1 | PRÉSENTATION GÉNÉRALE}

\section{1 | Contexte géographique et archéologique}

Le gisement est localisé sur la commune de Garlin (Pyrénées Atlantiques), sur la nappe alluviale Fv de la vallée du Lées, d'âge Pléistocène inférieur (Alimen 1964). L'évaluation archéologique a concerné la zone amont d'un petit bassin versant évoluant vers le ruisseau de Lagrave, affluent du Bahus qui comme le Lées rejoint au nord l'Adour (fig. 1). Le site occupe la partie orientale de ce bassin, sur une surface estimée à environ 4 ha. L'emprise de fouille, localisée dans un secteur à plus forte densité de mobilier, à proximité immédiate du sommet du versant, représente à peine 10 \% de la superficie estimée du site. La fouille archéologique s'est focalisée sur l'emprise d'un bassin de rétention d'eau', sur une superficie d'environ $2700 \mathrm{~m}^{2}$.

Le diagnostic de l'emprise du projet a mis en évidence des vestiges d'industrie lithique sur galets de quartzite attribués à l'Acheuléen de type pyrénéo-garonnais (Chopin et al. 2015), qui s'inscrivent dans une séquence pédosédimentaire semblable à celles décrites lors des opérations préventives menées précédemment dans le bassin de l'Adour : sites de Bénazit, Duclos, Romentères, Septsos sur le tracé de l'A65 (fig. 1, Defaye et al. 2009a ; Chopin et al. 2010 ; Bertran et al. 2011; Colonge et al. 2012; Hernandez et al. 2012 ; Fourloubey et al. 2013 ; Lelouvier et al. 2013), sites du Prissé et du Chemin de Jupiter à Bayonne,

[1] La fouille a été réalisée à l'initiative de la Société d'Equipement des Pays de l'Adour, dans le cadre du projet de création d'une zone d'activité économique intercommunautaire (ZAEI) dite « Parc d'activités du Nord Béarn », en marge du diffuseur autoroutier A65 PauLangon 


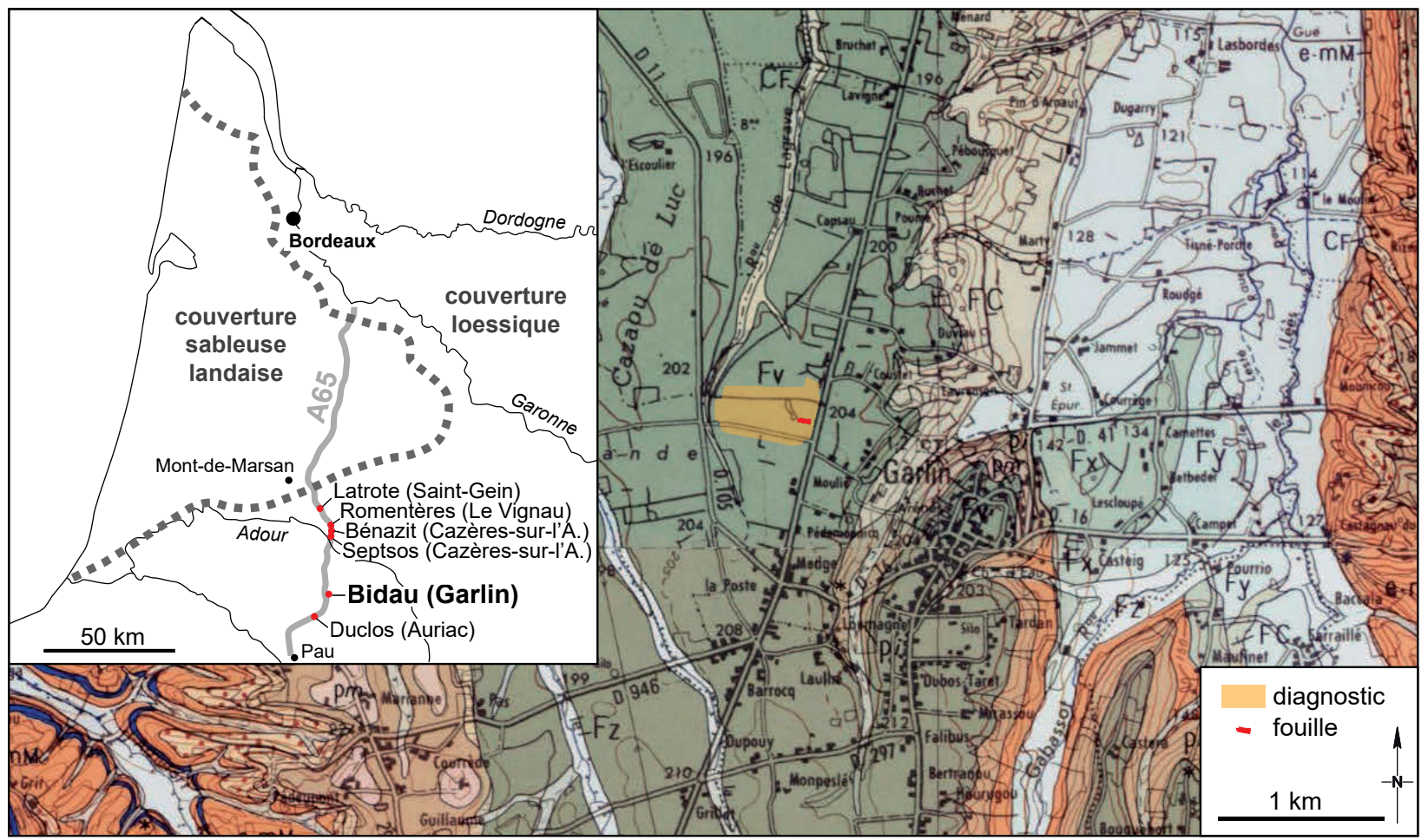

a

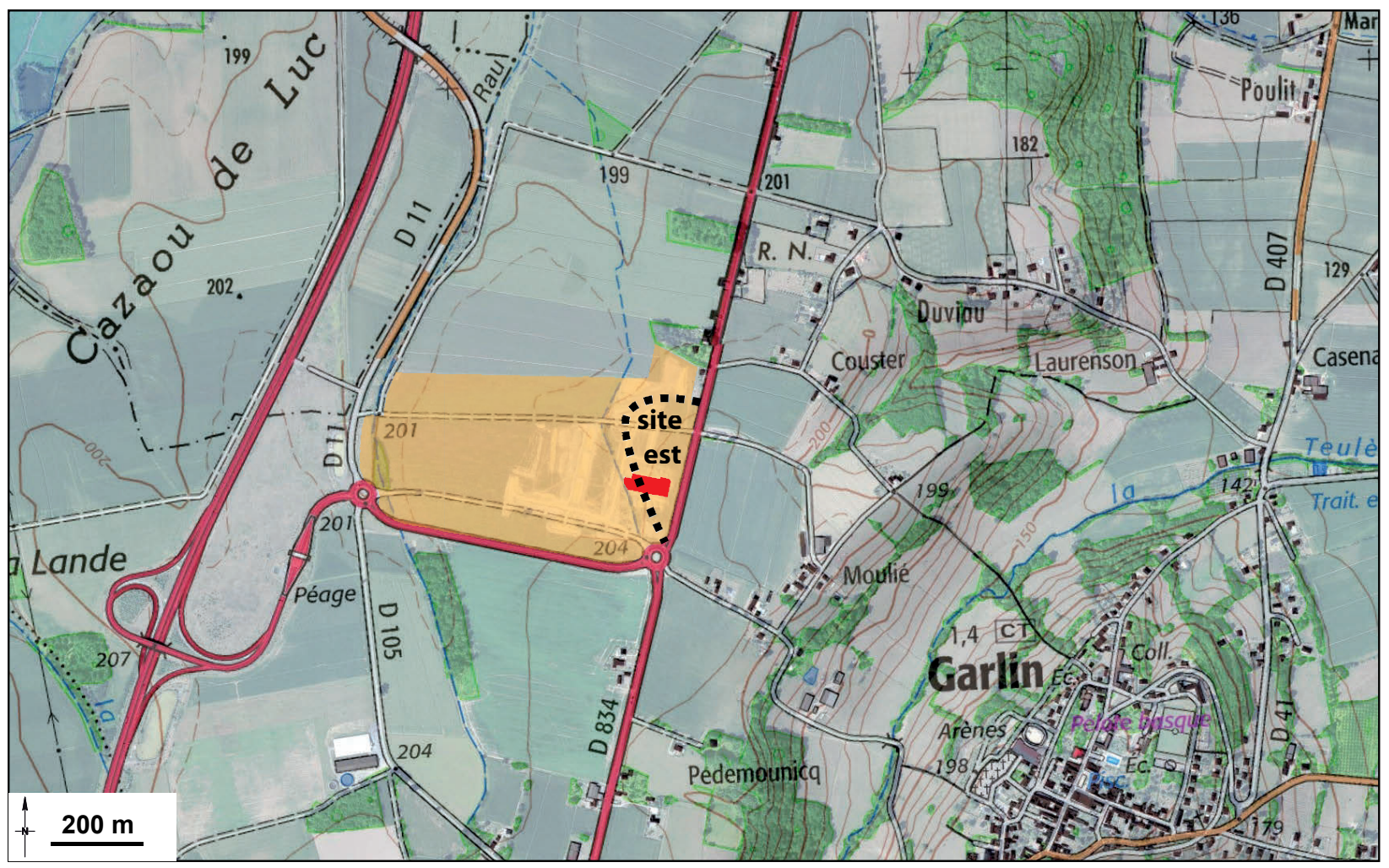

b

\section{- FIGURE 1 -}

Localisation du site (M. Rué). a: Plan d'après Bertran et al. 2011. Cartes géologiques à 1/50000 d'après Capdeville et al. 1998 (nord) et Karnay et al. 1998 (sud). Nappes alluviales : Fv : Pléistocène inférieur (+20-30 m), Fx : Pléistocène moyen récent (+10 m), Fy : Pléistocène supérieur (+5 m), Fz : Holocène. Colluvions : FC, CF. En orangé, les dépôts détritiques tertiaires. b : Carte topographique à 1/25000 superposée à la vue aérienne de 2015 (Géoportail, IGN). En jaune la surface diagnostiquée (25 ha), en rouge l'emprise de fouille. Le trait pointillé noir localise la limite occidentale du site principal découvert en 2014 (Chopin et al. 2015).
Site location a: Map after Bertran et al. 2011.1/50000 scale geological survey maps after Capdeville et al. 1998 (north) and Karnay et al. 1998 (south). Alluvial terrace: Fv: Lower Pleistocene $(+20-30 \mathrm{~m})$, Fx: late Middle Pleistocene $(+10 \mathrm{~m})$, Fy: Upper Pleistocene $(+5 \mathrm{~m})$, Fz: Holocene. Colluvial deposits: FC, CF. In orange, Tertiary detrital deposits. $b: 1 / 25000$ scaled topographic map overlaid on the 2015 aerial view (Géoportail, IGN). In yellow, the surveyed area prior to the archaeological excavation (25 ha), in red the excavated area. The black dotted line draws the limits to the west of the main site discovered in 2014 (Chopin et al. 2015). 
sur le tracé du gazoduc Artère de l'Adour (Fourloubey et Sellami 2008 et 2009, Fourloubey 2012 ; Colonge 2013 et 2014 ; Beague-Tahon et al. 2014 ; Colonge et al. 2014a). La fouille de la ZAEI de Garlin offrait donc une opportunité supplémentaire de consolider le cadre chronostratigraphique esquissé par ces précédentes opérations archéologiques et de compléter les données régionales sur la diversité du Paléolithique moyen dans sa phase ancienne.

\section{2 | Méthodologie}

La fouille s'est déroulée sur 6 semaines, en juillet et août 2015 (Taylor et al. 2017). Bien qu'entièrement mécanisée, l'approche a été couplée avec quelques tests de fouille manuelle sur les secteurs de plus forte densité. Parallèlement au décapage, un transect est-ouest orienté dans l'axe médian du bassin a été réalisé sur une longueur d'environ $100 \mathrm{~m}$ afin de préciser la position stratigraphique du mobilier au fur et à mesure de sa découverte et d'étudier l'évolution latérale des dépôts. Il a été complété par plusieurs sondages profonds. L'étude de la séquence pédosédimentaire s'est concentrée sur une coupe (CP1.3) située dans la partie la plus dilatée du site, à l'est. Elle a été complétée par des mesures de susceptibilité magnétique, des prélèvements micromorphologiques, des analyses microgranulométriques et géochimiques, ainsi que par six dates obtenues par luminescence stimulée optiquement (OSL). Seuls les résultats des datations sont présentés ici. En laboratoire, l'étude lithique a bénéficié d'une approche taphonomique du mobilier (analyse spatiale, distribution granulométrique, analyse des états de surface, recherche de remontages et raccords). L'analyse des fabriques n'a pas pu être menée en raison d'un effectif de mesures trop faible. La méthodologie employée pour les datations et les différents outils taphonomiques est précisée plus bas.

\section{2 | CADRE CHRONOSTRATIGRAPHIQUE ET PROCESSUS DE FORMATION DU SITE}

\section{1 | Séquence stratigraphique}

Le site s'insère dans un dépôt limoneux couvrant la nappe Fv et appartenant à une vaste formation allochtone d'origine éolienne en provenance de la façade atlantique (Bertran et al. 2011 ; Sitzia et al. 2015). Il est plus précisément localisé dans la zone des limons lœssiques, à une quarantaine de kilomètres de la couverture sableuse landaise (fig.1). Ces limons renferment la plupart du temps une fraction grossière éparse, qui s'organise localement en pavage (ou stone-line), indiquant que ces produits éoliens ne sont plus en position primaire. Postérieurement à leur dépôt, ces matériaux ont enregistré les principales grandes phases pédoclimatiques pléistocènes : formation progressive d'un horizon BT enrichi en argile par illuviation pendant les périodes tempérées, érosion et cryoturbation durant les périodes froides. Malgré l'imbrication de ces différentes phases les unes sur les autres, rendant difficile le décryptage paléoenvironnemental de ces matériaux, ces limons se sont suffisamment différenciés au cours du temps pour permettre un calage chronostratigraphique des nappes de mobilier qu'ils incluent.
L'étude stratigraphique, initiée par P. Bertran (Chopin et al. 2015), a permis de mettre en évidence les principaux points suivants :

1) La couverture limoneuse atteint au maximum 3,4 m d'épaisseur dans la partie est de l'emprise, où les dépôts sont plus dilatés en raison d'un probable accident néotectonique. Ces dépôts limoneux massifs ont été subdivisés en six principales unités pédosédimentaires (UPS1 à 6) surmontant la nappe alluviale Fv (UPS7). Les UPS3 à 6 correspondent à la superposition de trois horizons BT (correspondances sur fig.2). La majorité du mobilier lithique s'insère dans presque toute l'épaisseur de l'UPS3 qui correspond au premier horizon argilique (BT1).

2) L'UPS3 (BT1), limono-sableuse brun-jaune (10YR5/8), renferme une fraction $>2 \mathrm{~mm}$ peu abondante (moins de $1 \%)$, distribuée aléatoirement. La limite supérieure correspond aux profondes langues de dégradation qui s'organisent selon un réseau polygonal métrique au sommet de l'unité (fig. 3). Ce réseau, provoqué par d'anciennes fentes de contraction thermique, est associé à des glosses horizontales et à une structure lamellaire plus ou moins bien exprimée. Cette configuration traduit l'établissement de conditions périglaciaires après le dépôt des limons (formation d'un cryosol), expliquant en partie la dilatation verticale du mobilier et permettant de proposer une limite d'âge supérieure à la formation du site (fin MIS3 ou MIS2, Bertran et al. 2013). La limite inférieure de l'UPS3 est difficile à percevoir, elle correspond à l'apparition des volumes irréguliers orangés de l'horizon BT2.

3) En dessous, l'UPS4 (BT2), qui a livré quelques pièces lithiques, correspond à un matériau limono-sableux brun vif (7.5YR5/8) à fraction > $2 \mathrm{~mm}$ faible (autour de $3 \%$ ) et éparse. Les observations micromorphologiques basées sur plusieurs lames minces de grand format (Taylor et al. 2017) montrent que cette unité a supporté la pédogenèse du Début Glaciaire weichsélien caractérisée par une succession de fins revêtements illuviaux organo-minéraux reconnue dans plusieurs séquences datées du Sud-Ouest (Texier et Bertran 1990 ; Bertran in Jarry et al. 2007 ; Bernard-Guelle et al. 2017). D'après ces données paléopédologiques, le dépôt des limons de l'UPS4 s'est donc déroulé avant cette période, donnant ainsi un âge inférieur probable à la formation du site.

\section{2 | Résultats des datations par luminescence}

Les grains de quartz du sédiment constituent le seul support datable en l'absence de reste organique et d'élément brûlé. Cinq prélèvements pour datation par OSL issus de la coupe CP1.3 (fig. 2 et 3) ont été analysés par le centre GADAM de l'Université de Silésie à Gliwice (détails dans Taylor et al. 2017). Les doses équivalentes ont été déterminées selon le protocole Single Aliquot Regenerative dose (Murray et Wintle 2000). Les dates ont été obtenues en utilisant le Central Age Model (Galbraith et al. 1999). En l'absence de mesure du rayonnement gamma in situ et en raison des difficultés à estimer la variation de la teneur en eau du sédiment au cours du temps, les dates sont à utiliser avec précaution. Elles correspondent à la période de dernière exposition à la lumière des limons quartzeux de taille comprise entre 45 et $63 \mu \mathrm{m}$ (limons grossiers), et donc à la période de leur enfouissement définitif. 

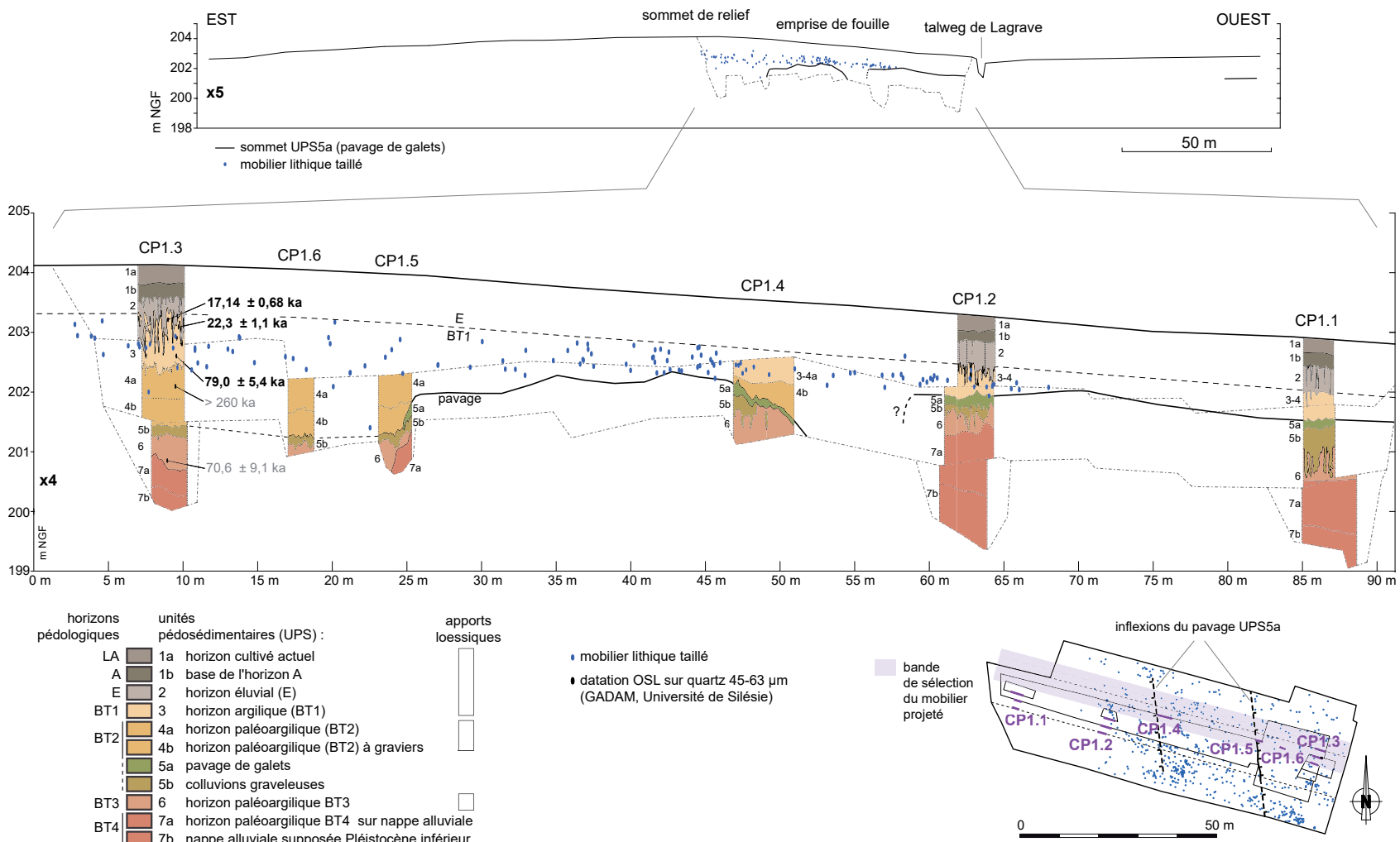

- FIGURE 2 -

Transect stratigraphique du site à l'emplacement de l'emprise de fouille (M. Rué, A. Ajas).

The site's stratigraphic cross-section at the archaeological excavation's location.

Les trois âges obtenus dans l'UPS3 (BT1) sont cohérents avec les données pédostratigraphiques : cet horizon s'est formé sur des limons mis en place progressivement durant le Pléistocène supérieur (fig. 3). L'analyse de l'échantillon situé dans la partie inférieure de l'UPS3, juste en dessous des plus fortes densités en mobilier, a donné un âge de $79 \pm 5,4 \mathrm{ka}$, soit à la fin du stade 5 (MIS5a). Au-dessus de la nappe de mobilier, les âges renvoient au stade 2. D'après ces dates, l'ordre de grandeur du taux de sédimentation des limons est de l'ordre de $1 \mathrm{~cm}$ par millénaire, ce qui donne une idée du temps théorique nécessaire pour qu'un artefact se retrouve enseveli.

Le prélèvement centré dans la partie supérieure de l'UPS4 (BT2) a donné un âge plus ancien que 260 ka. Même si ce résultat est conforme aux prévisions pédostratigraphiques, il ne repose que sur l'analyse d'une aliquote (fig.3). Cette unité correspond à un pédocomplexe qui couvre probablement plusieurs interglaciaires, dont l'avant-dernier (Eémien). Le dernier prélèvement, issu de la base de la couverture limoneuse (UPS6), a fourni un résultat à 70,6 \pm 9,1 ka BP qui s'avère incohérent en raison de sa position stratigraphique et du fort degré d'altération de l'unité datée. L'âge de la base de la séquence limoneuse reste donc inconnu.

\section{3 | Étude taphonomique des vestiges de l'UPS3 (horizon BT1)}

\subsection{1 | Caractéristiques générales des vestiges}

La série lithique recueillie comporte 608 objets paléolithiques, participant à un poids total de 423,24 kg. La proportion de nucléus est forte (27,6\%), tandis que les produits du débitage sont en comparaison relativement peu présents (40,3\%). Les phases d'acquisition et de sélection des volumes à débiter sont bien documentées par la présence de manuports (blocs de matière première réservés ou rejetés, percuteurs...) ainsi que de galets testés et fracturés. L'outillage est représenté par plusieurs galets aménagés et façonnés, ainsi que par quelques éclats retouchés, représentant 6,9\% de l'ensemble lithique. Le matériau est quasi exclusivement composé de quartzites $(98,2 \%)$ accompagnés de rares quartz $(n=7)$ et silicites $(n=9)$.

La plupart des objets proviennent de l'UPS3 (76 \% pour un total de 601 objets), dispersés sur toute la puissance de l'horizon, mais plusieurs d'entre eux ont également été collectés à l'interface des UPS3 et 4 (24\%). Le mobilier apparait dans son ensemble d'une fraicheur remarquable, les tranchants et arêtes des éclats et blocs exploités semblant peu affectés par une action mécanique contre le sédiment. 


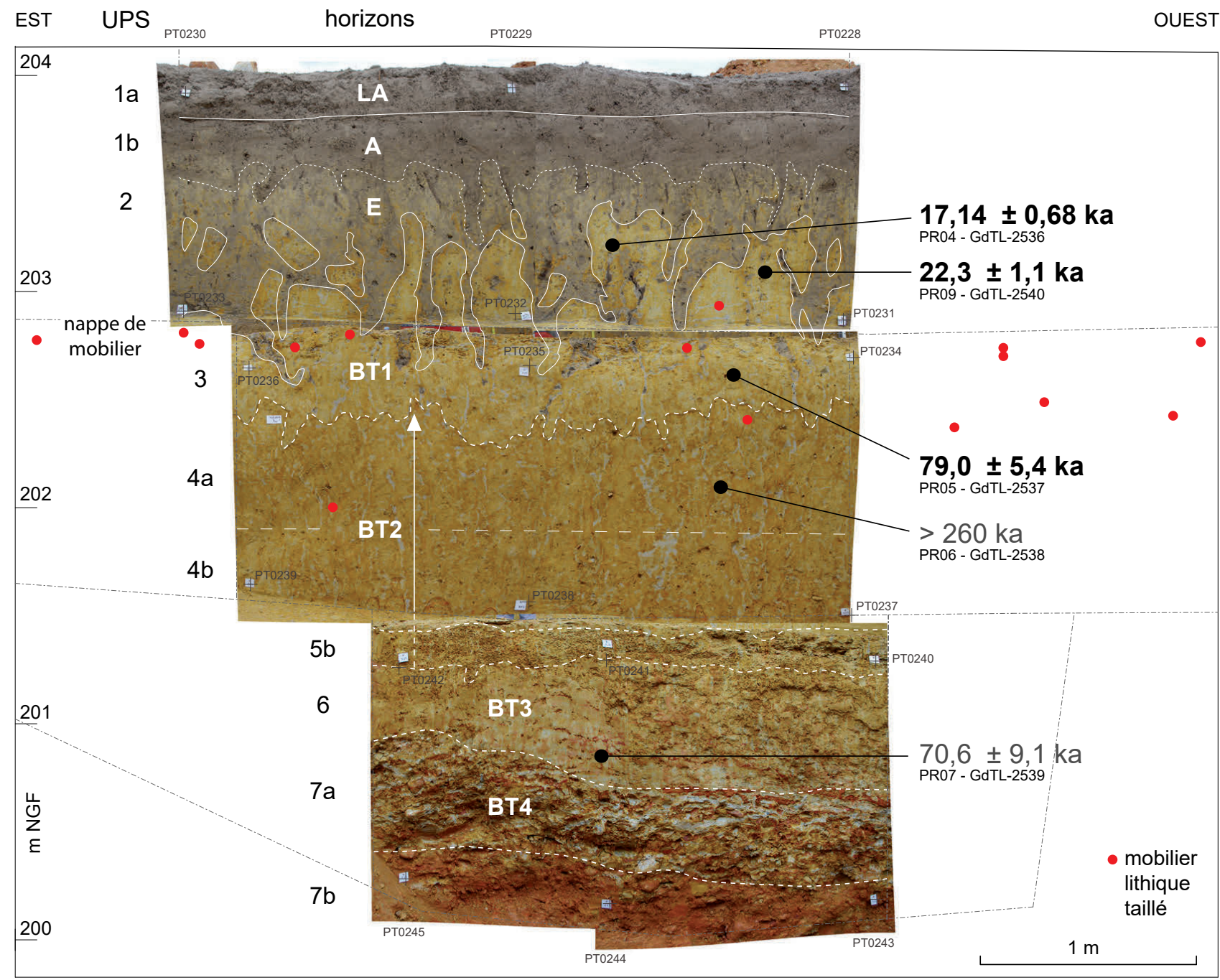

\begin{tabular}{|c|c|c|c|c|c|c|c|c|c|c|c|c|c|}
\hline \multirow[b]{2}{*}{ PR } & \multirow[b]{2}{*}{$\begin{array}{l}\text { référence } \\
\text { laboratoire }\end{array}$} & \multirow[b]{2}{*}{ UPS } & \multirow[b]{2}{*}{ horizon } & \multirow[b]{2}{*}{$\begin{array}{l}\text { profondeur } \\
\text { / surface } \\
\text { actuelle } \\
\text { (cm) }\end{array}$} & \multirow[b]{2}{*}{$\begin{array}{l}\text { teneur } \\
\text { en eau }\end{array}$} & \multirow[b]{2}{*}{$\begin{array}{c}\text { nombre } \\
\text { d'aliquotes }\end{array}$} & \multicolumn{5}{|c|}{ débit de dose (Gy/Ka) } & \multirow[b]{2}{*}{$\begin{array}{c}\text { dose } \\
\text { équivalente } \\
\text { (Gy) }\end{array}$} & \multirow[b]{2}{*}{ âge BP (ka) } \\
\hline & & & & & & & alpha & beta & gamma & cosmique & total & & \\
\hline 4 & GdTL-2536 & 3 top & BT1 & 92 & $18 \pm 5 \%$ & 15 & 0,057 & 1,123 & 0,922 & 0,194 & $2,296 \pm 0,070$ & $39,49 \pm 0,99$ & $17,14 \pm 0,68$ \\
\hline 9 & GdTL-2540 & 3 top & BT1 & 101 & $18 \pm 5 \%$ & 15 & 0,058 & 1,105 & 0,926 & 0,201 & $2,289 \pm 0,071$ & $51,2 \pm 1,9$ & $22,3 \pm 1,1$ \\
\hline 5 & GdTL-2537 & 3 base & BT1 & 147 & $18 \pm 5 \%$ & 15 & 0,055 & 0,978 & 0,851 & 0,183 & $2,067 \pm 0,061$ & $163,5 \pm 9,9$ & $79,0 \pm 5,4$ \\
\hline 6 & GdTL-2538 & $4 a$ & BT2 & 198 & $18 \pm 5 \%$ & 1 & 0,058 & 0,909 & 0,86 & 0,169 & $1,996 \pm 0,017$ & $>530$ & $>260$ \\
\hline 7 & GdTL-2539 & 6 & BT3 & 324 & $18 \pm 5 \%$ & 10 & 0,075 & 1,68 & 1,324 & 0,146 & $3,22 \pm 0,11$ & $228 \pm 28$ & $70,6 \pm 9,1$ \\
\hline
\end{tabular}

\section{- FIGURE 3 -}

Coupe 1.3 et résultats des datations OSL (M. Rué et GADAM). Localisation de la Section 1.3 and OSL datation results. Section's location and units' captions on coupe et légende des unités sur la figure précédente. Projection du mobilier topo- $\quad$ previous figure. Artifacts' projection on a 8m wide band centered on section CP1.3. graphié situé sur une bande de $8 \mathrm{~m}$ de large centrée sur CP1.3. 


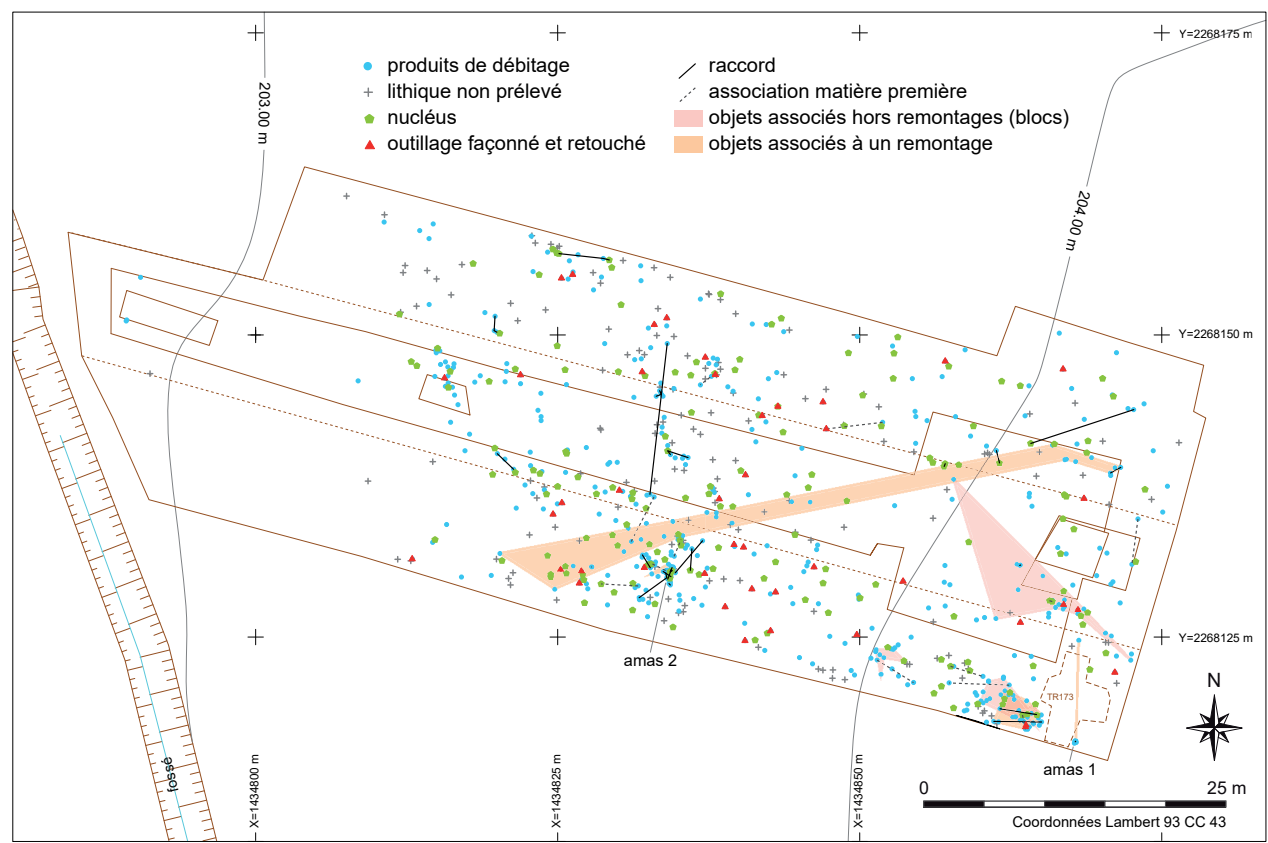

\section{FIGURE 4}

Distribution en plan des principales composantes technologiques et des liaisons de la série étudiée (A. Taylor, J.-B. Caverne, M. Rué)

Main technological features and refittings' distribution.

\subsection{2 | Distribution spatiale du mobilier archéologique}

L'ensemble du mobilier paléolithique forme une nappe d'objets qui témoigne d'un degré variable de dilatation. Les projections font apparaitre un pendage généralisé vers le nord-ouest, en direction du talweg actuel. Elles indiquent aussi une plus forte dispersion verticale des pièces dans la partie est de l'emprise. Dans ce secteur, la pente moyenne des objets situés dans le BT1 est faible (environ $1 \%$ ), mais la dispersion verticale couvre toute la moitié inférieure de cet horizon, soit sur près de $80 \mathrm{~cm}$ d'épaisseur (fig. 3).

En plan, on constate une distribution non homogène du mobilier, avec notamment sa disparition totale sur le tiers ouest de l'emprise (fig.4), ce qui correspond probablement à une limite d'érosion liée au fonctionnement du vallon de Lagrave. Le mobilier semble localement s'organiser le long de lignes orientées dans l'axe de la plus grande pente de la nappe, ce qui suggère des réorganisations postdépositionnelles de l'assemblage initial (par des écoulements concentrés ?).

L'extension de la nappe de vestiges reste inconnue, hormis à l'ouest où son arrêt est imputable à l'érosion. L'emprise de fouille est en revanche très proche du sommet du relief actuel (angle sud-est), et donc de la zone source des matériaux déplacés (limon ou mobilier). Au regard de la morphologie de la nappe de mobilier, en conformité avec celle du relief actuel, le déplacement des objets semble limité, de l'ordre d'une dizaine de mètres pour les pièces situées dans l'angle sud-est.

L'analyse de la densité des pièces, couplée à une analyse dimensionnelle de la variance (Whallon 1973 ; Bertran et al. 2005), souligne la présence de concentrations de mobilier, notamment dans la bande sud du décapage, où deux d'entre elles ont été testées en fouille manuelle (amas 1 et 2, respectivement 10 et 24 pièces, fig. 4 et 5). Les résultats du calcul de $\mathrm{R}$ (rapport variance / moyenne) indiquent en effet une distribution non aléatoire et non uniforme des densités, et ce pour des maillages de $50 \mathrm{~cm}$ $(R=1,6)$ à $2 m(R=3,8)$ (fig.5). Les projections par catégories techno-typologiques ne montrent néanmoins aucune distribution particulière (fig.4).

\subsection{3 | Composition granulométrique de l'assemblage lithique}

Après un tri par classes dimensionnelles, l'analyse granulométrique de l'ensemble des produits de débitage a permis de souligner un fort déficit en éclats de faibles dimensions puisqu'aucun éclat inférieur à $2 \mathrm{~cm}$ n'a été retrouvé. Si l'approche mécanisée de l'exploration de la nappe d'objets, bien que très précautionneuse, peut en être partiellement responsable, ce tri granulométrique s'est toutefois confirmé lors des tests de fouilles manuelles. Par ailleurs, les tamisages à l'eau réalisés sur la coupe 1.3, à l'aide d'une maille de $2 \mathrm{~mm}$, n'ont pas rencontré d'éléments lithiques alors même que 8 seaux de $10 \mathrm{~L}$ de sédiment ont été extraits de l'UPS3.

L'approche par classes de poids des objets inférieurs à $1 \mathrm{~kg}$ confirme le tri de la série lithique : la plupart des objets pèse entre 20 et $300 \mathrm{~g}$ et seulement 4 objets moins de $5 \mathrm{~g}$. Les objectifs et techniques de débitage adoptés peuvent expliquer en partie l'absence de produits de petites dimensions (peu de préparation des plans de frappe notamment, technique de percussion sur enclume), mais des chaînes opératoires de façonnage bifaciales semblent néanmoins présentes (abrasion nécessaire avant percussion?), ainsi que plusieurs éclats retouchés (menus éclats et esquilles liés à la retouche et/ou régularisation des parties actives de l'outil). La fabrication de ces objets aurait dû produire une fraction fine. En outre, plusieurs nucléus de dimensions réduites suggèrent que des éclats recherchés en fin d'exploitation pouvaient être inférieurs à $2 \mathrm{~cm}$. 


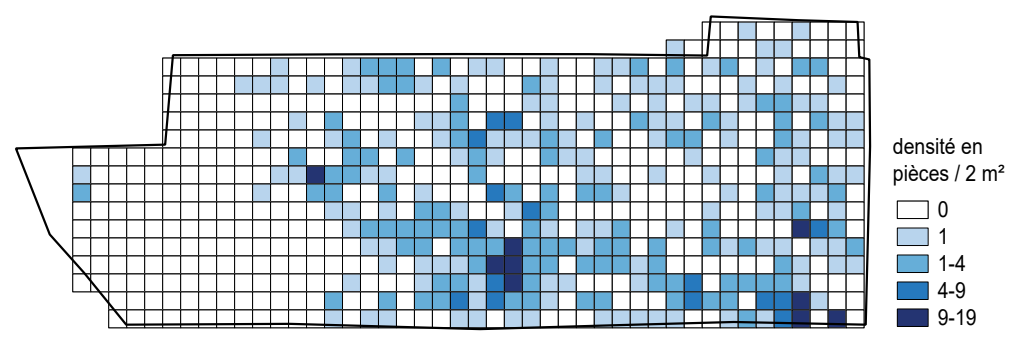

\begin{tabular}{|c|c|c|c|}
\hline maille & $2 \mathrm{~m}$ & $1 \mathrm{~m}$ & $0,5 \mathrm{~m}$ \\
\hline moyenne & 0,946 & 0,239 & 0,600 \\
\hline variance & 3,574 & 0,535 & 0,098 \\
\hline $\mathrm{R}$ & 3,777 & 2,239 & 1,628 \\
\hline
\end{tabular}
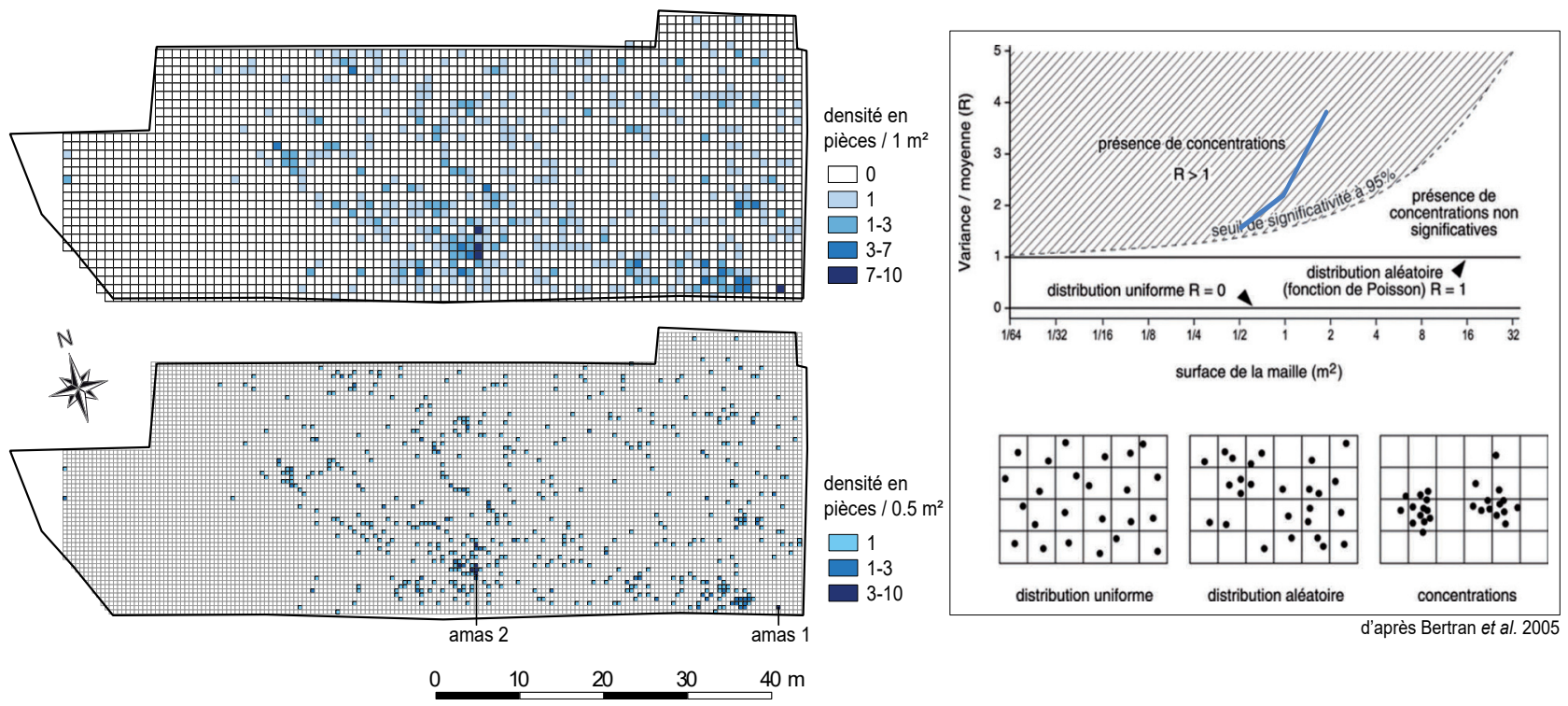

- FIGURE 5 -

Densité du mobilier lithique et résultats de l'analyse dimensionnelle de la variance (d'après Whallon 1973 et Bertran et al. 2005).
Lithic artifacts' distribution and dimensional analysis of variance results (from Whallon 1973 and Bertran et al. 2005).
Même si les tests de tamisage n'ont pris en compte que de faibles surfaces, ces résultats montrent que la série lithique a été triée par les processus géomorphologiques. La série apparait donc comme tronquée, sans doute privée des éléments lithiques les plus légers, une situation commune aux sites paléolithiques moyens fouillés le long de l'A65 (eg. Bertran et al. 2012 ; Bernard-Guelle et al. 2014).

\subsection{4 | Étude des états de surface des quartzites}

Son objectif visait à vérifier l'homogénéité taphonomique des quartzites et à rechercher des indicateurs de déplacement afin de préciser les modalités de formation de la nappe d'objets. Afin de répondre à ces questions, nous avons utilisé une méthode multiscalaire fondée sur le principe que les quartzites enregistrent les processus post-dépositionnels. Pour un même contexte environnemental, l'altération peut être utilisée comme marqueur de chronologie relative et témoin de l'intégrité de l'unité archéologique (Alimen 1964 ; Icole 1970 ; Bornand 1978 ; Coutard et Ozouf 2008 ; Fernandes 2012). Les surfaces observées à la loupe binoculaire (Leica M165C, x20 à X200) correspondent aux négatifs liés à la fabrication de l'objet et non à leur utilisation. En effet, pour décrypter la succession des mécanismes post-dépositionnels, on pratique une lecture microtopographique des stigmates et des traces qui bordent ou recouvrent les négatifs des enlèvements. Seuls les tranchants n'ont pas été observés mais traités dans le cadre de l'analyse fonctionnelle (cf. infra). En parallèle, nous prenons en compte la polarité taphonomique susceptible de renseigner sur les mécanismes à l'origine de la mise en place de l'unité archéologique (Hue 1929 ; Vignard et Vacher 1964 ; Fernandes 2012).

Le classement des objets en quartzite est basé sur la prise en compte des transformations relevées sur une soixantaine d'échantillons géologiques prélevés sur le site dans le pavage de galets (UPS5a) et au sein de la terrasse FV (UPS7b) et comparées aux transformations enregistrées par trente-six pièces archéologiques provenant essentiellement du cœur de l'UPS3. En raison de la dilatation verticale importante du mobilier, nous avons également sélectionné deux ensembles de pièces en nous appuyant sur la projection du mobilier, l'un pour le haut de la nappe (pièces $n^{\circ} 236$ à 239), le second pour le bas (pièces $n^{\circ} 255$ à 258 et remontages 10 et 12, fig. 6). Nos premiers résultats, détaillés dans Taylor et al. 2017, ont permis d'avancer les points suivants : 


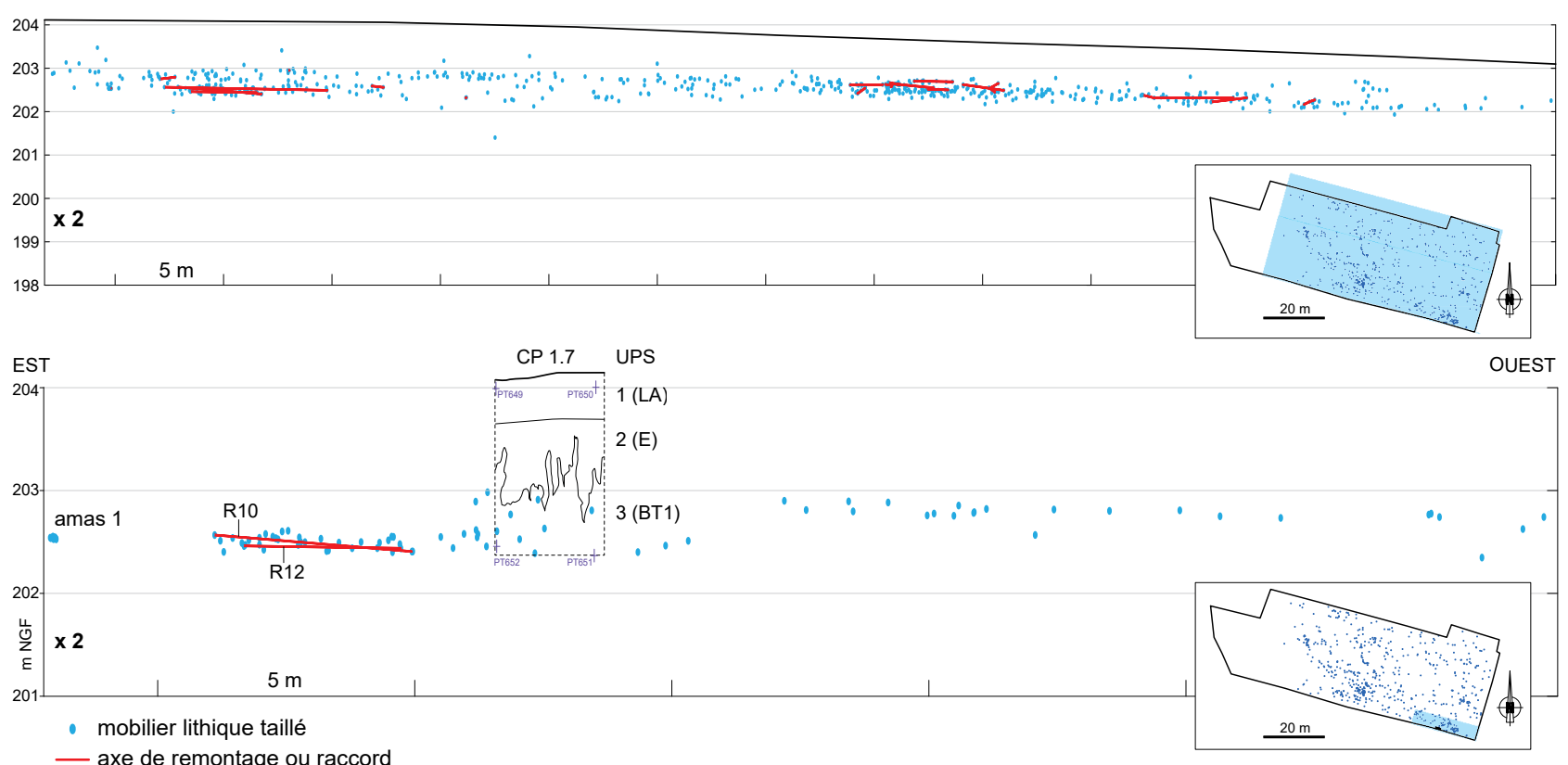

_ axe de remontage ou raccord

Projections en coupe du mobilier et des liaisons entre pièces lithiques (A. Taylor, J.-B. Caverne, M. Rué)

Artifacts and refittings' projection.

- les états de surface post-dépositionnels des pièces issues de l'UPS3 sont homogènes. Les différences sont essentiellement dépendantes de l'état d'altération prédépositionnel. Rien n'a permis de distinguer clairement les deux ensembles haut et bas sélectionnés. Les objets ont donc vraisemblablement subi les mêmes phénomènes quelle que soit leur position dans l'horizon archéologique; - ce sont les processus chimiques liés au lessivage (patine blanche, accélération de l'altération à la surface) qui ont le plus impacté les quartzites, ce qui est cohérent avec le contexte pédologique (sol lessivé dégradé). La fréquence des objets à polarité taphonomique permet par ailleurs de proposer une absence de remaniement au cours de l'Holocène ;

- l'analyse des états de surface indique une mobilité faible de la majorité des quartzites depuis leur abandon dans l'unité archéologique. Il faut toutefois rester prudent car les réactions de ce matériau aux différents types d'altération, ses capacités d'enregistrement et la cinétique des comportements sont encore loin d'être totalement décryptées.

Cette étude préliminaire a par ailleurs permis de poser les bases d'une méthodologie renouvelée issue des protocoles utilisés pour le silex. Nous savons que la composition minérale, la granulométrie, la cohésion des grains, leur orientation et la porosité ont une grande influence dans la capacité à enregistrer les processus taphonomiques. En conséquence, une description pétrologique avant toute analyse taphonomique est une étape nécessaire (Pedergnana et Ollé 2017). L'observation de la microtopographie des grains et du ciment livre des résultats exploitables (Clemente et Gibaja 2009). L'utilisation d'un MEB et d'un microscope confocal pourrait compléter cette démarche de façon utile.

\subsection{5 | Remontages, associations et rapprochements}

L'intérêt taphonomique de l'étude des remontages dans la compréhension de l'état de conservation d'un site n'est plus à démontrer. Une dizaine de jours ont ainsi été consacrés à cette recherche permettant la réalisation de 22 raccords physiques, comportant de 2 à 4 objets ou fragments d'objets, totalisant 52 pièces (taux de remontage de 8,5\%). À ces raccords physiques, peuvent être associés plusieurs pièces retrouvées à proximité dont l'aspect pétrographique (aspect du néocortex, teinte, grain, inclusions et veines) laisse à penser qu'elles peuvent appartenir au même bloc. Ces 28 éléments supplémentaires portent le taux de « remontage et associations » à 13,2\% de la série. Les raccords de débitage l'emportent largement sur les raccords de cassure, avec respectivement 16 unités contre 6 . Enfin, 63 pièces intègrent 19 rapprochements de matière première (2 à 13 pièces), représentant probablement tout autant de blocs.

En plan, les raccords apparaissent répartis sur toute la surface de fouille, sans concentration particulière, si ce n'est un taux plus élevé dans les zones de plus fortes densités de matériel (fig. 4). Les liaisons témoignent plutôt de raccords à courtes distances, inférieures à $50 \mathrm{~cm}$ 
(14 liaisons sur les 31 documentées), suivies de moyennes distances, comprises entre $50 \mathrm{~cm}$ et $2 \mathrm{~m}$ (10 liaisons), et enfin à grandes distances, de $2 \mathrm{~m}$ jusqu'à plus de $12 \mathrm{~m}$ (7 liaisons, la plupart comprises entre 3 et $4 \mathrm{~m}$ ). Plusieurs orientations de ces raccords s'inscrivent grossièrement dans l'axe du pendage de la nappe, sans que cet axe soit privilégié néanmoins. Si l'on considère les pièces que l'on peut rapprocher de ces remontages par association de matière première (figurées sous forme de polygones dont les sommets correspondent à ces objets, fig.4), on constate qu'elles soulignent la présence de concentrations de pièces pouvant provenir d'un même bloc (" amas de débitage ») dans la partie est de la bande de décapage sud.

En projection sur l'axe est-ouest, les remontages effectués apparaissent pour la plupart sur des plans horizontaux ou sub-horizontaux, suivant en ce sens le plan moyen de la nappe de mobilier (fig.6). De plus, sur la petite zone de fouille manuelle localisée autour de l'amas 2, plusieurs remontages à courtes distances associent de grandes pièces à de petites pièces plus légères, contredisant l'hypothèse d'un fort remaniement de la nappe dans ce secteur, qui aurait bouleversé l'horizontalité de la nappe et l'intégrité de ces remontages.

\section{4 | Discussion et conclusion}

Comme pour de nombreux sites pléistocènes de plein air, les indicateurs taphonomiques, qu'ils reposent sur le sédiment ou le mobilier, montrent que les vestiges ont subi une histoire post-dépositionnelle complexe depuis leur abandon sur le sol. Le site de Garlin n'échappe malheureusement pas à cette règle. Plusieurs de ces indicateurs vont en effet dans le sens d'une perturbation importante de l'assemblage initial :

- la partie supérieure de la nappe de mobilier a supporté le fonctionnement d'un cryosol durant la fin du dernier cycle glaciaire, expliquant en partie la forte dilatation verticale des objets;

- aucune structuration archéologique évidente de l'espace n'a été perçue au diagnostic ou en fouille. Les densités sont globalement toujours faibles, en moyenne inférieure à 0,5 pièces au $\mathrm{m}^{2}$ en prenant en compte l'ensemble des objets (taillés et non taillés);

- la série récoltée a subi un tri granulométrique important par évacuation des fractions fines et moyennes avant et/ou pendant son enfouissement par les limons.

Cette configuration rend illusoire toute lecture archéologique du plan de répartition spatiale des objets lithiques. Ce constat rejoint d'autres résultats obtenus sur les sites de l'A65 situés dans la zone des lœss. Toutefois, plusieurs indicateurs montrent que le mobilier recueilli dans l'UPS3 (BT1) ne correspond pas au produit de l'érosion d'un site beaucoup plus ancien initialement situé dans l'horizon BT2 et secondairement redistribué sur le versant :

- la partie orientale de l'emprise se situe à proximité immédiate d'un point haut du relief, les déplacements mis en évidence ne peuvent donc qu'être limités. De surcroît, la pente générale de la nappe d'objets est faible (environ $1 \%$ ) et l'horizon BT2 est conservé sur le point haut ;
- l'examen des limons aux échelles macro- et microscopiques n'a pas mis en évidence de figures de déplacement en masse, alors que le contexte limoneux enregistre généralement bien ces figures ;

- les stigmates post-dépositionnels liés au déplacement des quartzites dans le sol apparaissent faibles et moins prononcés que ceux observés sur les quelques pièces provenant de l'horizon BT2;

- des concentrations résiduelles subsistent, confirmées par l'analyse dimensionnelle de la variance. Deux d'entreelles concentrent un nombre plus élevé de remontages ; - le taux de remontage est relativement élevé et les axes ne sont pas préférentiellement orientés dans le sens de la plus grande pente vers le nord-ouest. Ces axes apparaissent en conformité avec la pente de la nappe et l'on n'observe pas de remontage entre deux pièces éloignées verticalement.

Ce contexte plaide ainsi en faveur d'un épandage archéologique qui s'est constitué en plusieurs phases de dépôt, mêlant probablement occupations in situ et mobilier érodé issu d'occupations antérieures dans l'horizon BT1. L'épaisseur occupée par l'épandage de mobilier représente un épisode de temps relativement long d'après les dates OSL obtenues (de l'ordre de $50 \mathrm{ka}$ ). À Garlin, nous sommes donc sans doute en présence de plusieurs ensembles taphonomiques, et donc d'un mélange d'industries, bien que probablement sub- ou pénécontemporaines comme semblent l'attester l'homogénéité des états de surface et la cohérence techno-économique de la série (cf. partie 3). Au regard des dates OSL et des données pédostratigraphiques, ces occupations polyphasées se sont vraisemblablement déroulées entre le MIS5 (post-Eémien) et le MIS3.

\section{3 | L'INDUSTRIE LITHIQUE : APPROCHES PÉTROGRAPHIQUE, TECHNO-TYPOLOGIQUE, ÉCONOMIQUE ET FONCTIONNELLE}

\section{1 | Approche pétrographique}

L'analyse pétrographique a porté sur près d'un tiers du mobilier recueilli intégrant l'évolution des quartzites et des quelques silex associés ( $n=7$ ) (Taylor et al. 2017). Ce travail s'appuie sur les recherches récentes qui ont abouti à un renouvellement de la connaissance des traceurs et des aires de disponibilités concernant le piémont occidental des Pyrénées (e.g. Colonge et al. 2002, 2010, et 2012a ; Colonge et Mourre 2009 ; Séronie-Vivien 2009 et 2010 ; Bernard-Guelle et al. 2010 ; Jarry 2010 ; Millet et Millet 2010 ; Colonge et al. 2011 ; Minet 2013 ; Fourloubey et al. 2013 ; Lelouvier et al. 2013).

Cette analyse n'a pas permis de déterminer les limites exactes du domaine minéral exploité par les occupants du site en raison de la connaissance imparfaite des cortèges de galets contenus dans les différentes formations superficielles. Il est tout de même possible de proposer des résultats sur la provenance des quartzites et d'avancer quelques hypothèses sur les aires d'approvisionnement en silex. 
Les quartzites sont ainsi majoritairement récoltés dans l'environnement immédiat du site. Il s'agit de galets pyrénéens similaires à ceux présents dans le pavage (UPS5a) situé sous la nappe de mobilier (fig.2). Ce sont essentiellement des quartzites à grains moyens à grossiers. Toujours altérés, ils présentent divers gradients d'épuisement matriciel ou de rubéfaction et une importante variabilité d'aspects corticaux. Une part réduite des quartzites provient des terrasses plus récentes (Fw ou Fx) aux cortèges grossiers non altérés. Quartz et lydiennes complètent le corpus de façon très anecdotique. Les quelques silex présents attestent d'une acquisition plus lointaine. Les blocs roulés de silex turoniens type Montgaillard-Hibarette peuvent avoir été collectés au sein d'une des formations alluviales de l'Adour ou de L'Échez. L'autre silex du Flysch présente de fortes similitudes avec les lits silicifiés de la région au sud-ouest de Pau. Le cas des silex à Lépidorbitoïdes est encore plus complexe car les trois silex présents dans la série n'ont pas été collectés sur un même gîte. Même si deux d'entre eux présentent des similitudes micropaléontologiques et altérologiques avec certains silex maastrichtiens des Pyrénées centrales (paléo-couloir Adour-Baïse), leur provenance exacte reste à déterminer.

Le site de Garlin entre parfaitement dans un cadre déjà évoqué par nos prédécesseurs (Colonge et al. 2012). Il appartiendrait au groupe à prépondérance de quartzites à double patine, pauvre en silex mais de provenance multiple, installé sur des épandages pléistocènes inférieurs assez éloignés des grands couloirs alluviaux riches en quartzites moins altérés.

\section{2 | Étude techno-typologique}

\subsection{1 | Caractérisation de la production lithique et des séquences opératoires}

L'observation technologique du mobilier, couplée à celle des remontages, souligne la présence in situ des témoins de l'ensemble des chaines opératoires de débitage. Les chaines opératoires de façonnage ne sont quant à elles documentées sur site que par le façonnage d'outils lourds (galets aménagés) et de bifaces (dont plusieurs ébauches).

\section{Modalités d'acquisition et d'introduction des blocs,}

\section{sélection des volumes}

Le premier apport des remontages est d'attester de l'introduction de grands volumes, fragmentés ensuite afin de produire des supports qui seront utilisés dans des chaines opératoires de débitage (notamment Discoïde) exploitant des volumes plus réduits. D'autres galets apparaissent simplement testés dès la phase de collecte $(n=17)$. Les galets exploités semblent dans l'ensemble parcourus de veines et de diaclases, contrecarrant parfois les objectifs des tailleurs (fractures accidentelles, réfléchissements).

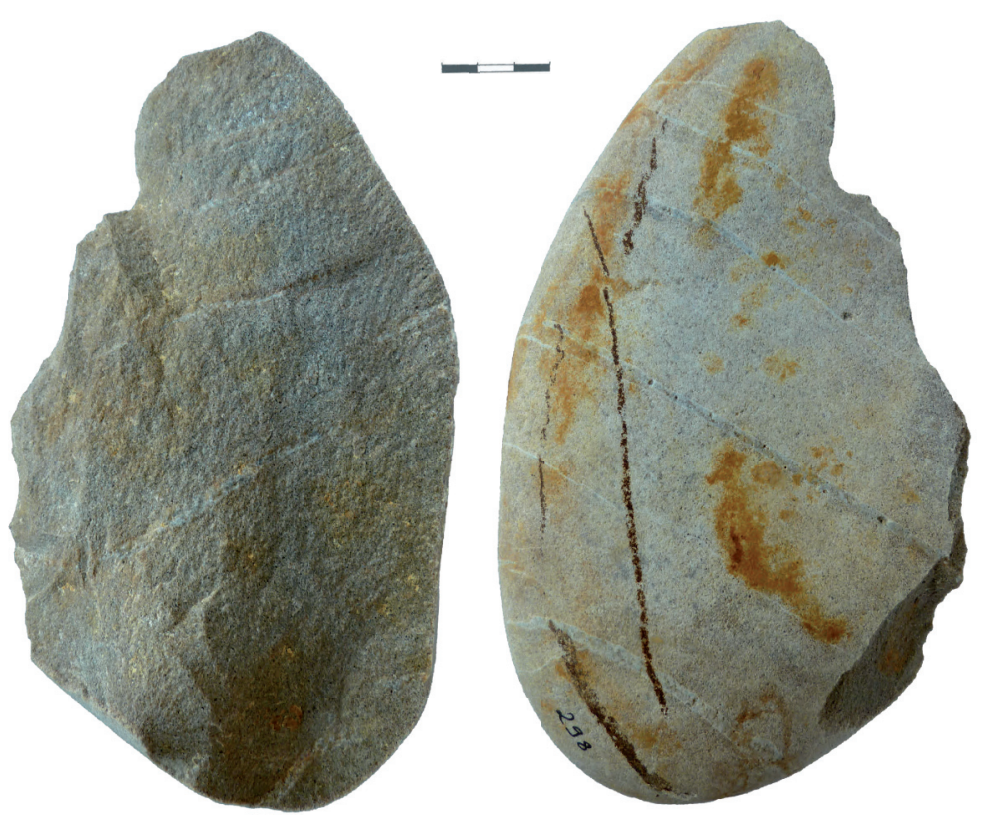

\section{FIGURE 7}

Grande entame (n²298) (A. Taylor, S. Bernard-Guelle). Échelle 2/3 Big primary flake ( $\left.n^{\circ} 298\right)$. Scale 2/3. 
De grands à très grands éclats sont également présents dans la série (plus de 10, voire $20 \mathrm{~cm}$ de longueur). Ce sont de grandes entames (e.g. fig. 7) provenant de galets de dimensions considérables. En l'absence de remontage, la question de leur production hors du site reste posée. Pourtant, la possibilité de collecte à proximité immédiate du site (cf. § 3.1 supra) et la présence de galets d'un poids conséquent (parfois plus de $7 \mathrm{~kg}$ ) sont des arguments en faveur d'une production sur place mais en dehors de l'emprise fouillée.

Au regard des manuports $(n=40)$, galets testés $(n=17)$, galets fracturés $(n=60)$, galets et entames aménagés et/ou retouchés $(n=32$ ), des remontages et rapprochements de matières premières, et des 157 nucléus hors remontages, le nombre minimal de galets introduits au niveau de l'emprise est estimé à 337 pour un poids moyen d'un galet de quartzite (ou assimilé hors silex) de $1228 \mathrm{~g}$. Cette valeur théorique reste proche du poids moyen constaté pour les manuports, nucléus et galets testés abandonnés (respectivement 1663, 1065 et 1222 g). L'introduction de silex a été bien plus modeste (821 g contre $422416 \mathrm{~g}$ de quartzite et assimilés) et manifestement sous forme d'éclats exceptés deux petits nucléus et un outil bifacial comptant à lui seul pour $700 \mathrm{~g}$.

Concernant la sélection des volumes exploités, si la morphologie des blocs sélectionnés apparait variée, la tendance semble privilégier les morphologies parallélépipédiques, souvent allongées et présentant au moins une face plate.

Enfin, plusieurs nucléus investissent des éclats épais, sous-produits de débitages précédents, voire de grandes entames. Ces dernières intègrent surtout la phase de retouche/façonnage, que l'on considère l'outillage fortement investi tel que les pièces bifaciales, ou un outillage lourd plus fruste (hachereau type 0, pièces tranchantes ou encochées...).

\section{Les produits de débitage (fragmentation, dimensions, morphologie)}

Les produits de débitage (éclats et fragments d'éclats) sont relativement peu nombreux dans la série ( $n=244$ bruts + 16 outils, rapport éclats/nucléus $=1,55$ ). Ils sont en outre fréquemment fracturés, sans doute en relation avec la technique de percussion employée, particulièrement violente (percussion sur enclume). On compte en effet 50 cassures de type accident Siret, soit plus de $20 \%$ des produits concernés. S'y ajoutent 33 fragments distaux et 22 fragments proximaux d'éclats.

L'ensemble témoigne d'un fort déficit de la fraction fine du débitage (aucun produit inférieur à $2 \mathrm{~cm}$ ). Les éclats supérieurs à $5 \mathrm{~cm}$ de longueur dominent de façon écrasante l'assemblage (65\%), suivis des éclats supérieurs à $10 \mathrm{~cm}(20 \%)$ et des éclats dont la longueur est comprise entre 3 et $5 \mathrm{~cm}(13 \%)$.

Les produits de débitage se répartissent principalement entre 3 morphologies: ovalaire $(n=78)$, quadrangulaire $(n=65)$ et triangulaire $(n=54)$. L'allongement des produits est limité, les éclats sont parfois bien plus larges que longs ( $n=50$ ), leur épaisseur est notable, particulièrement celle des talons, symptomatique d'une percussion minérale dure, parfois violente. De nombreux produits portent des plages corticales conservées, notamment en raison de la fréquence des dos naturels, mais on note aussi la présence d'entames entièrement néocorticales. Plus du tiers des produits ne présente toutefois aucune plage corticale, sauf leur talon, dont la préparation est rarissime à l'échelle de la série. De nombreux produits présentent un dos (95 sur les 245 collectés), néocortical le plus souvent, mais parfois de débitage (produit pseudoLevallois notamment) (fig. 8). Ce dos néocortical se prolonge en général à partir du talon et peut se développer sur toute la longueur du produit, voire se poursuivre dans sa partie distale (dos enveloppant). Au cours de l'exploitation de blocs plus étroits, le dos néocortical peut se prolonger sur les deux bords latéraux de l'éclat.

Les nucléus (concepts, schémas opératoires, objectifs du débitage, état d'abandon)

L'observation technologique des concepts, schémas opératoires et objectifs du débitage a pu être étudié sur 168 volumes exploités. Deux grands concepts semblent organiser la mise en œuvre de la production lithique, un débitage centripète (Discoïde) et un débitage frontal unipolaire (sur enclume) dont les modalités et la gestion sont modulées en fonction de la morphologie du volume investi, voire de sa réduction. Ainsi le débitage centripète se décline en modalités Discoïdes unifaciales ou bifaciales (Boëda 1993 ; Mourre 2003a), tandis que le débitage frontal unipolaire pourra présenter des changements d'orientation dans l'exploitation de la surface de débitage, voire plusieurs surfaces successives privilégiant toujours l'unipolarité de la production, et ce sur les volumes les plus massifs. Tous ces schémas opératoires produisent exclusivement des éclats, en général peu allongés. Les concepts Discoïdes et frontaux unipolaires regroupent respectivement 68 et 89 nucléus ( 40 et $53 \%$ des volumes débités). S'y ajoutent quelques volumes où la progression du débitage unipolaire est plus périphérique $(n=6)$, ou investit le plan d'aplatissement du volume sans adopter un schéma Discoïde (débitage « facial » unipolaire, $n=1$ ).

Le débitage Discoïde est mis en œuvre à partir de volumes de plus faibles dimensions que le débitage frontal unipolaire, et qui proviennent presque tous déjà de la réduction d'un bloc plus grand, éclats épais, entames et surtout fragments de galets fracturés sur enclume, opposant une surface néocorticale fortement convexe à la surface d'éclatement du support. La surface néocorticale convexe des matrices sert de plan de frappe et de surface réserve à la production d'éclat dans la modalité Discoïde unifaciale (majoritaire, $n=54$ ) (fig. 9 et 11) ou bifaciale partielle hiérarchisée, l'investissement d'une seconde face étant limité et lié à l'entretien des plans de frappe (minoritaire, $n=14$ ) (fig. 10 et 11). L'objectif du débitage semble être la production d'éclats centrés de morphologies diverses (ovalaires, quadrangulaires ou triangulaires). Peu de produits caractéristiques des productions Discoïdes « classiques » ont pu être retrouvés à l'exception de quelques éclats pseudo-Levallois $(n=9)$. Le détachement d'enlèvements cordaux prédéterminés ne semble ainsi pas faire partie des objectifs principaux du débitage. On peut sans doute rapprocher de ces productions Discoïdes la plupart des éclats légers témoignant d'une percussion directe dure, sans stigmates évidents de contre-coups évoquant la technique de percussion sur enclume. Sur quelques volumes, le 

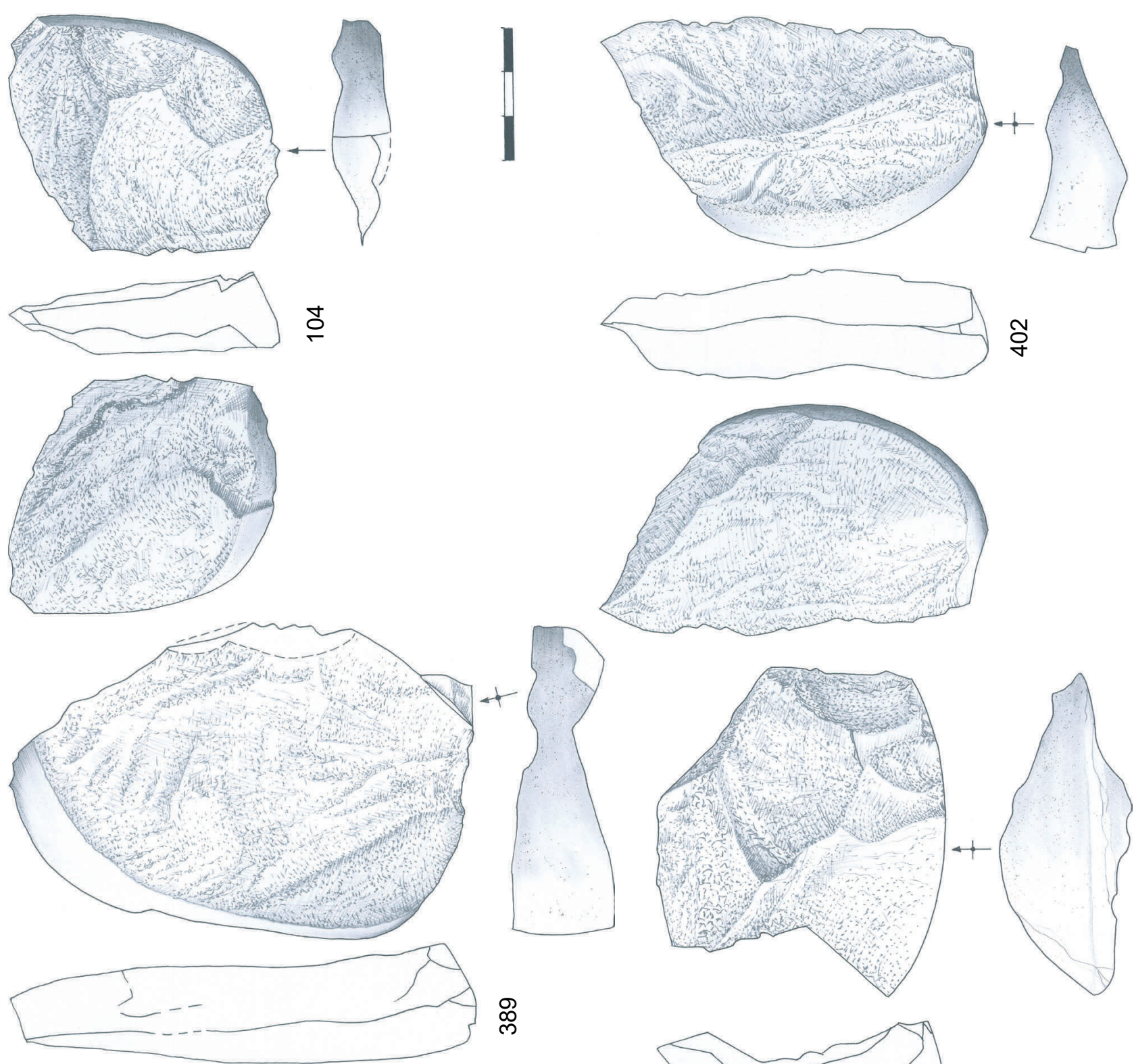

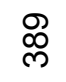
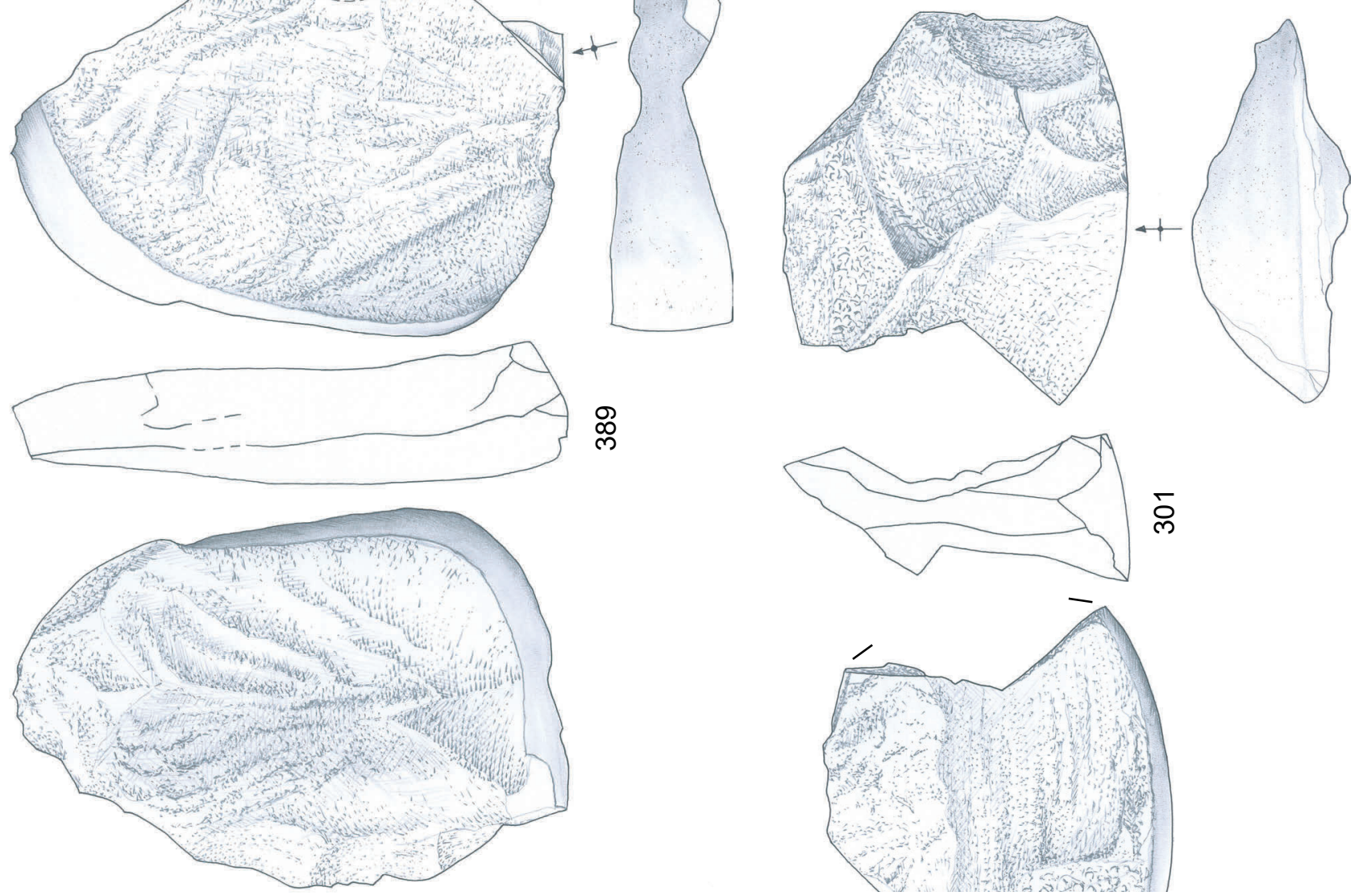

Бे

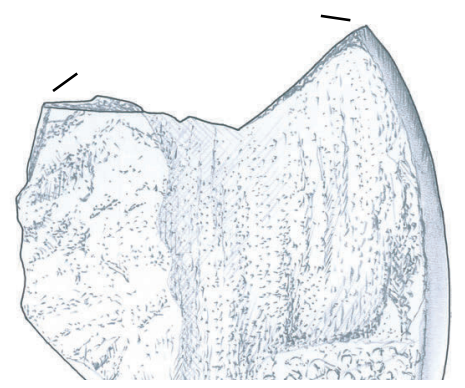

- FIGURE 8 -

Éclats à dos néocortical issus d'un débitage sur enclume (R. Picavet). Échelle 2/3. Neocortical backed flake from an anvil technique debitage. Scale 2/3. 

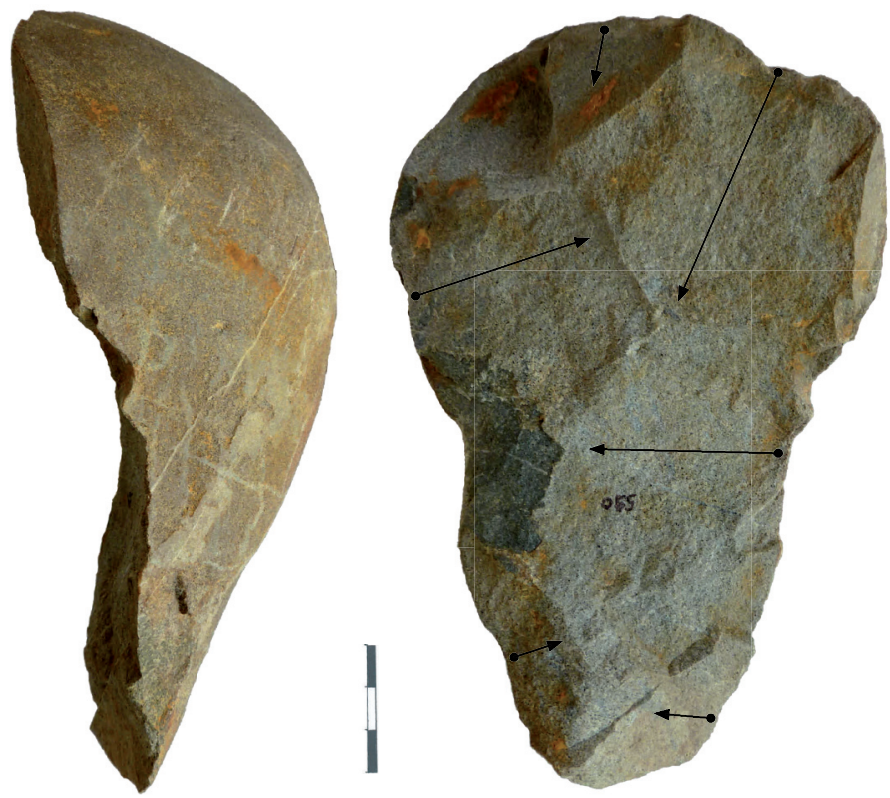

\section{FIGURE 9}

Nucléus Discoïde unifacial ( $n^{\circ}$ 590) (A. Taylor, S. Bernard-Guelle) Échelle 2/3.

Discoid unifacial core ( $n^{\circ}$ 590). Scale 2/3.

débitage a été poussé jusqu'à un aplatissement total de la surface de débitage, le plan de fracturation des derniers enlèvements n'étant plus du tout sécant mais parallèle au plan d'aplatissement du volume, ce qui explique les réfléchissements successifs plus fréquemment observés au centre de la surface de débitage de ces nucléus. Parmi les rares pièces en silex, un nucléus Discoïde bifacial (fig. 11) atteste d'un débitage particulièrement poussé avec un volume abandonné mesurant $40 \mathrm{~mm}$ de longueur pour une épaisseur inférieure à $20 \mathrm{~mm}$.

Le débitage frontal unipolaire investit bien plus volontiers des galets entiers ou fracturés plus massifs, une face naturelle (convexe ou plate) non préparée servant de plan de frappe. La surface de débitage s'inscrit dans l'épaisseur du support, le débitage progressant frontalement au moyen d'éclats larges et épais, le plus souvent dans l'axe de la largeur du support. La morphologie générale du nucléus abandonné évoque celle d'un galet aménagé unifacial (ou « chopper »), si ce n'est le caractère très abrupte de la surface de débitage (angle formé avec la surface de plan de frappe égal, voire supérieur à $90^{\circ}$ ), et l'absence de régularisation de la corniche. Des stigmates de contrecoups sont discernables et témoignent de l'utilisation d'une percussion sur enclume pour détacher des éclats qui présentent alors un dos néocortical lorsqu'ils sont détachés à proximité du bord de la surface de débitage, et éventuellement juste un dos néocortical distal lorsqu'ils sont détachés plus au centre de la surface (fig. 12) (Mourre 1996, 2004). Les cassures transversales et surtout les accidents de type siret sont fréquents. Hormis l'obtention d'un tranchant opposé à un dos ou de tranchants latéraux, le contrôle de la morphologie exacte de l'éclat pâtit de la violence de la percussion et de la qualité des galets de quartzite sélectionnés, veinés et fissurés. L'observation des produits de débitage indique fréquemment en effet une fissuration radiaire importante du point d'impact, causant la fracture du produit en 2 fragments, voire plus. La plupart des éclats présentant un dos se développant de manière importante à partir du talon, ou présentant une cassure type siret, sont sans doute à rapprocher de cette production sur enclume. Sur les volumes les plus massifs on note parfois des réorientations successives du débitage, la surface exploitée restant la même mais débitée à partir d'une nouvelle surface de plan de frappe (une autre face du galet), souvent perpendiculairement à la séquence unipolaire précédente. Une part au moins des volumes exploités frontalement par percussion sur enclume semble abandonnée de façon précoce, la technique de percussion sur enclume autorisant en théorie la réduction quasi complète du volume.

Quelques supports de nucléus présentent des plages localisées de percussion, témoins du recyclage d'anciens percuteurs, d'autres montrent un écrasement localisé d'une partie de leurs arêtes, probablement dans le cadre d'un remploi opportuniste du volume en tant qu'outil lourd (percussion, broyage ?). Certains présentent parfois des corniches fortement écrasées et pourraient correspondre à un des marqueurs typologiques de l'Acheuléen pyrénéo-garonnais (polyèdres ou galets à chant épannelé) dont la fonction reste encore mystérieuse.

\subsubsection{I'outillage}

Les 43 outils, tous en quartzite sauf un en silex, composent $6,9 \%$ de la série. L'outillage lourd est aménagé sur galets ( $n=20$, galets aménagés et bifaces et apparentés), grandes entames et éclats ( $n=6$, bifaces et apparentés, hachereaux), ou bloc de silex ( $n=1$, pièce bifaciale tranchante). Aux outils plus légers confectionnés sur éclats 


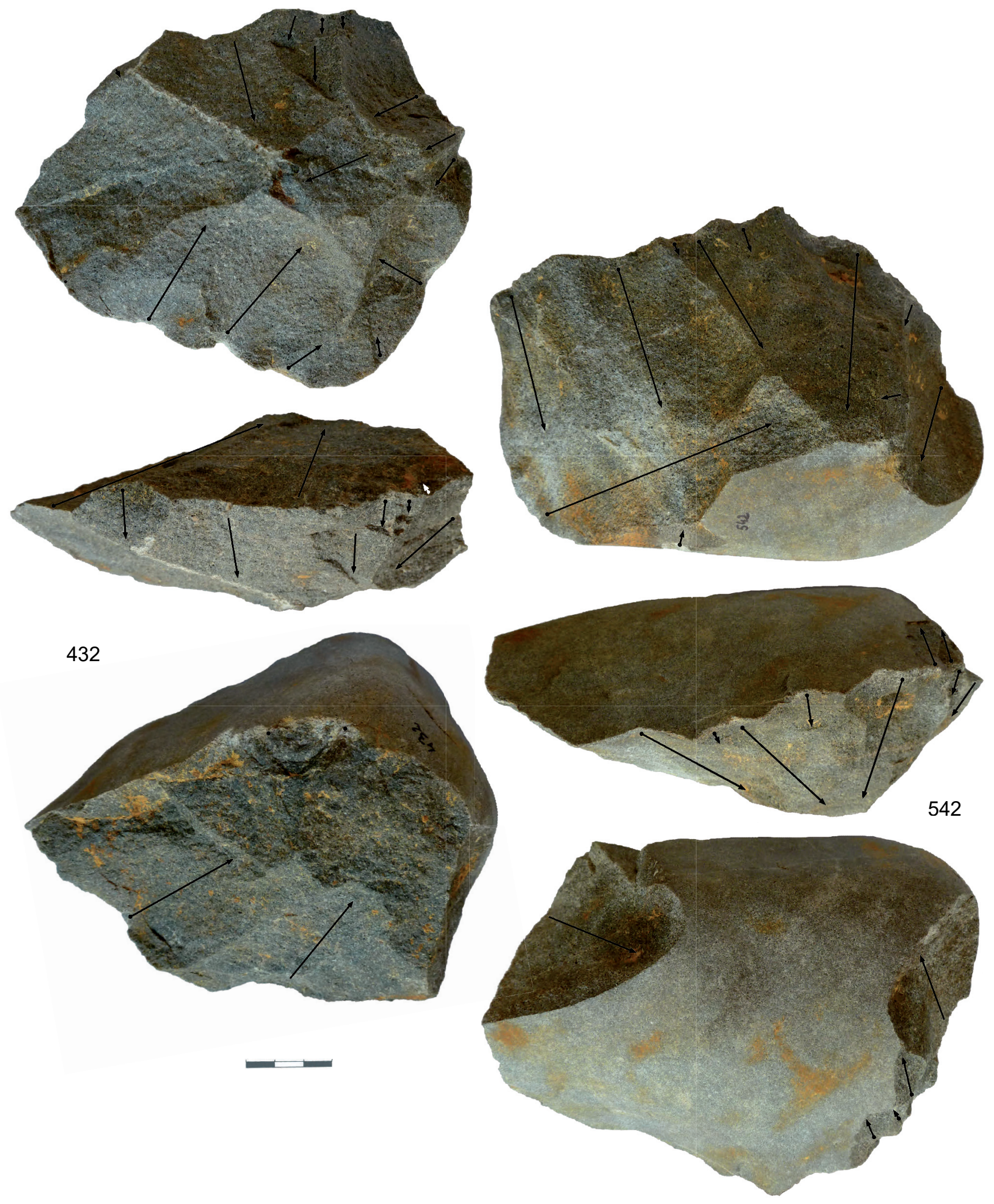

- FIGURE $10-$

Nucléus Discoïdes bifaciaux partiels (A. Taylor, S. Bernard-Guelle). Échelle 1/2.

Discoid partially bifacial cores. Scale 1/2. 

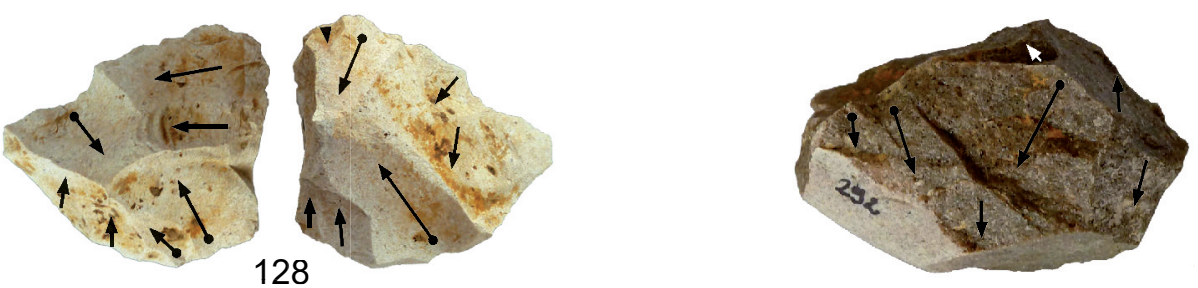

292
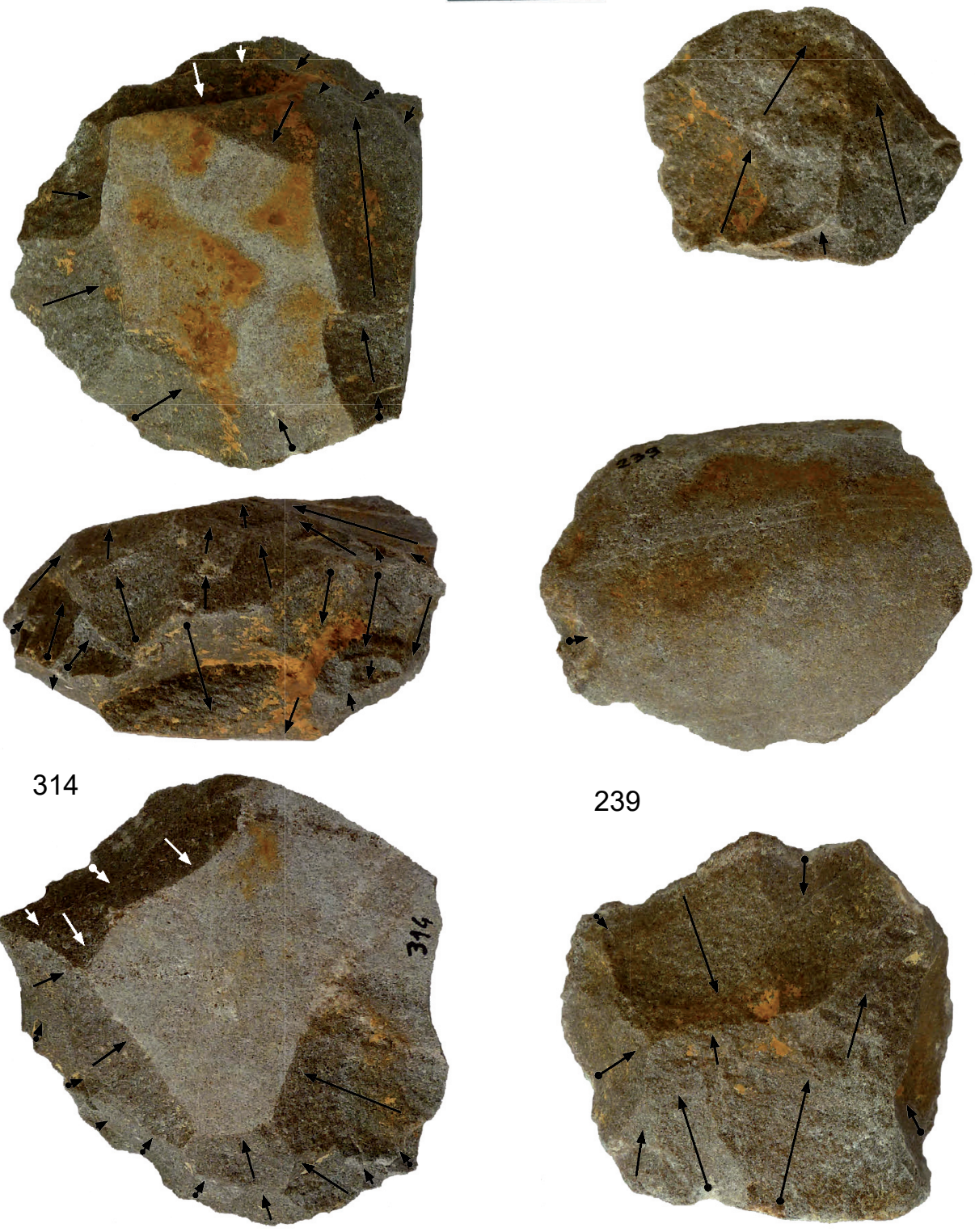

\section{FIGURE 11}

Nucléus Discoïde bifacial en silex (n 128) nucléus Discoïdes bifaciaux partiels ( $n^{\circ} 292$ et 314), nucléus Discoïde unifacial (n² 239) (A. Taylor, S. Bernard-Guelle). Échelle 2/3.

Flint discoid bifacial core ( $\left.n^{\circ} 128\right)$, discoid partially bifacial cores ( $n^{\circ} 292$ and 314), discoid unifacial core (n²39). Scale 2/3. 


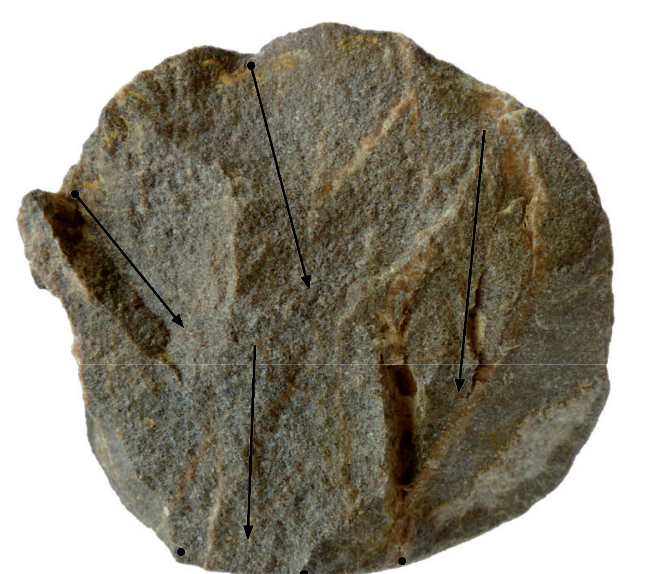

548
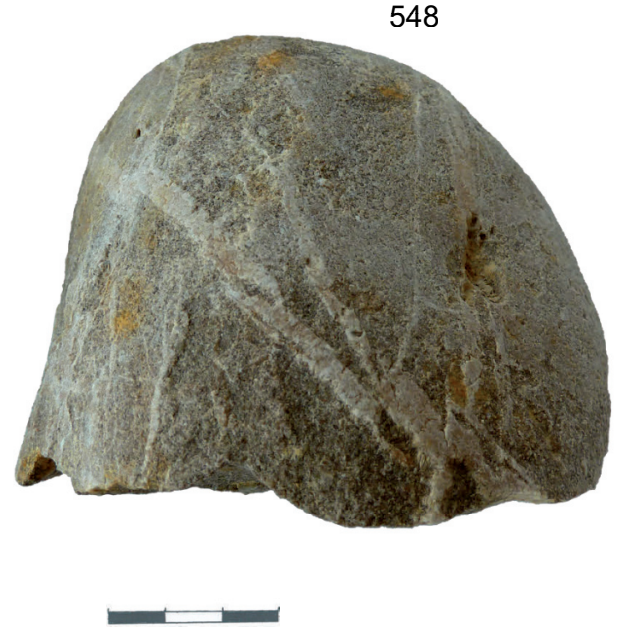

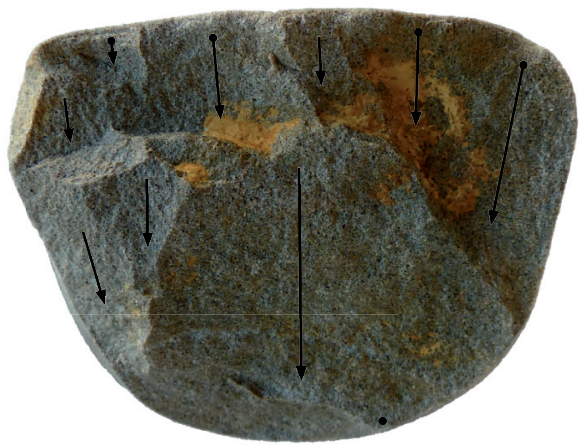

72

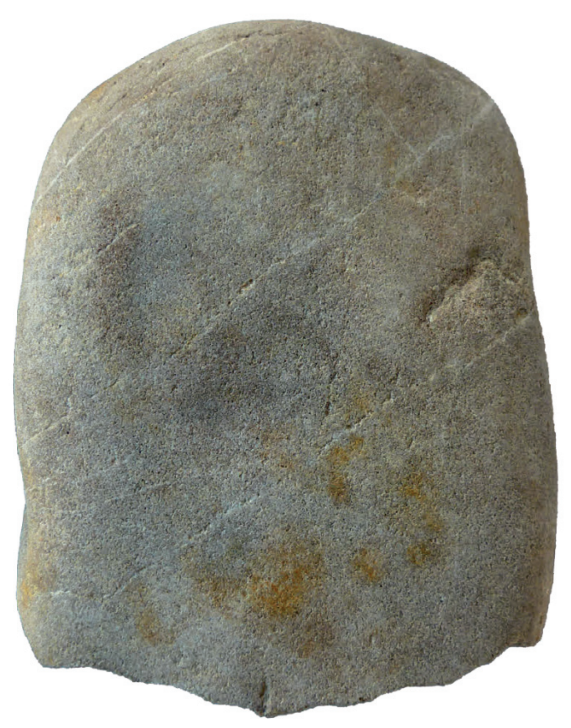

\section{FIGURE 12}

Nucléus à débitage frontal unipolaire sur enclume (A. Taylor, S. Bernard-Guelle). Échelle 2/3.

Anvil technique core, unipolar frontal progression. Scale 2/3.
( $n=11$, denticulés, racloirs...) s'ajoutent quelques tranchants d'éclats utilisés $(n=5)$. Avec ces derniers, le taux de transformation des supports débités atteint $9 \%$ contre $13,1 \%$ pour les galets.

\section{Les outils façonnés}

Le groupe est dominé par les galets aménagés unifaciaux $(n=9)$ sur lesquels une série d'enlèvements unipolaires dégage un bord actif rectiligne ou légèrement convexe, orienté le plus souvent dans la largeur du support (fig. 13 à 16). Il semble ensuite régularisé par une retouche plus fine, contrairement aux nucléus frontaux unipolaires, morphologiquement proches mais dont la corniche reste crénelée. Plus expéditifs, 5 galets ont été fracturés dans leur largeur selon un plan oblique, dégageant un tranchant convexe sur lesquels on observe de multiples écrasements. Un autre galet présente une succession de 4 encoches larges sur sa longueur, avec des écrasements localisés en fond d'encoches (fig. 17).

Les deux hachereaux de «type 0 » sur éclats néocorticaux ou semi-néocorticaux ont leurs bords latéraux succinctement aménagés par une retouche inverse envahissante (Tixier 1956 ; Mourre 2003b et 2006). Leur tranchant distal, laissé brut, présente des écrasements. La partie proximale épaisse et néocorticale du support reste quant à elle brute de débitage (fig. 18).

Une autre pièce, en silex, bifaciale et massive, oppose un tranchant distal transversal rectiligne et oblique dégagé par un enlèvement unique à un façonnage extensif du reste de l'objet, à l'exception d'une réserve corticale à la base de l'outil. Il s'agit d'une pièce bifaciale tranchante, dont le support, un bloc, l'éloigne de la définition typologique classique du hachereau (fig. 19).

Enfin, la série comporte 2 bifaces (dont un à base cassée) ainsi que 7 bifaces partiels à base réservée (fig. 20), 1 uniface partiel (fig. 21), et 4 ébauches de bifaces (fig. 22). Ces pièces portent les stigmates d'une percussion dure et rentrante. Les exemplaires les plus aboutis sont un biface lancéolé de dimensions modestes (fig.23), tout juste $10 \mathrm{~cm}$ de longueur, à base épaisse partiellement réservée, alors que la retouche de la pointe est particulièrement soignée sur un tel matériau (percuteur organique ?), ainsi qu'un biface plutôt cordiforme (fig. 23), dont la finition laisse à désirer malgré l'étendue du façonnage sur les deux faces de l'objet (façonnage quasi intégral). 

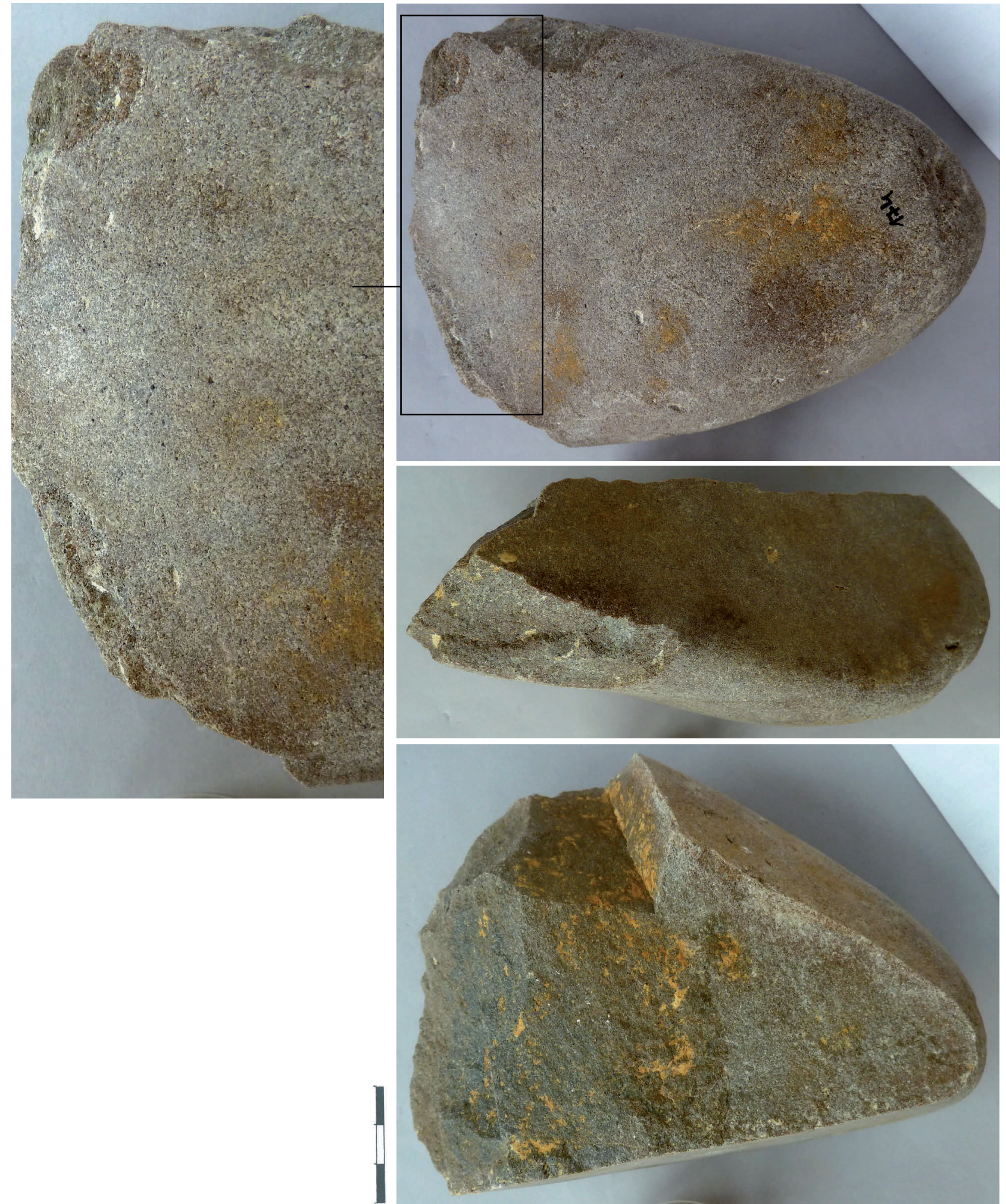

- FIGURE $13-$

Galet aménagé unifacial tranchant convexe $\left(n^{\circ} 174\right)$ et détail de l'endommagement du tranchant (A. Taylor, S. Bernard-Guelle). Échelle 2/3.

Unifacial convex cutting edge pebble tool ( $\left.n^{\circ} 174\right)$ and detail of the cutting edge's alteration. Scale 2/3. 

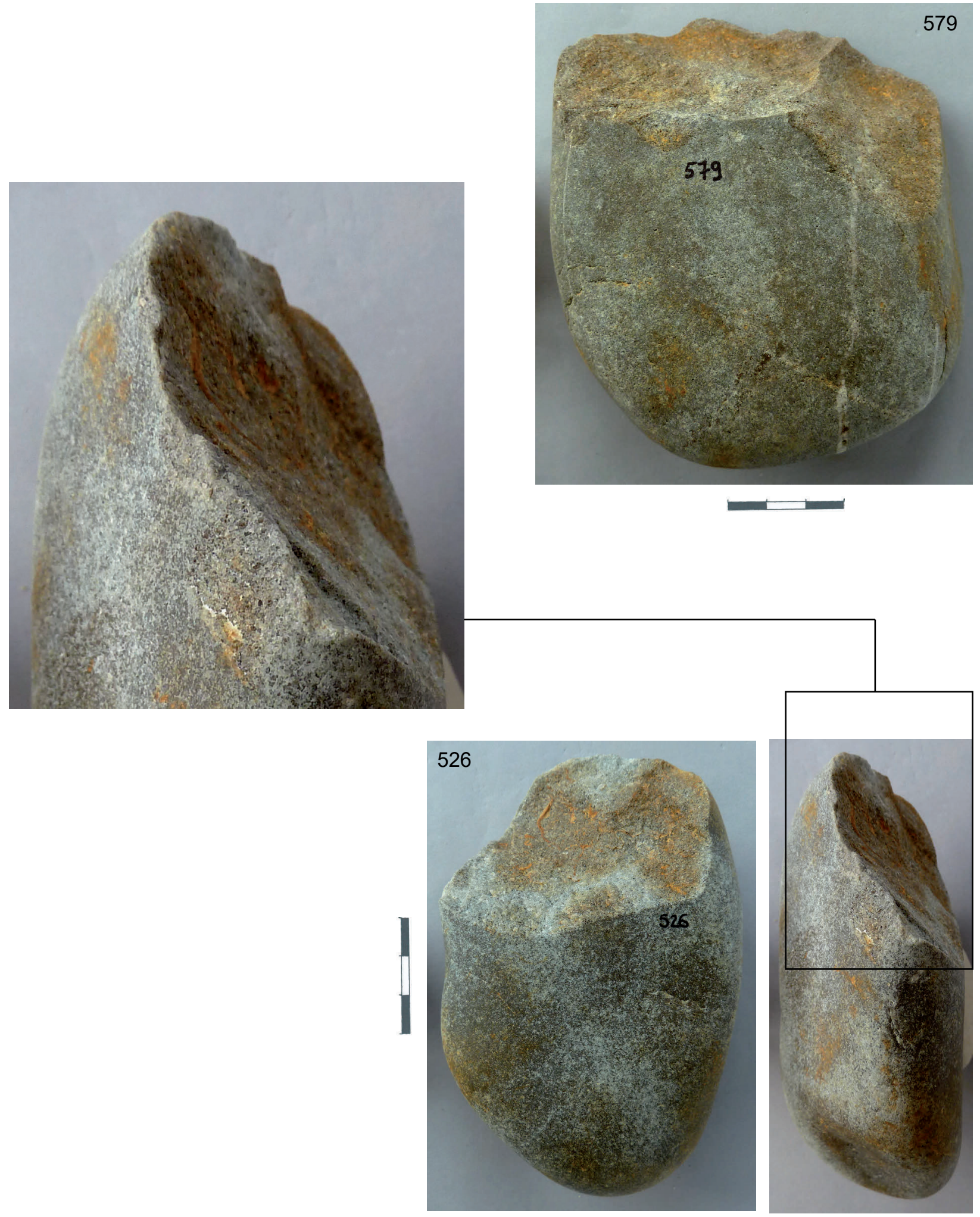

\section{- FIGURE 14 -}

Galet aménagé unifacial tranchant convexe ( $n^{\circ} 579$ ) et tranchant utilisé sur galet fracturé $\left(n^{\circ} 526\right)$ et détail de la modification de la partie active $(\times 1,5)$ (A. Taylor, S. Bernard-Guelle). Échelle 2/3.
Unifacial convex cutting edge pebble tool ( $\left.n^{\circ} 579\right)$, used cutting edge on fractured pebble $\left(n^{\circ} 526\right)$ and detail of the edge's alteration $(x 1,5)$. Scale 2/3. 

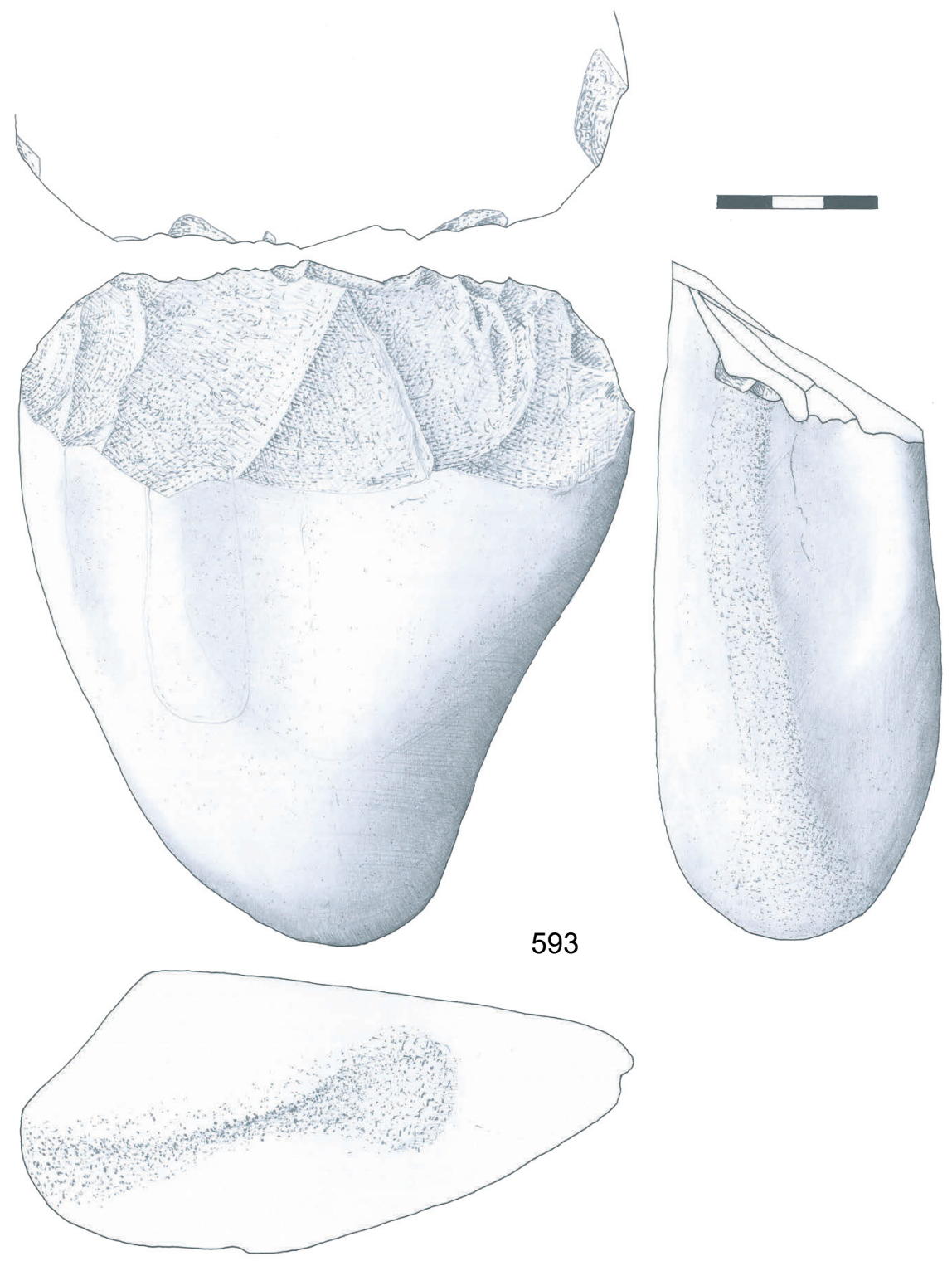

\section{FIGURE 15}

Galet aménagé unifacial rectiligne ( $n^{\circ} 593$ ) (R. Picavet). Échelle 2/3.

Unifacial straight cutting edge pebble tool ( $n^{\circ}$ 593). Scale $2 / 3$.

Les pièces façonnées sont largement dominantes (3/4 de l'outillage). Les galets aménagés sont surtout de grands outils à tranchants robustes et base réservée. Les bifaces et apparentés sont à de rares exceptions près plus légers, mais leur façonnage peut être tout aussi expédient que sur certains galets aménagés. A minima, une pointe est sommairement dégagée, associée au façonnage ou à la simple régularisation d'au moins un tranchant latéral. Le façonnage bifacial poussé de l'outil ne semble pas être une exigence, la base du biface étant le plus souvent totalement réservée, ou tout du moins plus sommairement aménagée.

\section{Les outils retouchés}

L'ensemble des outils sur éclats est composé de 4 racloirs simples (2 transversaux - fig. 24, 2 latéraux), de 4 pièces denticulées (fig. 25) dont 1 à microdenticulation, d'1 pièce à encoches sur grande entame ovalaire (fig.17), et enfin de 2 pièces à retouche bilatérale convergente, l'une de délinéation concave, dégageant un bec (fig. 25), l'autre de délinéation convexe dégageant une pointe de section triédrique (pic ? - fig. 21)

D'autre part, 5 éclats toujours corticaux et plutôt de grandes dimensions semblent porter des stigmates d'utilisation sur leurs tranchants bruts (écrasements et esquillements localisés - fig.26).

\subsection{Approche fonctionnelle}

L'observation s'est portée sur un ensemble de 40 objets comprenant divers outils et éclats issus d'un débitage bipolaire sur enclume ou d'une production Discoïde. Trenteneuf pièces sont en quartzite. Une seule est en silex ( $\left.n^{\circ} 325\right)$. Toutes présentaient des enlèvements d'aménagement et/ou enlèvements macroscopiques liés à une possible utilisation dont l'observation des bords devait confirmer ou non l'origine fonctionnelle. 


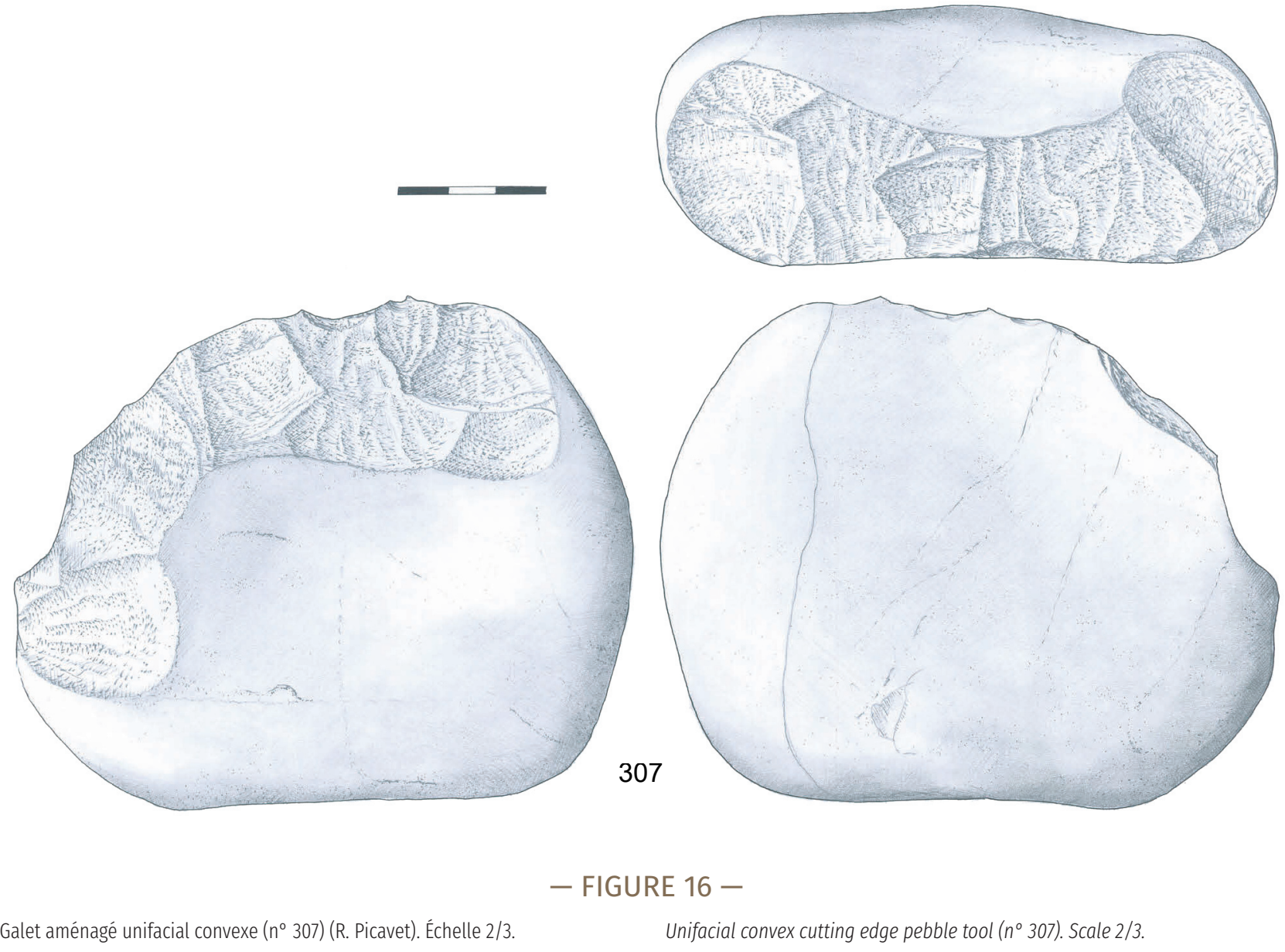

Du fait de la mauvaise conservation des micro-surfaces (matrice et grains de quartz particulièrement corrodés, ces derniers présentant à leur surface de nombreuses stries multidirectionnelles d'origine post-dépositionnelle - fig.27), nous avons décidé d'aborder ce mobilier d'un point de vue essentiellement macroscopique ce que nous permettait son état relativement bon. Pour cela, nous nous sommes fondée sur les travaux réalisés dans le cadre du PCR « des traces et des hommes » dirigé par C. Thiébault et réalisés principalement par E. Claud (Thiébault et al. 2009 ; Thiébault et al. 2011 ; Claud et al. 2015). Ces travaux montrent que, selon les activités pratiquées, la répartition, la quantité, le nombre de générations et la forme des enlèvements diffèrent. Ainsi l'organisation des enlèvements le long du bord permettent d'écarter l'hypothèse de leur origine taphonomique et d'émettre des hypothèses quant à leurs fonctions et fonctionnement.

Les principaux résultats peuvent se résumer en 3 points : (1) parmi les 40 objets, 29 présentent de probables traces macroscopiques d'utilisation ; (2) une certaine diversité des activités menées au moyen de ces outils est à noter, en lien avec une variabilité typologique assez importante : 8 zones utilisées concernent des actions en percussion, 10 des actions transversales (de type raclage), 4 des actions longitudinales (de type découpe), 1 une action

rotative (de type désarticulation) et enfin 6 des actions indéterminées ; (3) l'unicité des zones utilisées sur chacune des pièces est quasi systématiquement observée. L'outil est donc en général mono-tâche.

\section{4 | Approche techno-économique}

Au vu de l'approche taphonomique, la nappe d'objets lithiques, triée et partiellement redistribuée le long de la pente, pourrait correspondre à un épandage archéologique constitué en plusieurs phases de dépôt, mêlant probablement plusieurs phases d'occupations plus ou moins érodées. L'homogénéité des états de surface et la cohérence techno-économique de la série permettent néanmoins d'avancer que, si mélange il y a, il affecte des ensembles archéologiques d'un même techno-complexe. Malgré ces facteurs limitant (série triée, absence de structuration spatiale, fenêtre de fouille réduite), les remontages permettent d'esquisser, en appui de l'analyse pétrographique, quelques hypothèses d'ordre technoéconomique.

Ainsi, le site a probablement pu être occupé à plusieurs reprises et les occupants se sont presque exclusivement approvisionnés en galets de quartzites présents dans l'en- 

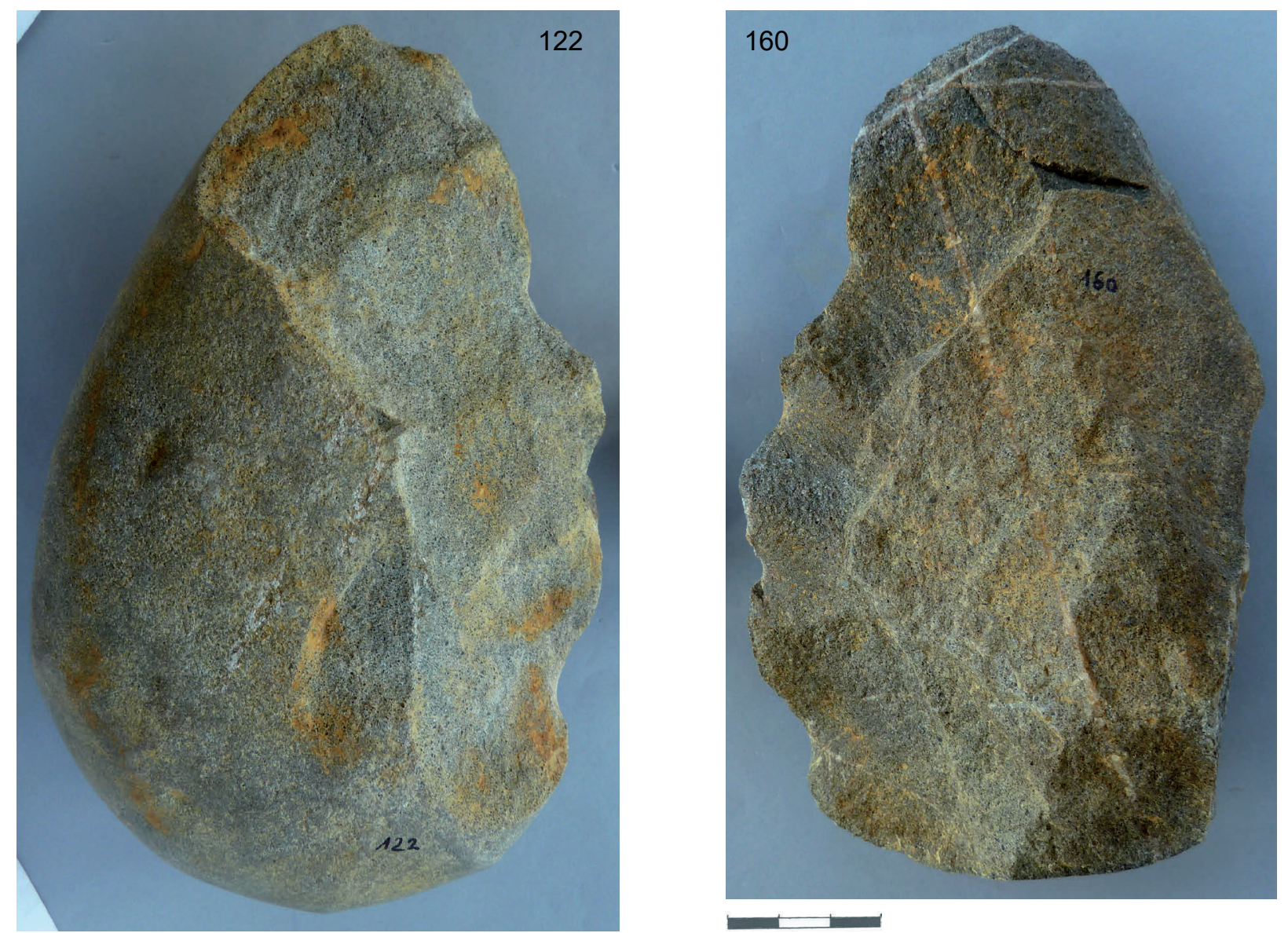

- FIGURE 17 -

Encoches sur grande entame $\left(n^{\circ} 160\right)$ et sur galet ovalaire aplati ( $\left.n^{\circ} 122\right)$ (A. Taylor, S. Bernard-Guelle). Échelle 2/3.
Notched big first flake ( $\left.n^{\circ} 160\right)$, notched flat pebble ( $\left.n^{\circ} 122\right)$. Scale 2/3. vironnement local voire immédiat. Des volumes parfois considérables (galets de plusieurs kg) ont été introduits et exploités sur place et l'ensemble des chaînes opératoires de débitage et de façonnage s'est intégralement déroulé sur site. Les productions issues de séquences de débitage sont dominantes comme en atteste l'importance des nucléus au sein de la série (27,6\%). Les activités de production d'éclats sont réalisées selon deux chaînes opératoires principales (Discoïde et frontale unipolaire sur enclume) fournissant une gamme d'éclats variés, souvent à dos naturels et de grandes dimensions $(5-10 \mathrm{~cm})$. Les galets les plus imposants sont fracturés de manière ordonnée afin de produire des supports de plus faibles dimensions qui intégreront notamment les chaines de débitage Discoïde, mais également frontale unipolaire. Les deux concepts de débitage principaux apparaissent donc synchrones, puisqu'un même volume peut fournir des supports de nucléus illustrant les deux concepts (R19 - fig. 28 et 29). Ce remontage est un argument fort en faveur de l'homogénéité de l'ensemble lithique collecté. Les galets moins massifs (décimétriques) sont exploités frontalement par débitage unipolaire sur enclume et une partie des éclats obtenus (particulièrement de gros éclats corticaux) sont, à l'image des fragments issus de la fracturation des gros blocs, utilisés comme supports au débitage Discoïde. En parallèle, une partie de ces galets, ainsi que certains galets fracturés, intègrent une chaine opératoire de façonnage essentiellement tournée vers la confection d'outils lourds, parfois de pièces bifaciales. Le façonnage bifacial est également mis en œuvre sur grosses entames probablement issues du débitage sur place de galets pluridécimétriques. Ces entames semblent en outre particulièrement prisées pour une utilisation brute ou parfois retouchée.

À côté de cette gestion des quartzites locaux, on note l'importation de rares silex depuis des sources d'origine variée et plus éloignée. Une partie de ces silex atteste d'une acquisition dans le secteur de MontgaillardHibarette ou même en aval de celui-ci au sein d'une des formations alluviales de l'Adour ou de L'Échez. Le deuxième groupe présente de fortes similitudes avec les silicifications de la région au sud-ouest de Pau. Le cas du troisième groupe, les silex à Lépidorbitoïdes est plus délicat puisque nous n'avions pas assez d'éléments pour 


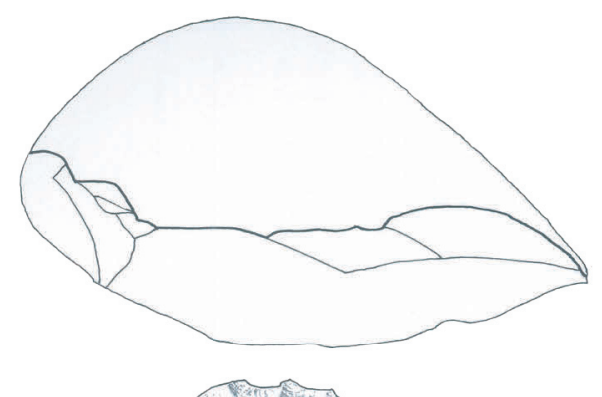

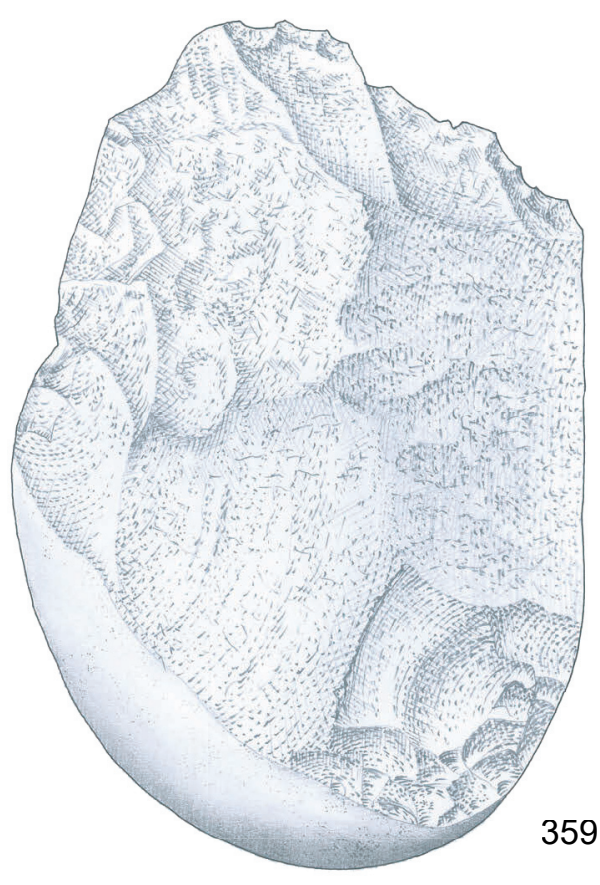

359

Hachereau type 0 ( n 359) (R. Picavet). Échelle 2/3.

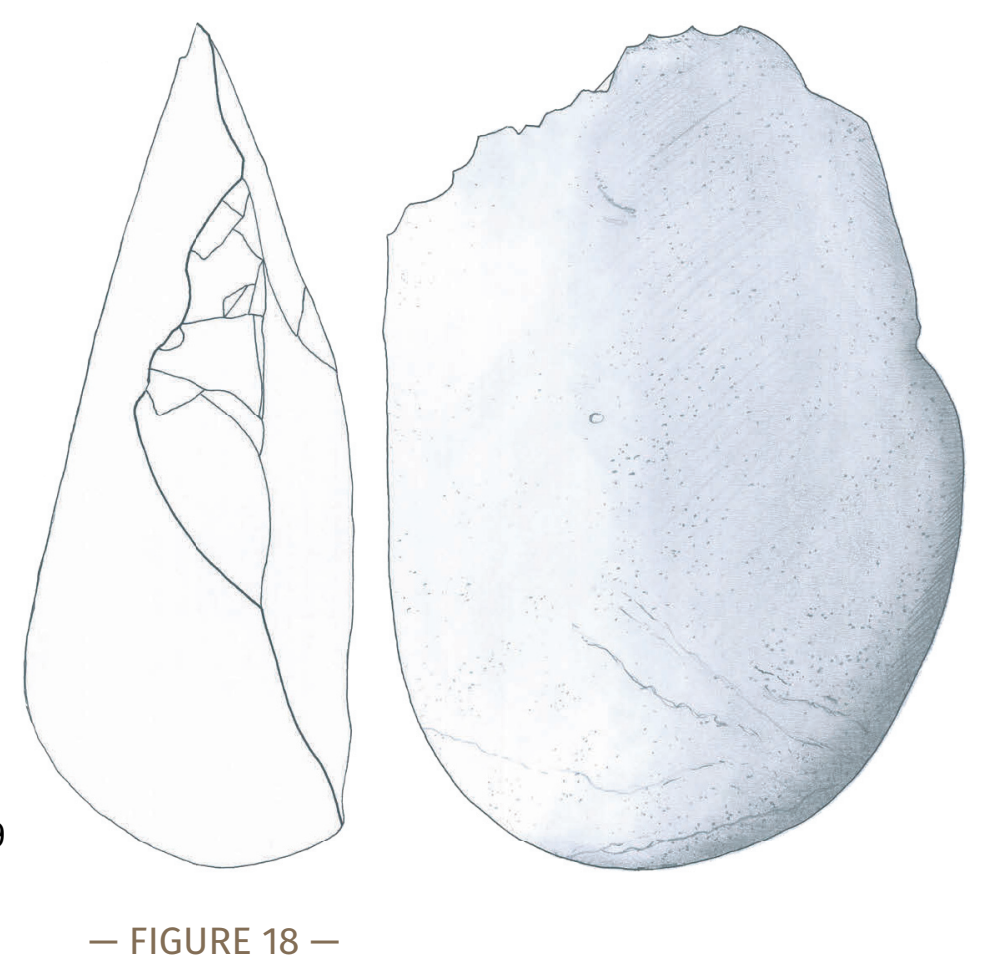

Type 0 "hachereau" (n³59). Scale 2/3. déterminer leur origine. En plus de l'outil bifacial, les quelques éclats/fragments d'éclats et les 2 petits nucléus attestent donc d'une introduction sur site très ponctuelle de petits galets, probablement en partie exploités sur place selon un concept Discoïde.

L'utilisation in situ d'une partie des productions est attestée par une approche fonctionnelle de la série qui révèle en effet la présence de macro-traces d'utilisation sur l'outillage retouché et façonné, ainsi que sur des supports bruts, tout en soulignant le caractère monospécifique des activités réalisées. Au regard de la sousreprésentation des supports débités (1,55 éclat par nucléus), tout en gardant à l'esprit qu'une portion de la fraction fine a été tronquée, une autre part de la production a pu semble-t-il faire l'objet d'une exportation ou au moins d'une délocalisation.

\section{4 | DISCUSSION : CONTEXTE RÉGIONAL ET ATTRIBUTION CHRONOCULTURELLE}

Les diagnostics et fouilles préventives réalisés à l'occasion des travaux de l'A65 ont fourni pour le bassin de l'Adour, un corpus de séries lithiques sur quartzite auxquelles l'industrie de Garlin peut être comparée, notamment avec les sites de Romentères (série A : Paléolithique moyen ancien et série B : Acheuléen pyrénéo-garonnais), Bénazit, Duclos et Septsos (Acheuléen pyrénéo-garonnais) (Defaye et al. 2009b ; Spinapolice et al. 2010 ; Colonge et al. 201 ; Hernandez et al. 2012, Lelouvier et al. 2013 ; Fourloubey et al. 2013) (fig. 30). Le mobilier lithique s'y présente essentiellement sous forme de nappes de vestiges résidualisées, s'inscrivant dans des dépôts lœssiques colluvionnés et secondairement altérés par une 

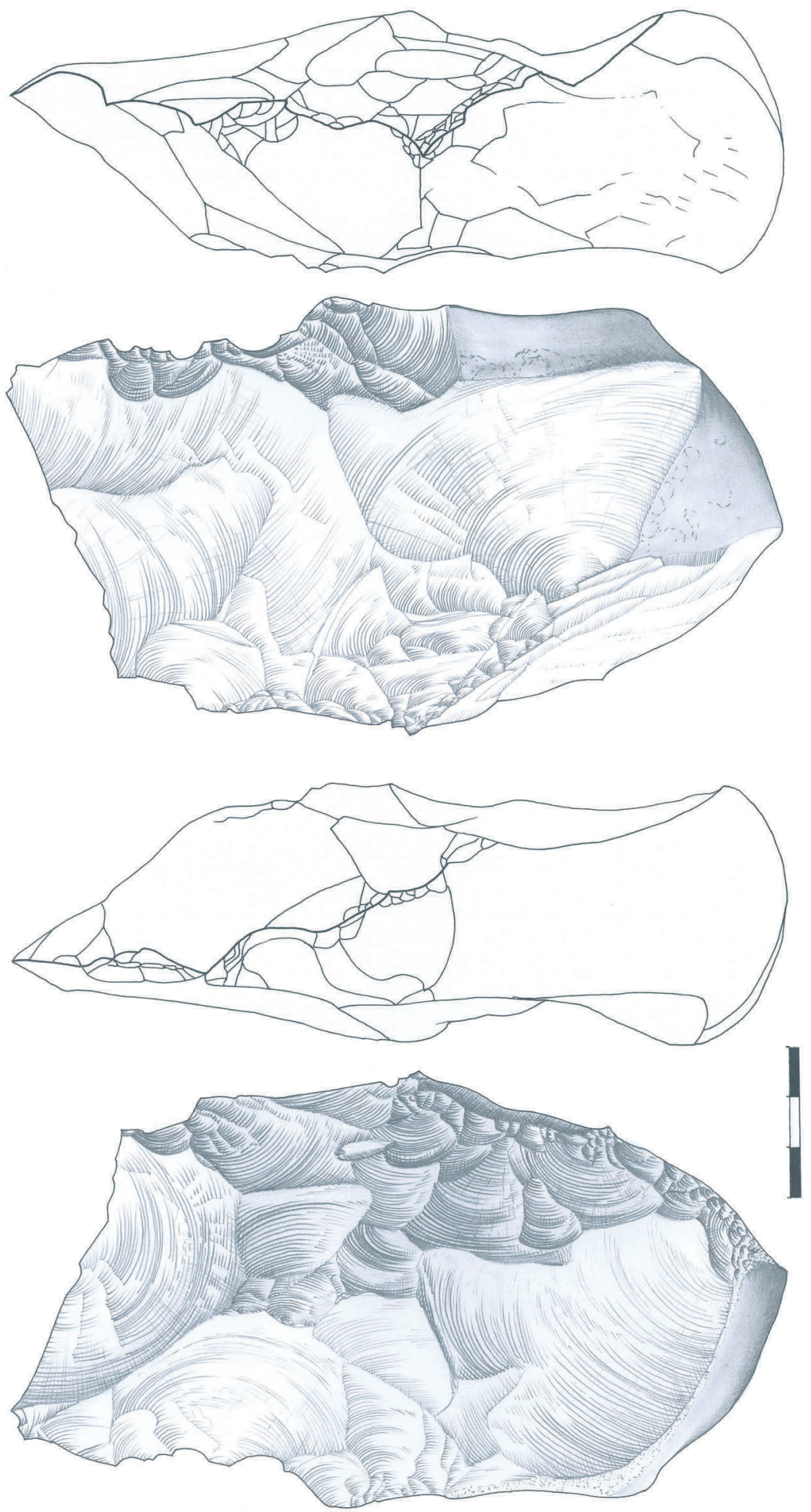

FIGURE 19

Pièce bifaciale à tranchant transversal en silex (n³25) (R. Picavet). Échelle $2 / 3$.

Flint bifacial tool with transverse cutting edge (n³25). Scale $2 / 3$.

pédogenèse de type Luvisol dégradé. Tous ces sites présentent une économie des matériaux tournée majoritairement vers l'acquisition et l'exploitation de galets de quartzites locaux $(90,4 \%$ à Septsos, $94 \%$ à Romentères, 95 \% à Bénazit, 95,8 \% à Duclos), comme à Garlin (98\%).
Bénazit, Duclos et Septsos ont tout trois été attribués à un faciès acheuléen du sud du bassin aquitain, d'influence ibérique, un Acheuléen pyrénéo-garonnais qui s'étend notamment sur le piémont nord des Pyrénées (bassins de l'Adour et de la Garonne) (Mourre et Colonge 2007 ; Colonge et al. 2014b). Cet Acheuléen se singularise par : 

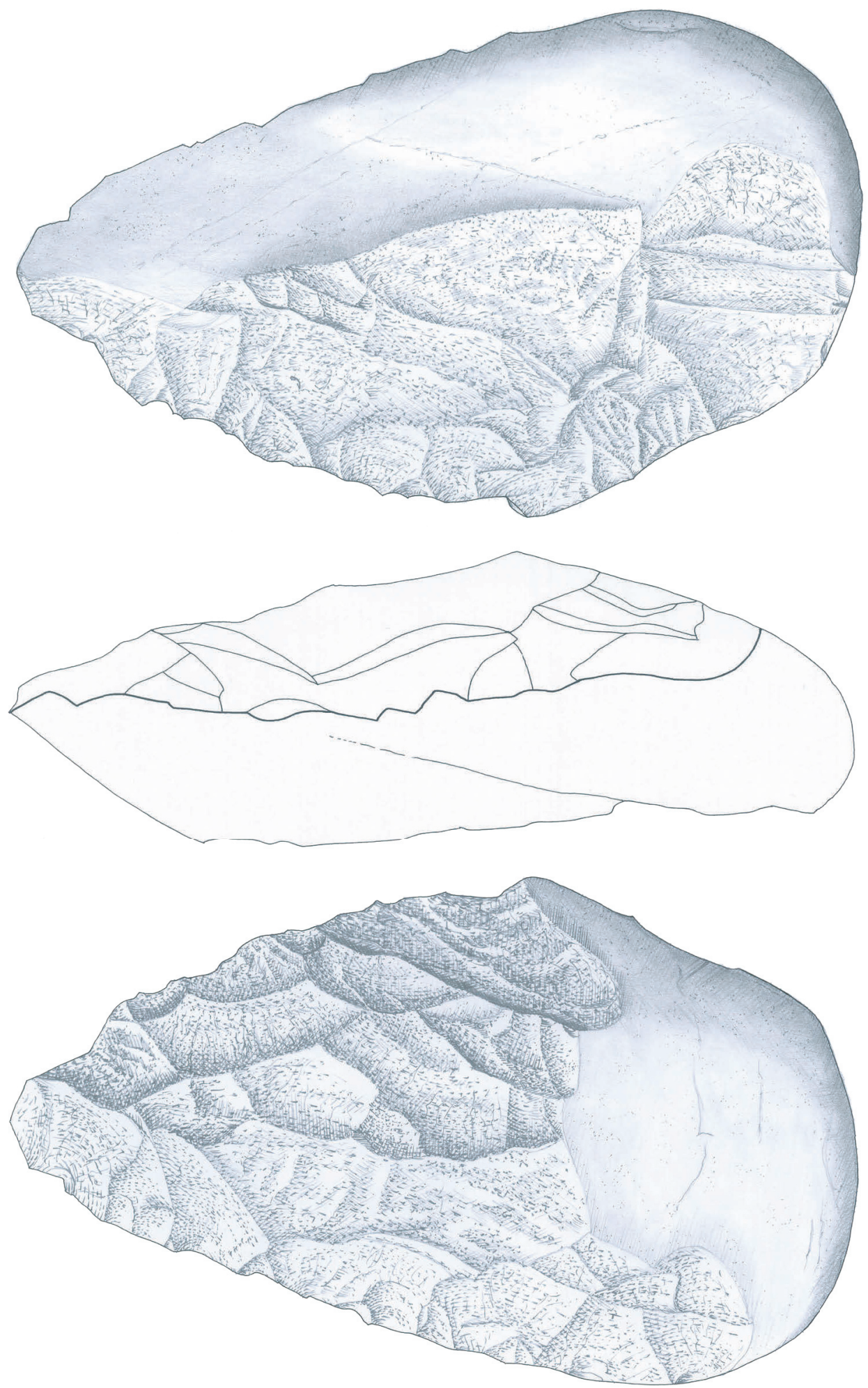

FIGURE 20

Biface partiel à base réservée (n 145) (R. Picavet). Échelle $2 / 3$.

Reserved base partial "biface" (no 145). Scale 2/3. 


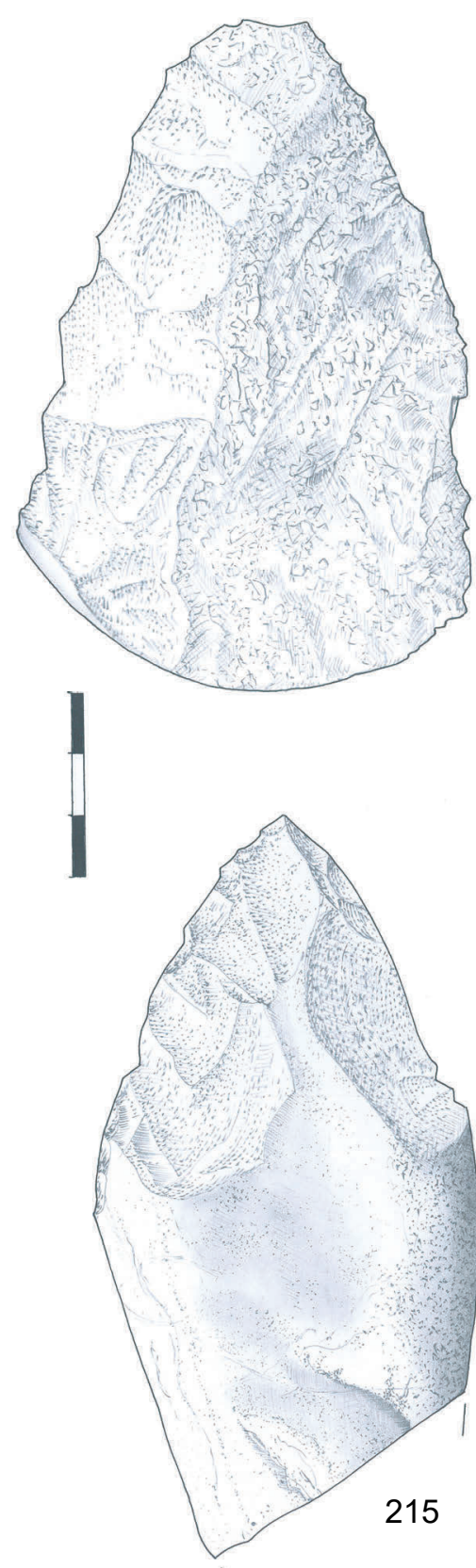

326
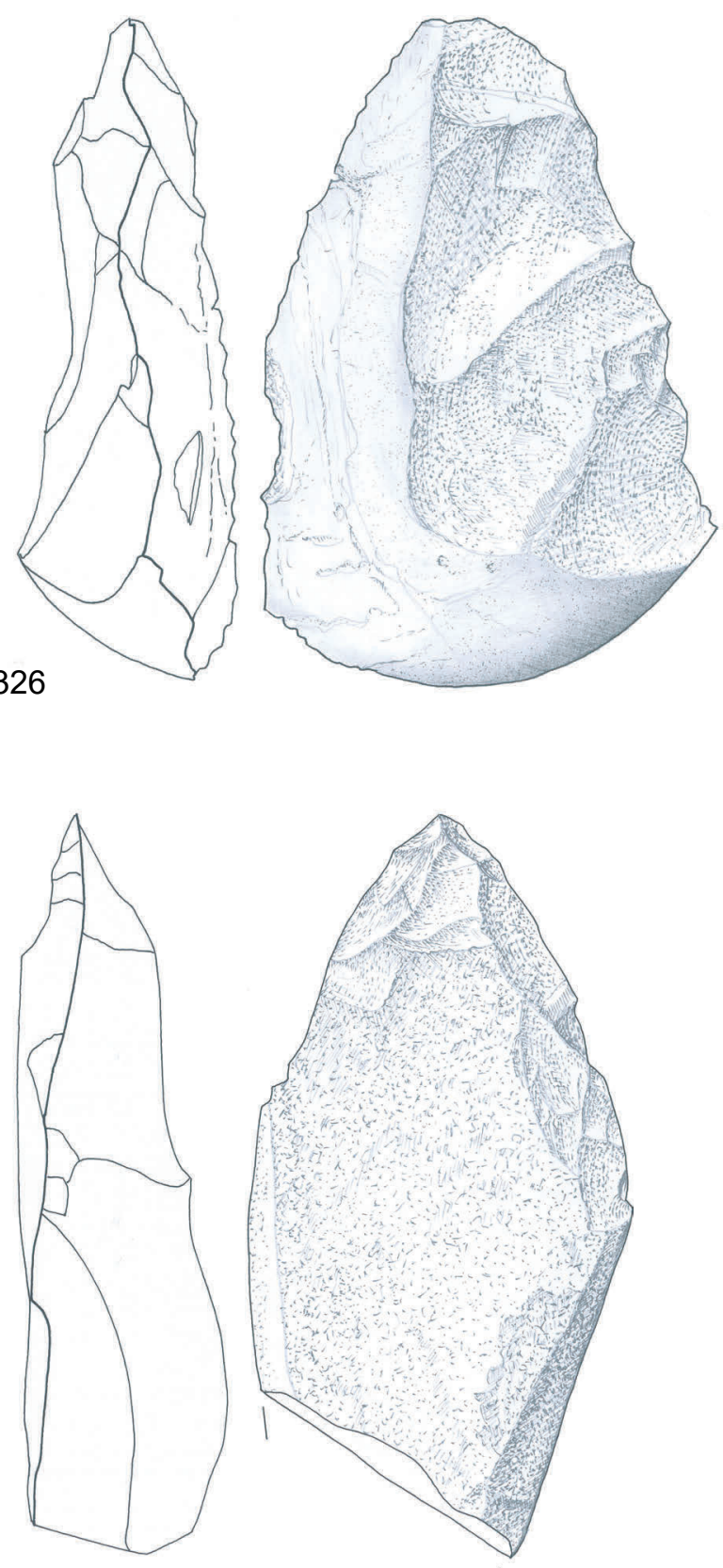

\section{FIGURE 21}

Uniface/ biface partiel à base réservée $\left(n^{\circ} 326\right)$ et pic ( $\left.n^{\circ} 215\right)$ (R. Picavet). Échelle 2/3.

Reserved base "uniface" / partial "biface" (n० 326), "pic" (n²15). Scale $2 / 3$.
- la production de grands éclats, objectif d'une chaine opératoire vraisemblablement autonome, plutôt destinés à fournir les supports d'un façonnage bifacial ou de hachereaux qu'à faire l'objet de retouche ou être utilisés bruts;

- une place importante de l'outillage lourd sur galet dans le panel typologique de l'outillage (galets aménagés type chopper notamment, cas particulier des polyèdres), équivalente à celle des bifaces ;

- la présence de hachereaux, le plus souvent de type 0 ; - des pièces bifaciales en quartzite, partielles, massives, irrégulières, aux arêtes finalisées/régularisées de manière très localisée relevant d'un façonnage majoritaire dit « mixte-combiné », à percussion dure rentrante, évoquant à la fois un façonnage mais possiblement un débitage de supports également; un mode de façonnage bifacial secondaire, plus classique, couvrant et abouti, réalisé au percuteur dur selon un geste tangentiel, la percussion tendre organique intervenant en finition sur les exemplaires les plus investis techniquement (façonnage strict) ; - un débitage dominé par le concept Discoïde, surtout de modalité unifaciale mais également bifaciale partielle ; - un recours fréquent au débitage sur enclume ;

- l'extrême rareté des méthodes Levallois, y compris lorsque les matériaux s'y prêtent (silex);

- un outillage retouché faiblement présent, peu varié et défini, plutôt dominé par le groupe des denticulés et encoches.

Si une certaine unité typo-techno-économique (et géographique) se dégage des industries lithiques de ces gisements, leur position chronostratigraphique reste discutée. En effet, traditionnellement perçu comme 

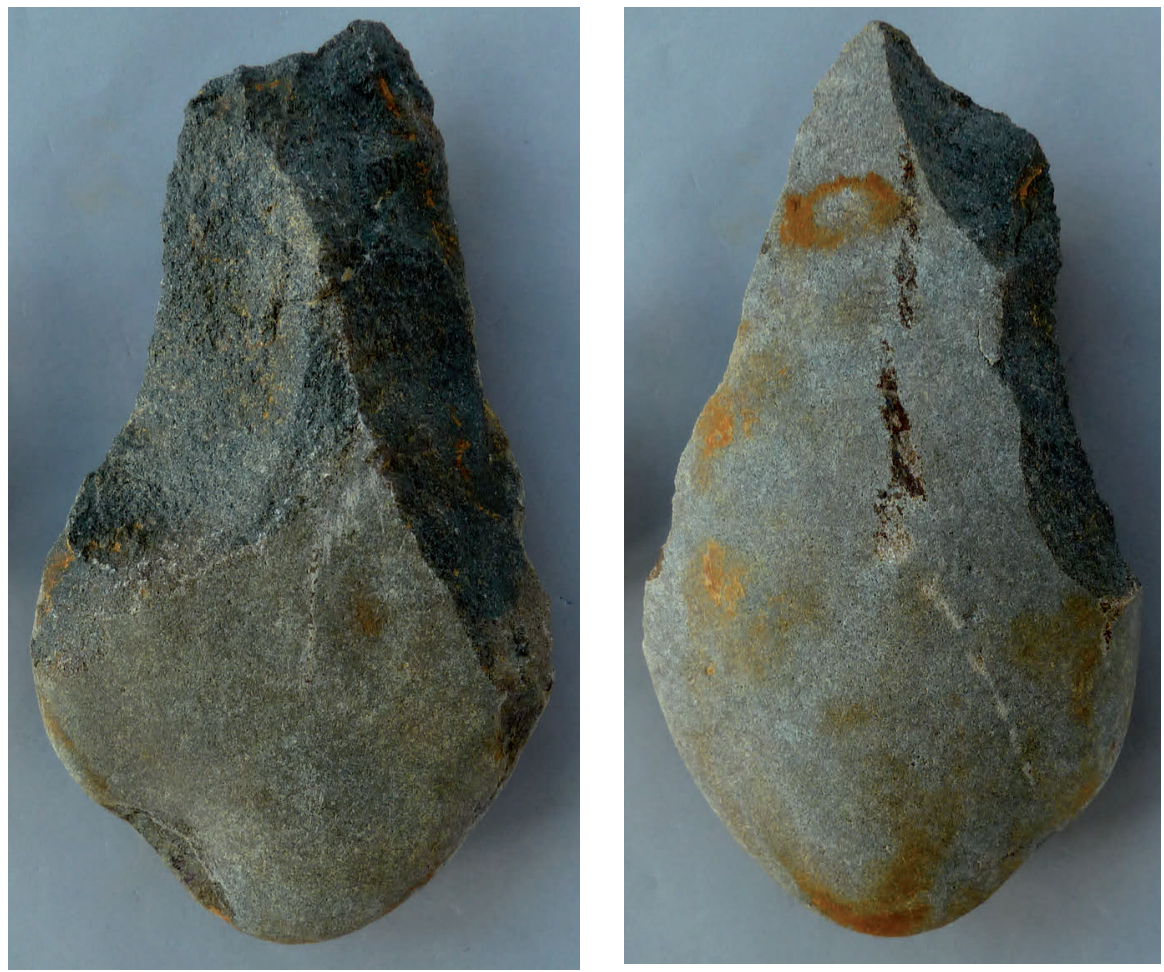

FIGURE 22

Biface partiel à base réservée - ébauche? ( $\left.n^{\circ} 21\right)$ (A. Taylor, S. Bernard-Guelle). Échelle 2/3.

Reserved base partial "biface" - preform ? (n²1). Scale 2/3.

antérieur à la transition MIS8-9 (300 ka, limite conventionnelle Paléolithique inférieur/moyen) dans le sud du Bassin aquitain, l'Acheuléen s'étend de part et d'autre de cette limite, l'Acheuléen pyrénéo-garonnais étant une spécificité locale recouvrant plusieurs millénaires depuis le MIS11 jusqu'à la fin du MIS6, depuis l'Acheuléen moyen archaïque à l'Acheuléen supérieur (Jarry 2010 ; Colonge et al. 2014b). Ainsi une datation par thermoluminescence sur pièce chauffée de Duclos a donné un âge de $169 \pm 19$ ka (début MIS6) mais une partie de l'industrie attribuée à l'Acheuléen pyrénéo-garonnais, conservée plus ou moins in situ dans les sédiments de l'horizon BT2 qui se sont mis en place au cours du MIS7, indiquerait quant à elle plutôt la transition MIS6-7. À Romentères, la série de datations OSL situe la séquence entre 2,0 $\pm 0,1$ et $317 \pm 23 \mathrm{ka}$, et les 3 dates TL (172 $\pm 9,246 \pm$ 22 et $296 \pm 22 \mathrm{ka}$ ) placent les deux industries collectées au MIS6 pour la série A (Paléolithique moyen ancien, horizon BT2) et entre les MIS7 et 9 pour la série B (Acheuléen pyrénéo-garonnais résidualisé, horizon BT2). À Septsos, la séquence sédimentaire, contractée et peu lisible, n'a pu être datée. La série s'insère comme à Duclos et Romentères dans un horizon BT développé sur des lœss colluvionnés mais il s'agit cette fois du BT1 (MIS2 à 5.4). Elle serait en position secondaire, ayant été fortement remobilisée sur le versant en bordure duquel est implanté le gisement: usures liées au ruissellement sur les objets lithiques, associés à de nombreux graviers, distribués en nappe lâche sans concentrations, composition granulométrique de la série éloignée des débitages expérimentaux.
Les objets pourraient alors provenir de la remobilisation d'une industrie datée du Pléistocène moyen, issue de l'horizon BT2 sous-jacent représentant le bilan de plusieurs interglaciaires de cette période du Pléistocène (MIS6 à 9). À Bénazit, le mobilier acheuléen a été retrouvé en position secondaire à l'interface des horizons BT1 et BT2, malheureusement peu distinguable au décapage mécanique. Les deux seules dates OSL situent l'enfouissement des objets entre 40 et 53 ka (première moitié du MIS3) pour un âge supposé de l'industrie situé au cours des MIS6 à 7 si l'on considère les données archéologiques régionales.

Si les deux complexes chronoculturels, bien que distingués, sont mêlés à Romentères, le site de Duclos semble suggérer que l'Acheuléen pyrénéo-garonnais puisse être subcontemporain du Paléolithique moyen ancien et coexister autour de la transition MIS6-7 dans sa phase récente. Des industries aux caractères acheuléens situées dans l'horizon BT1 (MIS5 à 3) seraient alors forcément en position secondaire. Pourtant, d'autres industries présentant des traits acheuléens, liés à un recours aux roches dures pyrénéennes (quartzites, ophites...) et à la confection d'un outillage lourd (hachereaux, pièces bifaciales, galets aménagés) ont bien été décrites et datés du Pléistocène supérieur. C'est notamment le cas de plusieurs sites diagnostiqués et fouillés dans la région de Bayonne (Le Basté, Le Prissé et Le Chemin de Jupiter, silex essentiellement - Colonge et al. 2014a), et dans les Landes (Latrote, quartzite et silex à 

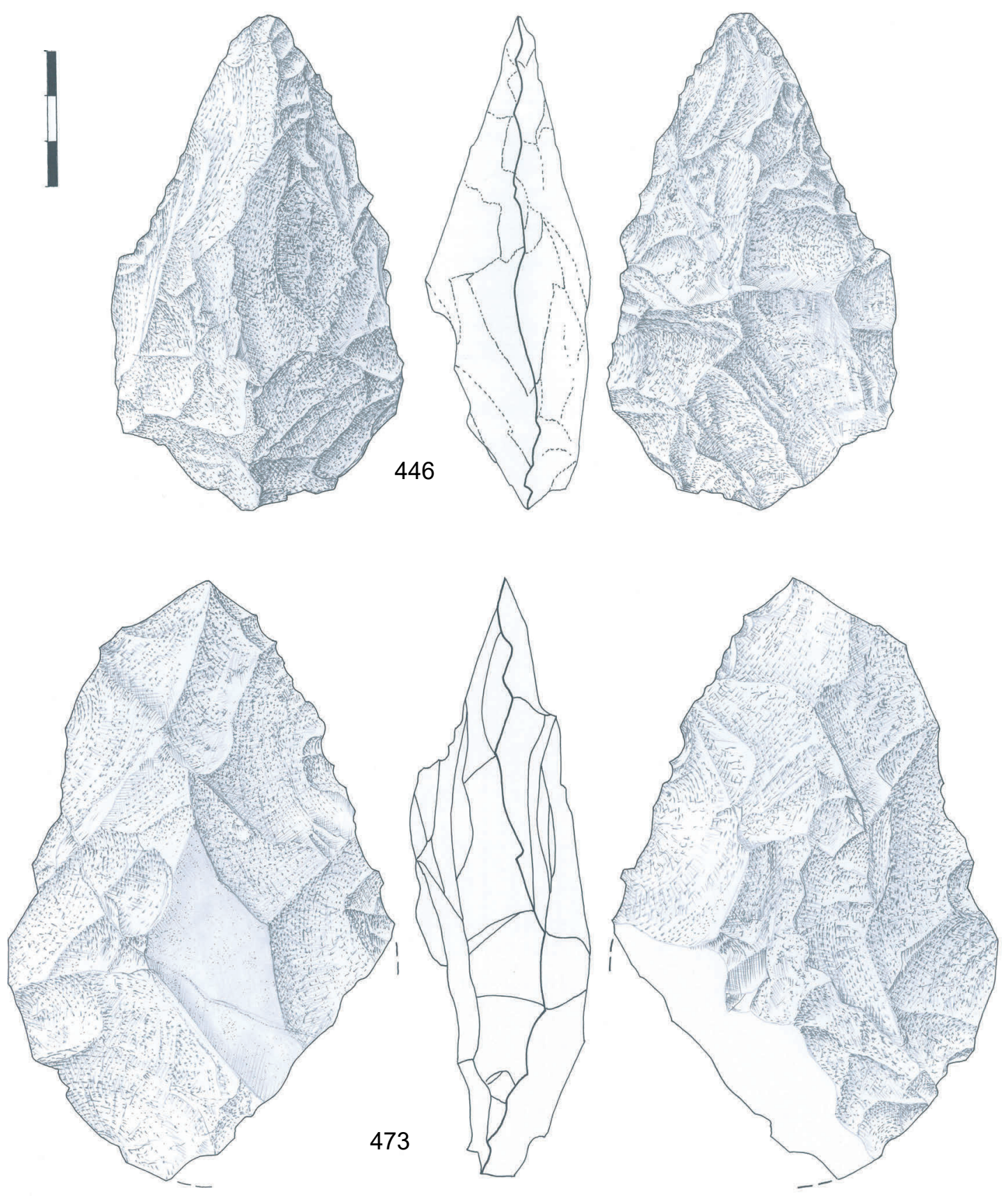

\section{- FIGURE 23 -}

Petit biface lancéolé ( $\left.n^{\circ} 446\right)$ et biface partiel ( $n^{\circ}$ 473) (R. Picavet). Échelle 2/3

parts égales), attribué à un faciès du Moustérien récent à hachereaux vasco-cantabrique, le Vasconien (BernardGuelle et al. 2010 et 2014, Deschamps 2014 et 2016). Les âges déterminés par OSL et TL de ces gisements se situeraient entre 45 et 50 ka (MIS3), avec une bonne convergence des résultats.

Ce Moustérien récent se distinguerait des industries acheuléennes par:
Small lanceolated "biface" ( $\left.n^{\circ} 446\right)$ and partial "biface" ( $\left.n^{\circ} 473\right)$. Scale 2/3.

- un outillage lourd façonné sur quartzite plus discret (quelques galets aménagés de type chopper), avec notamment la présence de hachereaux toujours sur quartzite, de type 0 mais également de type 1 et 2 , dont le débitage du support induit un degré de prédétermination en général plus élevé que ceux de l'Acheuléen, et ne présentant pas de standardisation morphométrique mais des dimensions moyennes plus réduites et notamment un plus faible allongement que les exemplaires plus anciens ; 

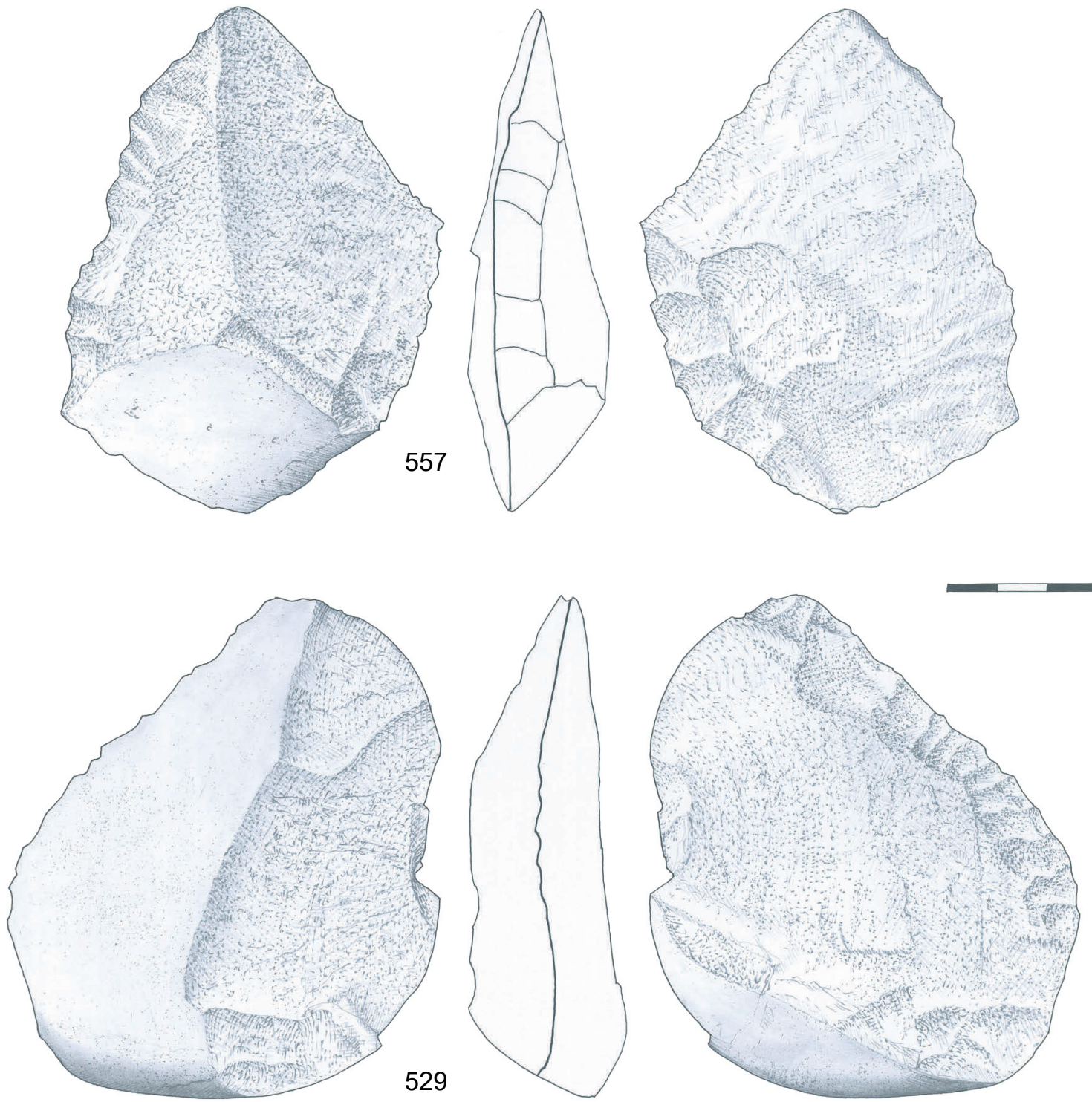

- FIGURE 24 -

Racloirs transversaux sur éclat dont un à retouche inverse (nº 529) (R. Picavet,

Transverse scrapers, one with inverse retouch ( $\left.n^{\circ} 529\right)$. Scale 2/3. A. Taylor, S. Bernard-Guelle). Échelle 2/3.

- des bifaces à base réservée avec retouche secondaire de finition des arêtes latérales partielle mais systématique témoignant d'un façonnage bifacial strict dominant, de dimensions modestes;

- un outillage sur quartzite toujours inférieur en nombre à celui sur silex, ce dernier étant mieux défini et plus diversifié ;

- le débitage sur enclume y semble plus discret, tout comme les méthodes Levallois, un débitage Discoïde hiérarchisé dominant en général dans les ensembles lithiques ;

- les chaines opératoires de débitage l'emportent largement sur les chaines de façonnage ;
- une diversification et une véritable économie des matières premières.

À première vue, l'industrie collectée à Garlin peut être rapprochée du techno-complexe Acheuléen pyrénéogaronnais puisqu'elle en présente les principaux marqueurs typo-technologiques: faible économie et diversification des matières premières, débitage Discoïde unifacial et sur enclume dominants, forte présence de l'outillage lourd, façonnage bifacial réduit proche du façonnage mixte-combiné souligné par D. Colonge à Duclos, production de grands éclats-supports, hachereaux, présence (certes discrète) de galets de type à chant épannelé... Or, l'approche géoarchéologique combinée aux datations OSL situe cet ensemble archéologique au sein 

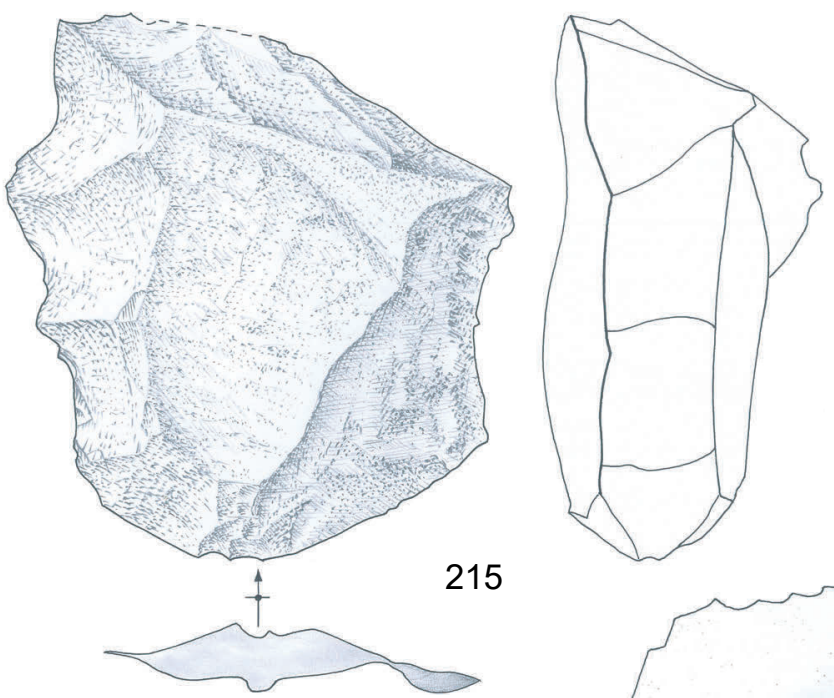

215
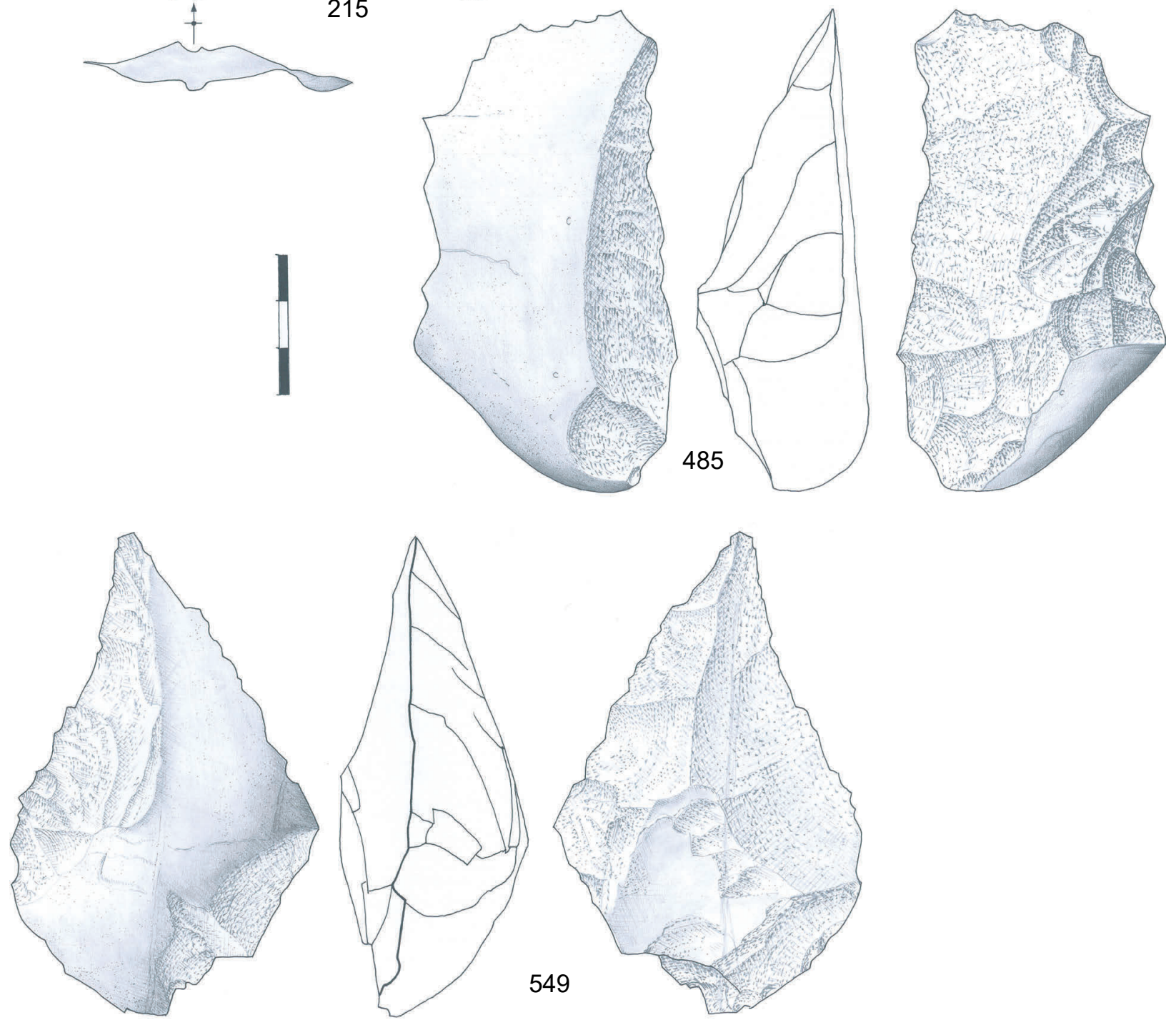

- FIGURE $25-$

Denticulé sur éclat $\left(n^{\circ} 215\right)$, denticulé ou hachereau type 0 ? $\left(n^{\circ} 485\right)$, bec alterne sur éclat (n549) (R. Picavet). Échelle 2/3.

Denticulate on flake ( $\left.n^{\circ} 215\right)$, denticulate or possible type 0 « hachereau » $\left(n^{\circ} 485\right)$ Alternate "bec" on flake ( $\left.n^{\circ} 549\right)$. Scale 2/3. 

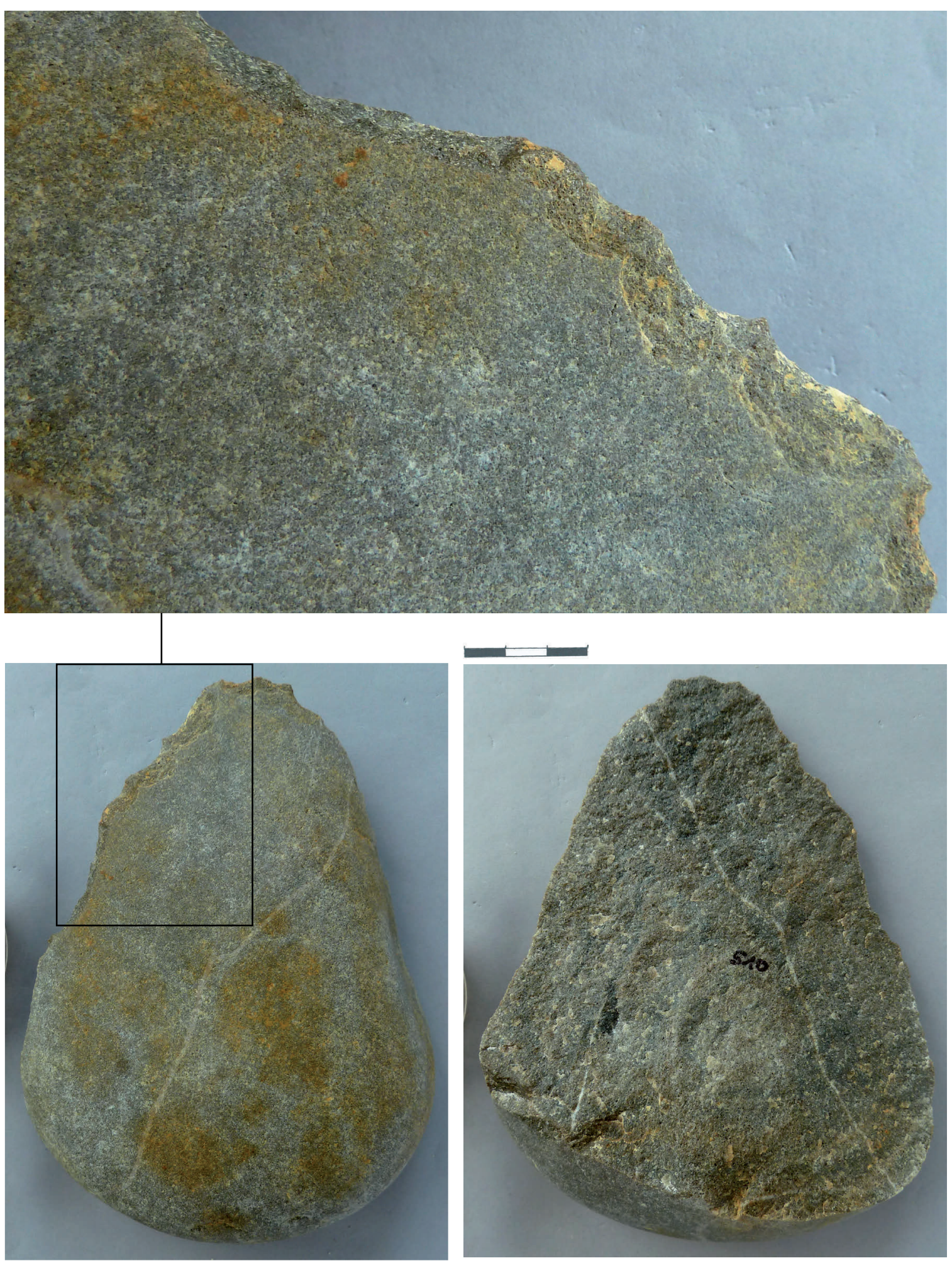

\section{- FIGURE 26 -}

Tranchant utilisé sur entame ( ${ }^{\circ} 510$ ) et détail de la modification de la partie active (x2) (A. Taylor, S. Bernard-Guelle). Échelle 2/3.
Used cutting edge on primary flake $\left(n^{\circ} 510\right)$ and detail of the edge's alteration (x2). Scale $2 / 3$. 

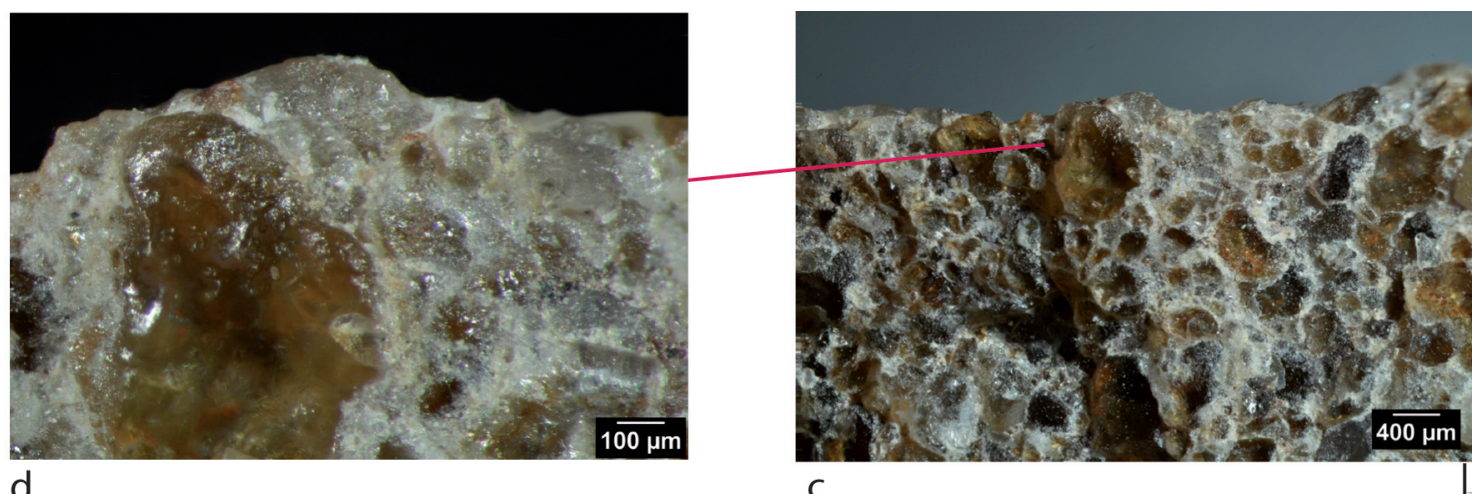

d

C

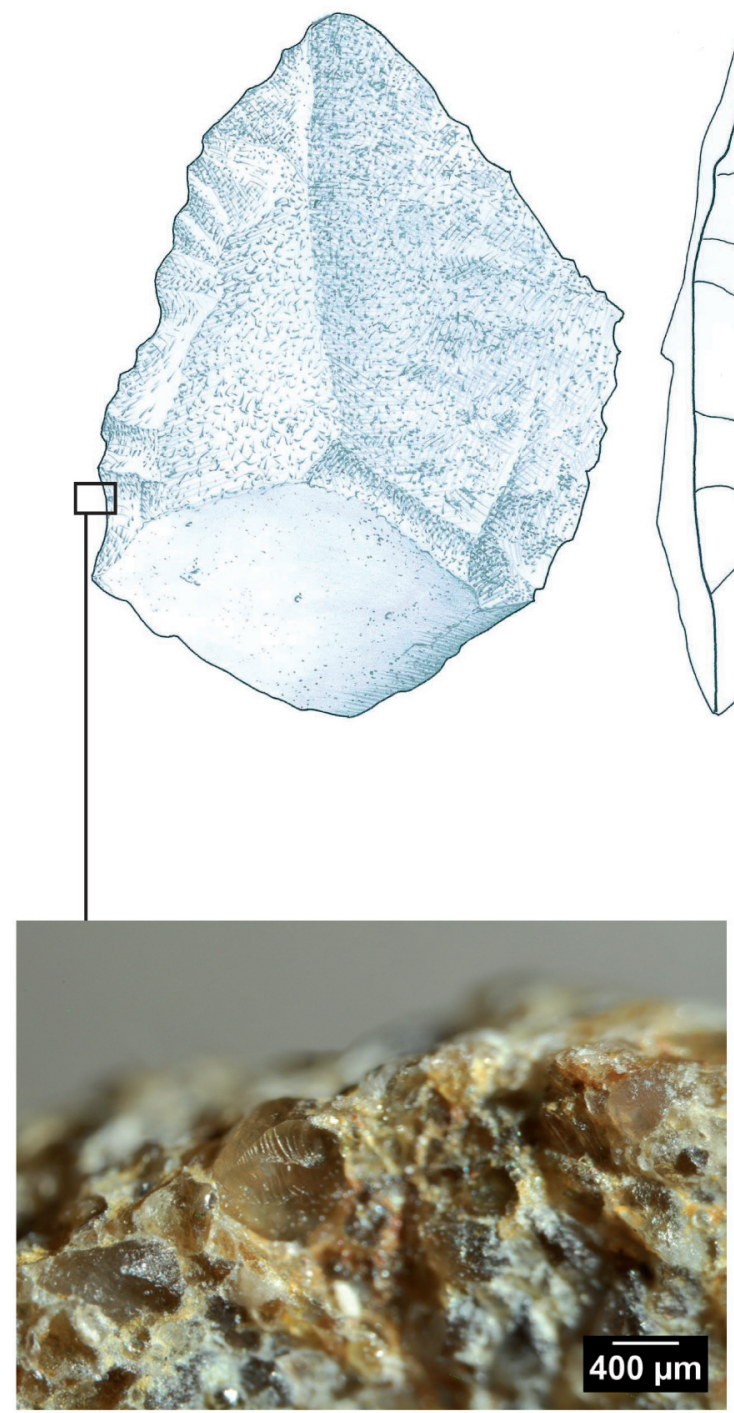

a
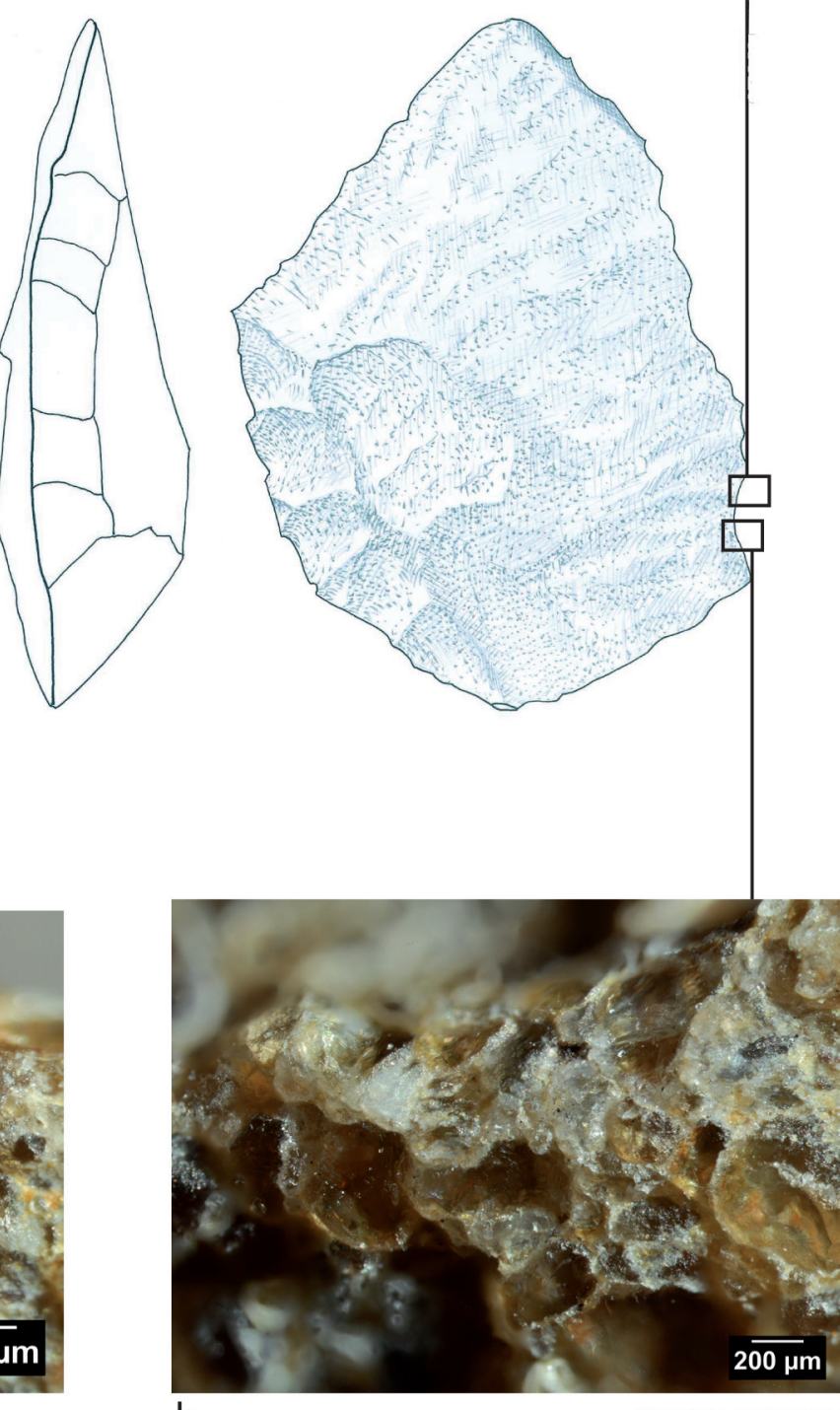

- FIGURE 27 -

Vues macroscopiques du bord émoussé de la pièce nº 557 (L. Chesnaux P. Fernandes, R. Picavet). a. et b. Images permettant d'observer la corrosion importante de la matrice. c. Emoussé des grains de quartz lié à l'utilisation. d. Vue rapprochée de l'émoussé d'un grain de quartz.
Macroscopic magnifications of the blunt edge on object $n^{\circ}$ 557. $a$. and $b$. Important corrosion of the matrix. c. Quartz grains' use-wear related rounding. d. Close-up view of a rounded quartz grain. 


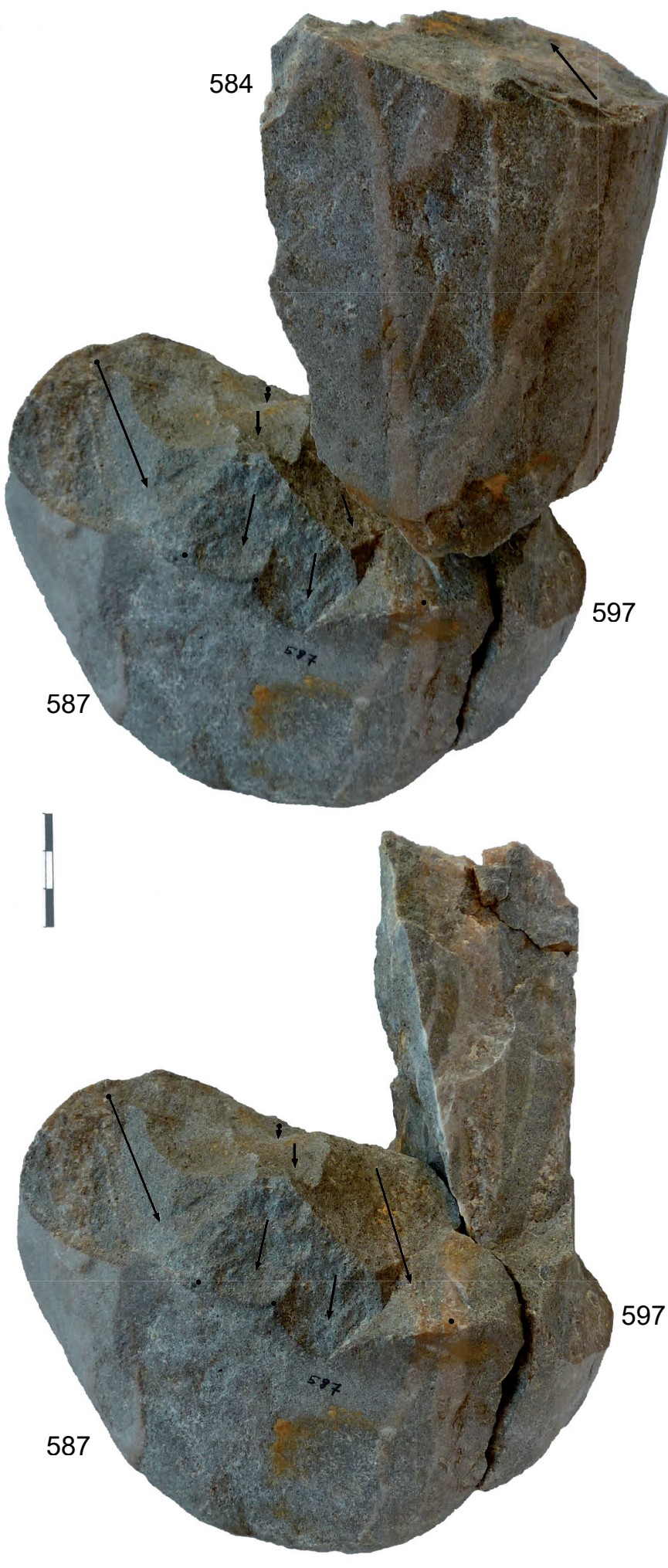

\section{FIGURE 28}

597 Remontage 19, états 1 et $2: 3$ éléments composent ce raccord de débitage ( ${ }^{\circ} 584,587$ et 597). Il témoigne d'une phase de fracturation volontaire d'un galet allongé sur enclume, avec la reprise de deux de ces fragments comme supports de nucléus, l'un frontal unipolaire ( $n^{\circ} 587$ ), l'autre Discoïde unifacial (n 597) (A. Taylor, S. Bernard-Guelle). Échelle 1/2.

Refitting 19, state 1 and 2: this refitting comprises 3 objects ( $n^{\circ}$ 584, 587 and 597). It testifies to the purpose driven fracturation of an elongated pebble on an anvil, and the selection of two pieces as core blanks, one showing a frontal unipolar progression ( $n^{\circ} 587$ ), the other of the discoid unifacial type ( $n^{\circ} 597$ ). Scale $1 / 2$. 

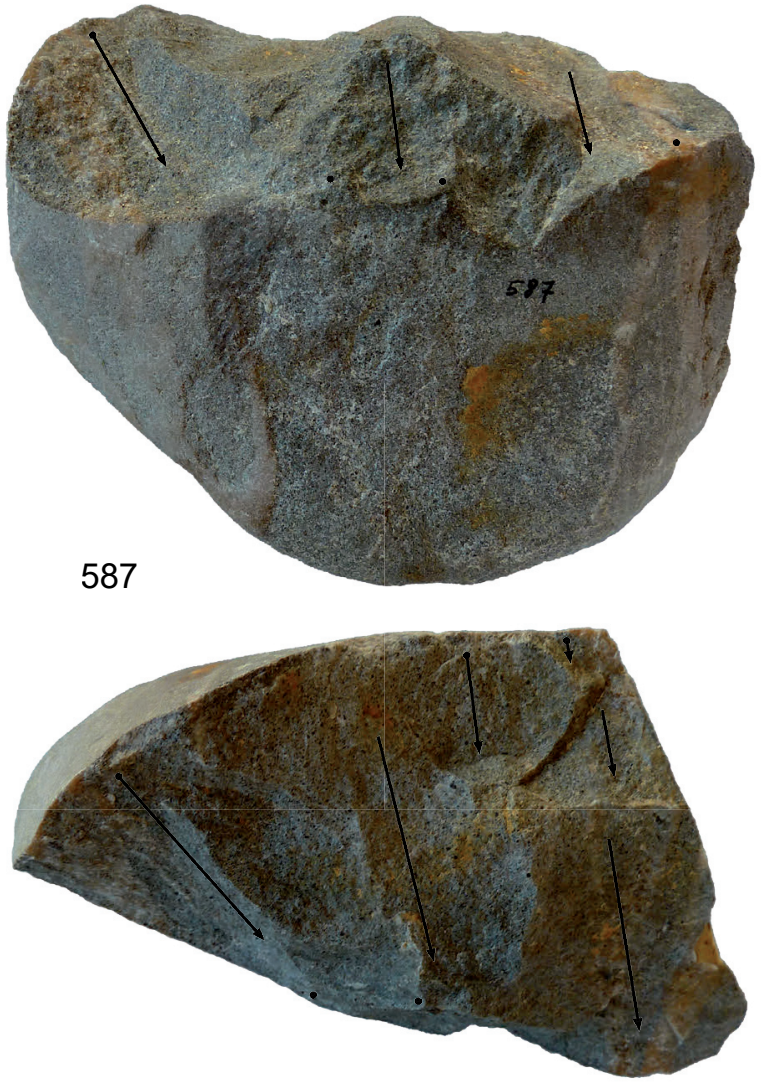

- FIGURE $29-$

Remontage 19, état 3 : les 2 fragments utilisés comme nucléus à débitage fronta unipolaire ( $n^{\circ} 587$ ) et Discoïde unifacial ( $\left.n^{\circ} 597\right)$ (A. Taylor, S. Bernard-Guelle). Échelle $1 / 2$.

d'un horizon BT1 qui s'est développé sur des limons déposés au cours du dernier cycle glaciaire, soit clairement post-éemiens, ce qui est en contradiction avec la lecture techno-typologique qui tend donc plutôt vers une attribution à la sphère acheuléenne. L'industrie de Garlin est ainsi plus récente d'au moins un interglaciaire et, sauf à reconsidérer l'extension des faciès acheuléen bien au-delà de la fin du MIS6, nous avons ici affaire à un acheuléen en apparence seulement. S'il s'agit d'un faciès moustérien, il faut alors envisager que les caractéristiques de la série soient la résultante d'un possible déterminisme pétrographique et/ou fonctionnel. La proximité technotypologique de la série de Garlin avec certaines industries moustériennes dont on ne retiendrait que la part réalisée sur quarzite, au sens large (quartzite ou quartz), pose en effet question car les convergences sont troublantes (fig.31). Afin de faciliter les comparaisons, nous évoquerons ici des sites que nous avons fouillés récemment et pour lesquels seules sont prises en compte les composantes en matériaux durs, souvent fortement représentées (quartzite à Saint-Gein « Latrote », Bernard-Guelle et al. 2014) voire ultra dominantes (quartz à Saint-Sulpice « Bois de l'Hôpital », Bernard-Guelle et al. 2019). Prises isolément,

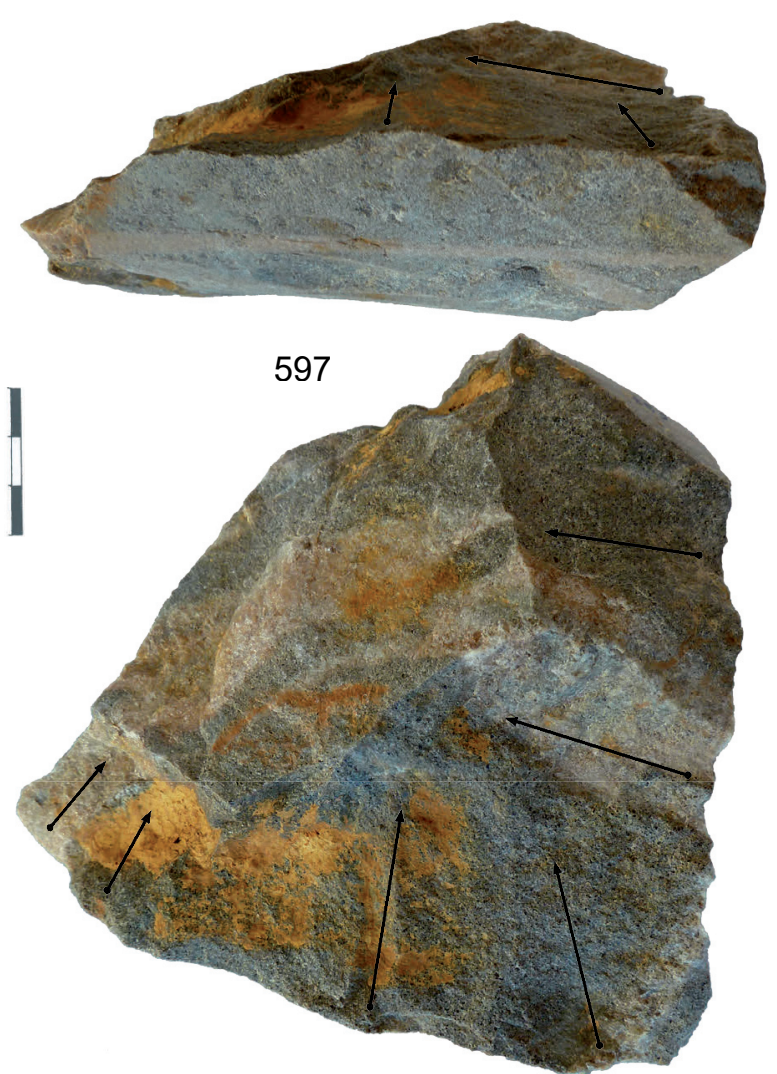

Refitting 19, state 3: the two pieces used as unipolar frontal ( $n^{\circ}$ 587) and unifacial discoid cores ( $\left.n^{\circ} 597\right)$. Scale $1 / 2$.

ces composantes sont très proches de la série de Garlin, que ce soit dans les concepts et procédés de débitage, l'investissement souvent limité du façonnage, ou encore les types et proportion d'outillages (fig. 31). Elles sont pourtant issues de sites rattachés à divers technocomplexes moustériens récents bien calés chronostratigraphiquement et dont la part en silex ne prête à aucune ambiguité. Sur cette seule composante, l'attribution chronologique repose souvent sur quelques critères quantitatifs (part de tel ou tel objet), qualitatifs/techniques (finition de la retouche ou du façonnage bifacial), voire morphologiques ou dimensionnels (bifaces notamment) pourtant là encore potentiellement soumis à l'influence des contraintes des matériaux (présence/absence, abondance, dimensions, qualité) et/ou à des exigences fonctionnelles (types d'activités, fonction du site...). Sur la base d'un seul type de matériau aux contraintes techniques fortes (quartz et quartzite), la frontière entre une attribution au Moustérien ou à l'Acheuléen peut être finalement très ténue, le basculement d'un faciès à l'autre pouvant dépendre finalement d'un détail. Il suffirait ainsi de quelques pièces en silex «typées» moustériennes pour rattacher définitivement la série de Garlin au monde Moustérien. 


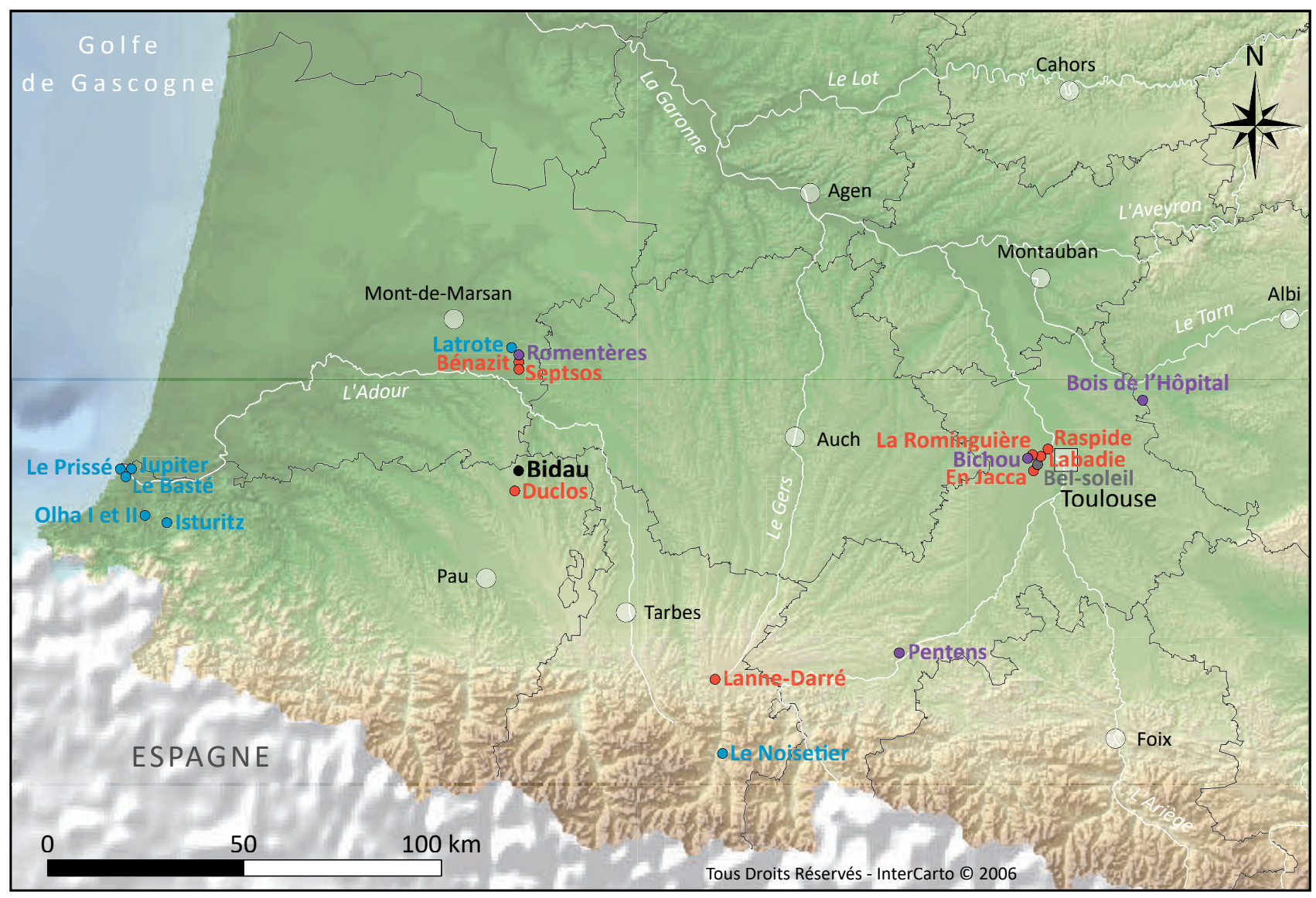

- FIGURE $30-$

Contexte archéologique régional (sélection de données récentes). En rouge : techno-complexe acheuléen pyrénéo-garonnais. En bleu : techno-complexe moustérien à hachereaux. En violet : techno-complexes acheuléens et moustériens. En gris : techno-complexe moustérien indéterminé (A. Taylor, S. Bernard-Guelle).

Signalons à ce sujet la présence, hors emprise fouillée mais dans un sondage du diagnostic situé $150 \mathrm{~m}$ plus au nord, d'un biface lancéolé en silex d'aspect très soigné (Chopin et al. 2015 - p. 43) découvert en position stratigraphique similaire (BT1).

\section{CONCLUSION}

Pourtant typologiquement proche de la composition classique de l'Acheuléen Pyrénéo-Garonnais qui suggère une attribution au Pléistocène moyen (et au complexe du Paléolithique Inférieur), la série lithique de Garlin est datée d'une phase centrale du Pléistocène supérieur. En y regardant de plus près, les caractéristiques technotypologiques de l'assemblage ne sont pas si différentes de certains techno-complexes moustériens. Le site de Bidau contribue ainsi à alimenter le débat sur les difficultés d'attribution chronoculturelle de ces séries lithiques sur quartzite du Sud-Ouest de la France et sur la place de ce type de mobilier dans le contexte foisonnant des industries de la fin du Paléolithique moyen. Gageons que de nouvelles prescriptions et fouilles archéologiques dans ces limons loessiques apporteront de nouveaux éléments stratigraphiques et taphonomiques qui aideront à mieux appréhender et comprendre ces industries.
Regional archaeological context (recent data selection). Red: pyreneo-garonnais Acheulean complex. Blue: Mousterian complex with hachereau shaping. Purple: Acheulean and Mousterian complex. Gray: indiscriminate Mousterian complex.

\section{REMERCIEMENTS}

Il nous est agréable de remercier Céline Vacher de la Société d'Équipement des Pays de l'Adour pour son suivi de l'opération et la coordination entre les différents acteurs du projet et la fouille archéologique. Nos remerciements vont également au Service Régional de l'Archéologie, particulièrement à Olivier Ferullo pour le suivi scientifique du chantier et les nombreux échanges sur les stratégies et méthodes de fouille, ainsi que sur le mobilier lithique collecté. Sa disponibilité et sa réactivité ont été des atouts majeurs pour le bon déroulement de cette opération. Nous remercions tout particulièrement les membres de l'équipe de fouille qui ne figurent pas parmi les auteurs de cet article : Jean-Baptiste Caverne, Gilles Gazagnol, Audrey Lafarge et Chloé Pfister. Cette publication a profité des conseils avisés d'Elisa Nicoud (rapporteur CTRA) et de la relecture constructive d'Alain Turq et de Marc Jarry. Qu'ils soient ici tous remerciés. 


\begin{tabular}{|c|c|c|c|c|c|}
\hline & Garlin "Bidau" & Saint Gein "Latrote" & $\begin{array}{l}\text { Saint-Sulpice "Bois de } \\
\text { l'Hôpital" unité } 1\end{array}$ & $\begin{array}{l}\text { Saint-Sulpice "Bois de } \\
\text { |'Hôpital" unité } 2\end{array}$ & $\begin{array}{l}\text { Saint-Sulpice "Bois de } \\
\text { l'Hôpital" unité } 3\end{array}$ \\
\hline Matériau & quartzite* & quartzite* & quartz $^{*}$ & quartz $^{*}$ & quartz $^{*}$ \\
\hline N pièces & 608 & 1165 & 321 & 2001 & 13665 \\
\hline$\%$ total série & $98,2 \%$ & $48,7 \%$ & $92,4 \%$ & $91,5 \%$ & $88 \%$ \\
\hline Diversité matières premières & - & ++++ & + & +++ & ++++ \\
\hline Façonnage versus débitage & débitage dominant & débitage dominant & débitage dominant & débitage dominant & débitage dominant \\
\hline Nucléus & $27 \%$ & $7,5 \%$ & $5,6 \%$ & $4,9 \%$ & $5,4 \%$ \\
\hline Ratio éclats $(>20 \mathrm{~mm}) /$ Nucléus & 1,55 & 7,2 & 8,6 & 9,3 & 9,4 \\
\hline \begin{tabular}{|l|l} 
Débitage Discoïde \\
\end{tabular} & gestion unifaciale dominante & gestion unifaciale dominante & gestion unifaciale dominante & gestion unifaciale dominante & gestion unifaciale dominante \\
\hline Débitage sur enclume & frontal & frontal & frontal & frontal & frontal \\
\hline $\begin{array}{l}\text { Ramification et contemporanéité stricte } \\
\text { des chaines opératoires de débitage }\end{array}$ & $\begin{array}{l}\text { récupération de matrices produites } \\
\text { par débitage sur enclume comme } \\
\text { supports au débitage Discoïde }\end{array}$ & $\begin{array}{l}\text { récupération de matrices produites } \\
\text { par débitage sur enclume comme } \\
\text { supports au débitage Discoïde }\end{array}$ & non attesté & $\begin{array}{c}\text { récupération de matrices } \\
\text { produites par débitage sur } \\
\text { enclume comme supports au } \\
\text { débitage Discoïde } \\
\end{array}$ & $\begin{array}{c}\text { récupération de matrices } \\
\text { produites par débitage sur } \\
\text { enclume comme supports au } \\
\text { débitage Discoïde } \\
\end{array}$ \\
\hline \begin{tabular}{|l|} 
Débitage Levallois \\
\end{tabular} & non reconnu & rare, sur variété la plus fine & non reconnu & rare, sur varièté la plus fine & rare, sur variété la plus fine \\
\hline Giant core technology & non reconnue & non reconnue & non reconnue & non reconnue & non reconnue \\
\hline $\begin{array}{l}\text { Production de grands éclats (entames 10- } \\
20 \mathrm{~cm} \text { ) }\end{array}$ & $\begin{array}{l}\text { supports de bifaces, hachereaux, } \\
\text { outils bruts }\end{array}$ & $\begin{array}{l}\text { supports au débitage, bifaces, } \\
\text { hachereaux, outils bruts }\end{array}$ & & supports au débitage & $\begin{array}{l}\text { supports au débitage, outils } \\
\text { retouchés, outils bruts }\end{array}$ \\
\hline Chaines opératoires de façonnage & galets aménagés et bifaces & galets aménagés et bifaces & bifaces et galets aménagés & bifaces et galets aménagés & galets aménagés et bifaces \\
\hline Outillage lourd dominant & galets aménagés unifaciaux $(55 \%)$ & galets aménagés unifaciaux $(50 \%)$ & $\begin{array}{c}\text { galets aménagés variés dont } \\
\text { pics }\end{array}$ & $\begin{array}{l}\text { galets aménagés unifaciaux } \\
(40 \%)\end{array}$ & $\begin{array}{l}\text { galets aménagés unifaciaux } \\
(90 \%)\end{array}$ \\
\hline Biface type & base réservée opposée à pointe & base réservée opposée à pointe & $\begin{array}{l}\text { base réservée opposée à pointe, } \\
\text { souvent à pans latéraux abrupts }\end{array}$ & $\begin{array}{c}\text { base réservée opposée à pointe } \\
\text { (dont } 1 \text { lancéolé) }\end{array}$ & base réservée opposée à pointe \\
\hline Dimensions & autour de 10 à $15 \mathrm{~cm}$ & $<15 \mathrm{~cm}$ et souvent $<10 \mathrm{~cm}$ & autour de 10 à $15 \mathrm{~cm}$ & autour $10 \mathrm{~cm}$ & souvent $<10 \mathrm{~cm}$ \\
\hline Finition & $\begin{array}{c}\text { biface partiel (façonnage "mixte- } \\
\text { combiné"), façnnage limité à la } \\
\text { phase de mise en forme, sans } \\
\text { adjonction d'une phase de } \\
\text { confection sauf } 1 \text { exemplaire } \\
\text { attestant d'une possible percussion } \\
\text { tendre } \\
\end{array}$ & $\begin{array}{c}\text { biface partiel, façonnage limité à la } \\
\text { phase de mise en forme, avec } \\
\text { adjonction d'une phase de confection } \\
\text { pour plusieurs exemplaires attestant } \\
\text { d'une percussion tendre }\end{array}$ & $\begin{array}{c}\text { biface partiel, façonnage limité à } \\
\text { la phase de mise en forme, sans } \\
\text { adjonction d'une phase de } \\
\text { confection }\end{array}$ & $\begin{array}{c}\text { biface partiel, façonnage limité à } \\
\text { la phase de mise en forme, } \\
\text { sans adjonction d'une phase de } \\
\text { confection sauf } 1 \text { exemplaire } \\
\text { attestant d'une percussion } \\
\text { tendre }\end{array}$ & $\begin{array}{c}\text { biface partiel, façonnage limité à } \\
\text { la phase de mise en forme, } \\
\text { sans adjonction d'une phase de } \\
\text { confection }\end{array}$ \\
\hline Hachereau & 2 (type 0) & 2 (type 0 ) & 1 (atypique) & 0 & 1 (type 2, mais en schiste) \\
\hline Dimensions & $13 \mathrm{et} 10 \mathrm{~cm}$ & $12 \mathrm{~cm}$ & $13 \mathrm{~cm}$ & & $13 \mathrm{~cm}$ \\
\hline Galets à chant épannelé & + & + & + & + & ++ \\
\hline \begin{tabular}{|l|} 
Part outils façonnés/retouchés \\
\end{tabular} & $63 / 37 \%$ & $55 / 45 \%$ & $88,9 / 11,1 \%$ & $56,5 / 43,5 \%$ & $42,4 / 57,6 \%$ \\
\hline Outil dominant & chopper/biface & chopper & biface & chopper/biface & chopper \\
\hline Outil retouché & $\begin{array}{c}\text { rare et peu diversifié } \\
\text { (denticulés/encoches et racloirs) }\end{array}$ & $\begin{array}{l}\text { rare et peu diversifié (denticulés et } \\
\text { racloirs) }\end{array}$ & $\begin{array}{l}\text { très rare et peu diversifié } \\
\text { (encoche et racloir) }\end{array}$ & $\begin{array}{l}\text { très rare et peu diversifié } \\
\text { (denticulés/encoches et } \\
\text { racloirs) }\end{array}$ & $\begin{array}{c}\text { très rare et peu diversifié } \\
\text { (denticulés/racloirs dont grands } \\
\text { racloirs) }\end{array}$ \\
\hline Technocomplexe & Moustérien? & Moustérien - Vasconien & Acheuléen? & Moustérien & Moustérien \\
\hline $\begin{array}{l}\text { Chronostratigraphie du dépôt limoneux } \\
\text { encaissant }\end{array}$ & MIS5-MIS3 & MIS3 & MIS6-MIS5? & fin MIS5 & MIS4-MIS3 \\
\hline
\end{tabular}

- FIGURE 31 -

Tableau comparatif de plusieurs sites sur la base exclusive de la matière première Site comparison on the basis of main raw materials presence. dominante dans chacune des séries (A. Taylor, S. Bernard-Guelle).

\section{RÉFÉRENCES BIBLIOGRAPHIQUES}

ALIMEN H. 1953 - Pétrographie des nappes alluviales de la Bigorre. Essai de corrélation et de chronologie. Bulletin S.G.F., 6, III, p. 377-391, 4 fig.

ALIMEN H. 1964 - Le Quaternaire des Pyrénées de la Bigorre. Mém. Serv. Carte géol. Fr., 394 p.

BEAGUE-TAHON N., FOURLOUBEY C., BERTRAN P., COLONGE D. 2014 - Artère de l'Adour - Bassussarry, Ustaritz, Villefranque, Mouguerre, Briscous, Urt, Bardos (64), Misson, Estibeaux, Mouscardes, Tilh, Pomarez, Castel-Sarrazin, Bastennes, Gaujacq, Brassempouy, Saint-Crica Chalosse, Serreslous et Arribans, Hagetmau, Horsarriue : rapport de diagnostic. Bègles: INRAP GSO, 2 vol., 343 et 42 p.

BERNARD-GUELLE S., RUÉ M., FERNANDES P., COUDENNEAU A., COURTY M.-A., FEDOROFF N., DAWSON M.-C., TACUSSEL P., SERONIE-VIVIEN M. et M.-R. 2010 - Le site paléolithique moyen de "Latrote " Saint-Gein, Aquitaine, Landes (40). Rapport Final d'Opération de fouille archéologique. Villard-de-lans: Paléotime, 3 vol., 358 p.
BERNARD-GUELLE S., RUÉ M., FERNANDES P., COUDENNEAU A., COURTY M.A., FEDOROFF N., SÉRONIE-VIVIEN M. et M.-R., PICAVET R., AIRVAUX J. et M.-C. DAWSON 2014 Comportements techniques et stratégies de subsistance sur le site moustérien de plein air de Latrote (Saint-Gein, Landes), in: Actes du XXVIle Congrès préhistorique de France - "Transition, rupture et continuité en Préhistoire », Session E - Exploitation des ressources organiques à la fin du Paléolithique moyen et au début du Paléolithique supérieur: interactions entre environnement et comportements techniques, Bordeaux - Les Eyzies, 31 mai - 05 juin 2010, p. 229-255.

BERNARD-GUELLE B., TAYLOR A., RUÉ M., FERNANDES P., AJAS A., COUDENNEAU A., HERNANDEZ M., MERCIER M. 2018 - Le site stratifié du Bois Clair à Montguyon (Charente-Maritime, France) : récurrences paléolithiques, brièveté des occupations et aires de débitage spécialisées. Paléo, 28, p. 31-69.

BERNARD-GUELLE S., TALLET P., AJAS A., BOUFFARD L., CHASSAN N., CHESNAUX L., FERNANDES P., GRIGGO C., KREUTZER S., MERCIER N., MINET T., MONIN G., RUÉ M., VIALLET C. 2019 - Saint-Sulpice-la-Pointe, Le Bois de l'Hôpital (Tarn). Rapport final d'opération, fouille préventive, Service Régional de l'Archéologie Midi-Pyrénées, Toulouse, Paléotime, 3 vol., 1155 p. 
BERTRAN P., LENOBLE A., LACRAMPE F., BRENET M., CRETIN C., MILOR F. 2005 - Le site aurignacien de plein-air de Combemenue à Brignac-la-Plaine (Corrèze) : apport de la géoarchéologie et de l'étude de l'industrie lithique à la compréhension des processus taphonomiques. Paleo, 17, p. 7-29.

BERTRAN P., BATEMAN M. D., HERNANDEZ M., MERCIER N., MILLET D., SITZIA L., TASTET J.-P. 2011 - Inland aeolian deposits of south-west France: facies, stratigraphy and chronology. Journal of Quaternary Science, 26, 4, p. 374-388.

BERTRAN P., LENOBLE A., TODISCO D., DESROSIERS P., SØRENSEN M. 2012 - Particle size distribution of lithic assemblages and taphonomy of Paleolithic sites. Journal of Archaeological Science, 39, p. 3148-3166.

BERTRAN P., ANDRIEUX E., ANTOINE P., COUTARD S., DESCHODT L., GARDERE P., HERNANDEZ M., LEGENTIL C., LENOBLE A., LIARD M., MERCIER N., MOINE O., SITZIA L., VAN VLIET-LANOË B. 2013 - Distribution and chronology of Pleistocene permafrost features in France: Database and first results: Pleistocene permafrost features in France, Boreas, p. 699-711.

BOËDA E. 1993 - Le débitage Discoïde et le débitage Levallois récurrent centripète. Bulletin de la SPF, 90, p. 392-404.

BORNAND M. 1978 - Altération des matériaux fluvio-glaciaires, genèse et évolution des sols des terrasses quaternaires dans la moyenne vallée du Rhône. Thèse Doctorat d'Etat, Publication du SES, INRA-Montpellier, n²44, 329 p.

CAPDEVILLE J.-P., DARBOUX F., MILLET D. MILLET F. 1998 Carte géologique de la France à 1/50 000, feuille d'Airesur-l'Adour (n979), BRGM, Orléans, notice de 51 p.

CHOPIN J.-F., BERTRAN P., COLONGE D. 2010 - Autoroute A65, Section 4 : rapport de section. Pessac : INRAP GSO, 1 vol., $328 \mathrm{p}$.

CHOPIN J.-F., BERTRAN P., BRENET M. 2015 - Garlin, Diffuseur autoroutier A65, ZAEI de Garlin Pyrénées, rapport de diagnostic. Bègles : INRAP GSO, 1 vol., 144 p.

CLAUD E., DESCHAMPS M., COLONGE D., MOURRE V., THIEBAUT C. 2015 - Experimental and functional analysis of late Middle Paleolithic flake cleavers from southwestern Europe (France and Spain), Journal of Archaeological Science, 62, p.105-127.

CLEMENTE CONTE I., GIBAJA BAO J.-F. 2009 - Formation of use-wear traces in non-flint rocks : the case of quartzite and rhyolite, differences and similarities. In: Sternke, F., Eigeland, L., Costa, L.-J. (eds.) - Non-Flint Raw Material Use in Prehistory. Old Prejudices and New Directions. Oxford: BAR International Series, vol. 1939, p. 93-98.

COLONGE D. 2013 - Bayonne (64), Avenue du Prissé, Chemin d'llbos : rapport de diagnostic. Pessac : INRAP GSO, 1 vol., $63 \mathrm{p}$.

COLONGE D. 2014 - Bayonne, (64), 9 chemin d'Ilbos : rapport de diagnostic. Bègles : INRAP GSO, 1 vol., 51 p.
COLONGE D., MOURRE V. 2009 - Quartzite et quartzites, aspects pétrographiques, économiques et technologiques des matériaux majoritaires du Paléolithique ancien et moyen du Sud-Ouest de la France. In : Grimaldi (S.), Cura (S.) (dir.) - Technological analysis on quartzite exploitation - Analyse technologique de l'exploitation du quartzite. Session WS15, XVIème Congrès de l'UISPP - Lisbonne, septembre 2006. Oxford: Archaeopress, BAR International Series 1998, p. 3-12, 2 fig.

COLONGE D., DELFOUR G., FONDEVILLE C., JARRY M., avec la collaboration de ARNOUX T., BERTHET A.-L. 2002 - Raspide 2 (Blagnac, Haute-Garonne). Rapport Final d'Opération de diagnostic archéologique. Toulouse : INRAP GSO, 83 p.

COLONGE D., JARRY M., DELFOUR G., FONDEVILLE C., ARNOUX T., BERTHET A.-L. 2010 - De la transition paléolithique inférieur-moyen dans la vallée de la Garonne : l'Acheuléen supérieur de Raspide 2 (Blagnac, HauteGaronne). Paris : Bulletin de la SPF, 107, 2, p. 205-225.

COLONGE D., CHALARD P., BILOTTE M., DUCASSE S., PLATEL J.-P. 2011 - Nouvelle découverte d'un gite à silex a Lépidorbitoïdes dans le Sud-Ouest de la France (SaintAubin, Gers) et implications archéologiques, Bulletin de la Société préhistorique française, 108, 3, p. 561-563.

COLONGE D., BERTRAN P., BRENET M., BUSSEUIL N. 2012 A65 - Auriac (64), Duclos - Pléistocène moyen et Antiquité en Béarn : rapport de fouilles. Pessac : INRAP GSO, 1 vol., $475 \mathrm{p}$.

COLONGE D., CLAUD E., DESCHAMPS M., FOURLOUBEY C., HERNANDEZ M., SELLAMI F., ANDERSON L., BUSSEUIL N., DEBENHAM N., GARON H., O'FARELL M. 2014a - Preliminary results from new Palaeolithic open-air sites near Bayonne (south-western France). Quaternary International, p. 1-17.

COLONGE D., HERNANDEZ M., LELOUVIER L.-A., MERCIER N., MOURRE V., BUSSEUIL N. 2014b - Paléolithique ancien et Paléolithique moyen ancien dans le piémont pyrénéen occidental: relations entre les chaînes opératoires, continuités et ruptures, in : Transitions, ruptures et continuité en Préhistoire, Jaubert, J., Fourment, N. et Depaepe, P., (Éds.), Société Préhistorique Française, XXVIIe Congrès Préhistorique de France, Bordeaux - Les Eyzies (31 mai 5 juin 2010), vol. 2, pp. 119-137.

COUTARD J.-P., OZOUF J.-C. 2008 - Nouvelle approche de l'altération des galets de silex dans les dépôts marins Pléistocènes : contribution à l'étude des plates-formes marines du val de Saire (Normandie, France). Quaternaria, 19, 4, p. 335-344.

DEFAYE S., BERTRAN P., COLONGE D., BALLARIN C., LAGORSSE K., RÉCHIN F. 2009a - A65 - Le Vignau, Cazèressur-l'Adour, Aire-sur-l'Adour: rapport de diagnostic. Rapport de section - section 3B. Pessac : INRAP GSO, 1 vol., $217 \mathrm{p}$.

DEFAYE S., BERTRAN P., COLONGE A., MOURRE V. 2009b - A65, Section 3B (Landes, Aquitaine). Rapport Final d'Opération de diagnostic archéologique. Bègles : INRAP GSO, 1 vol., $213 \mathrm{p}$. 
DESCHAMPS M. 2014 - La diversité culturelle au Paléolithique moyen récent: le Vasconien et sa signification au sein des faciès moustériens. Thèse de doctorat, Université Toulouse 2, 1 volume, 589 p.

DESCHAMPS M. 2016 - Late Middle Palaeolithic assemblages with flake cleavers in the western Pyrenees: The Vasconian reconsidered. Quaternary International, p. 1-17.

FERNANDES P. 2012 - Itinéraires et transformations du silex: une pétroarchéologie refondée, application au Paléolithique moyen. Thèse de doctorat, Université Bordeaux 1, 623 p.

FOURLOUBEY C. 2012 - Bayonne (64), chemin de Jupiter 4 : rapport de diagnostic. Pessac : INRAP GSO, 1 vol., 55p.

FOURLOUBEY C., SELLAMI F. 2008 - Bayonne: Prissé Haut, Chemin de Jupiter : rapport de diagnostic. Pessac : INRAP GSO, 1 vol., 97 p.

FOURLOUBEY C., SELLAMI F. 2009 - Bayonne, avenue du Prissé : rapport de diagnostic. Pessac : INRAP GSO, 1 vol., $53 \mathrm{p}$

FOURLOUBEY C., CHALARD P., BERTRAN P., CLAUD E. 2013 A65 - Cazère-sur-l'Adour (40), Septsos, Acheuléen de plein air dans la vallée de l'Adour: Rapport de fouille. Pessac: INRAP GSO, 1 vol., 289 p.

GALBRAITH R.F., ROBERTS R.G., LASLETT G.M., YOSHIDA H., OLLEY J.M., 1999 - Optical dating of single and multiple grains of quartz from Jinmium rock shelter, northern Australia: Part I, Experimental design and statistical models. Archaeometry, 41 (2), p. 339-364.

HERNANDEZ M., MERCIER N., BERTRAN P., COLONGE D., LELOUVIER L.-A. 2012 - Premiers éléments de datation des industries du Pléistocène moyen (Acheuléen Paléolithique moyen ancien) de la région pyrénéo-garonnaise : une approche géochronologique pluri-méthodes ( $T L, O S L$ et TT-OSL) des sites de Duclos et Romentères. Paleo, 23, p. 155-170.

HUE E. 1929 - Recherches sur la patine des silex. Paris : Bulletin de la Société préhistorique française, 26 (9), p. 461-468.

ICOLE M. 1970 - Une nouvelle méthode pour la paléopodologie du Pliocène et du Villafranchien des Pyrénées centrales: l'étude des galets de quartzite à cortex d'altération. Bulletin de l'Association française pour l'étude du Quaternaire, 7, 2, p. 135-143.

JARRY M., COLONGE D., LELOUVIER L.-A., MOURRE V. (dir.) 2007 - Les Bosses (Lamagdelaine, Lot, France) : un gisement paléolithique moyen antérieur à l'avant-dernier Interglaciaire sur la moyenne terrasse du Lot. SPF, Travaux, $n^{\circ} 7,158 p$

JARRY M. 2010 - Les groupes humains du Pléistocène moyen et supérieur en Midi toulousain : contextes, ressources et comportements entre Massif Central et Pyrénées. Thèse de doctorat, Université Toulouse II - le Mirail, $470 \mathrm{p}$.
JARRY M., LELOUVIER L.-A. 2014 - Façonnage et débitage en Midi toulousain du Paléolithique inférieur au Paléolithique moyen : changements et continuités, in : Transitions, ruptures et continuité en Préhistoire, Jaubert, J., Fourment, N. et Depaepe, P., (Éds.), Société Préhistorique Française, XXVIIe Congrès Préhistorique de France, Bordeaux - Les Eyzies (31 mai - 5 juin 2010), vol. 2, p. 103-118.

KARNAY G., DUBREUILH J., MAUROUX B., CHATEAUNEUF J.-J. 1998 - Carte géologique de la France à 1/50 000, feuille de Lembeye ( $\left.n^{\circ} 1005\right)$, BRGM, Orléans, notice de 50 p.

LELOUVIER L.-A., CHALARD P., BERTRAN P., DEFAYE S., DAYRENS O., BUSSEUIL N. 2013 - A65 - Le Vignau (40), Romentères, un site du Pléistocène moyen sur les hautes terrasses de l'Adour: Rapport de fouille. Pessac: INRAP GSO, 1 vol., 363 p.

MILLET D., MILLET F. 2010 - Paléolithique inférieur et moyen dans les vallées du Luy de France, du Gabas, du Lèes et sur la bordure méridionale de la nappe de Limendous (64). Notice du Bilan Scientifique Régional d'Aquitaine 2008. Bordeaux : Service Régional de l'Archéologie, p. 157-158.

MINET T. 2013 - L'exploitation des silex au paléolithique ancien et moyen dans l'avant-pays nord-pyrénéen : approche gîtologique, pétroarchéologique et techno-économique. Mémoire de Master 2 mention Histoire, histoire de l'art et archéologie, vol 1, 80 p

MOURRE V. 1996 - Le débitage sur enclume au Paléolithique inférieur et moyen - Techniques, méthodes et schémas conceptuels. Article de DEA, Université de Paris X-Nanterre, $55 \mathrm{p}$.

MOURRE V. 2003a - Discoïde ou pas Discoïde ? Réflexions sur la pertinence des critères techniques définissant le débitage Discoïde. In : PERESANI (M.) (dir.) - Discoid Lithic Technology - Advances and implications. Oxford : Archaeopress, BAR International Series, 1120, p. 1-18.

MOURRE V. 2003b - Implications culturelles de la technologie des hachereaux, thèse de doctorat, Université de Paris X-Nanterre, 3 vol., 880 p.

MOURRE V. 2004 - Le débitage sur enclume au Paléolithique moyen dans le Sud-Ouest de la France. In : VAN PEER (P.), BONJEAN (D.), SEMAL (P.) (Eds) - Session 5 : Paléolithique moyen, Actes du XIVème Congrès de l'UISPP, Liège, 2-8 sept. 2001. Oxford: Archaeopress, BAR International Series, 1239, p. 29-38.

MOURRE V. 2006 - Emergence et évolution de la prédétermination au Paléolithique. In : ASTRUC L., BON F., LÉA V., MILCENT P.-Y., PHILIBERT S. (dir.) - Normes techniques et pratiques sociales. De la simplicité des outillages pré-et protohistoriques, XXVIe rencontres internationales d'archéologie et d'histoire d'Antibes. Antibes : Éditions APDCA, p. $61-74$

MOURRE V., COLONGE D. 2007 - Et si l'Acheuléen méridional n'était pas là où on l'attendait... In : EVIN (J.) (dir.) - Congrès du Centenaire: un siècle de construction du discours scientifique en Préhistoire. Volume 3: "... Aux conceptions d'aujourd'hui », actes du XXVIe congrès préhistorique de France - Avignon, 21-25 septembre 2004. Paris : Société Préhistorique Française, p. 63-78. 
MURRAY A.S., WINTLE A.G. 2000 - Luminescence dating of quartz using an improved single-aliquot regenerative-dose protocol. Radiation Measurements, 32 (1), p. 57-73.

PEDERGNANA A., OLLE A. 2017 - Monitoring and interpreting the use-wear formation processes on quartzite flakes through sequential experiments. Quaternary International, 427, p. 35-65.

SERONIE-VIVIEN M.-R. 2009 - Répartition géographique des différents types de silex a lépidorbitoïdes utilisés au Paléolithique supérieur en Aquitaine. Première contribution: Dordogne (Caminade), Lot (Le Piage - Pegourie Cloup de l'Aze), Gironde (Beauregard), Bulletin de la Société préhistorique française, 106, p. 293-296.

SERONIE-VIVIEN M.-R. 2010 - Le silex a Lépidorbitoïdes en Aquitaine. État de la question, in BRESSY C., GREGOIRE S., BAZILE F. (dir.) Silex et territoires préhistoriques. Avancées des recherches dans le Midi de la France. Actes de la table ronde de Lattes (13-14 juin 2008), Les C@hiers de Geopre, 1, p. 31-37.

SITZIA L., BERTRAN P., BAHAIN J.-J., BATEMAN M.D., HERNANDEZ M., GARON H., DE LAFONTAINE G., MERCIER N., LEROYER C., QUEFFELEC A., VOINCHET P. 2015 - The Quaternary Coversands of Southwest France. Quaternary Science Reviews, 124, p. 84-105.

SPINAPOLICE E., RUÉ M., BERNARD-GUELLE S., FEDOROFF N., MARTINEAU A.-S., SCHWENNINGER J.-L., 2010 - Le site acheuléen de Bénazit 1, Cazères-sur-l'Adour (Landes). RFO fouille préventive, Villard-de-Lans, Paléotime, SRA Aquitaine, 3 vol., 302 p.

TAYLOR A., BERNARD-GUELLE S., CHESNAUX L., FÉNÉON L., FERNANDES P., RUÉ M. 2017 - «L'industrie sur quartzite de Garlin, «ZAEI Garlin - Pyrénées», Rapport final d'opération, Paléotime, Service Régional de l'Archéologie d'Aquitaine, $320 \mathrm{p}$.

TEXIER J.-P., BERTRAN P. 1990 - L'enregistrement des phénomènes pédo-sédimentaires et climatiques. L'exemple de la coupe des Tares (Dordogne). Quaternaire, 1, 1, p. 77-90.
TIXIER J. 1956 - Le hachereau dans l'Acheuléen nord-africain. Notes typologiques, Congrès préhistorique de France, Compte rendu de la XVe session, Poitiers-Angoulême, 1522 juillet 1956, Paris: Société Préhistorique Française, p. 914-923.

THIEBAUT C., CLAUD E., COSTAMAGNO S., COUDENNEAU A., COUMONT M.-P., DESCHAMPS M., GERBE M., MALLYE J.-B., MOURRE V., ASSELIN G., BRENET M., CHACON M.G., COLONGE D., LEMORINI C., PARAVEL B., PROVENZANO N., SERVELLE C., SOULIER M.-C. 2009 - Des Traces et des Hommes: Projet de recherche interdisciplinaire sur l'identification des modalités d'acquisition et de traitement des matières végétales et animales au Paléolithique moyen en Europe occidentale, rapport annuel du PCR (Programme 3). Service Régional de L'Archéologie de Toulouse : 2009, 218 p.

THIÉBAUT C., CLAUD E., COSTAMAGNO S., COUDENNEAU A., DESCHAMPS M., MOURRE V., VAL A., BRENET M., CHACON G., CHONG S., COUMONT M.-P., COLONGE D., GERBE M., ASSELIN G., MUSSINI C., SOULIER M.-C. 2011 - Des traces et des Hommes. Projet de recherche interdisciplinaire sur l'identification des modalités d'acquisition et de traitement des matières végétales et animales au Paléolithique moyen en Europe occidentale, Rapport annuel, Service Régional de l'Archéologie, 280 p.

VIGNARD E., VACHER G. 1964 - Altérations des silex préhistoriques de Neumours sous l'influence des climats qui se sont succédés du Périgordien Gravettien au tardenoisien locaux. Paris: Bulletin de la Société Préhistorique Française, Études et travaux, 61, 1,. p. 45-55.

WHALLON R. 1973 - Spatial analysis of occupation floors I: application of dimensional analysis of variance. American Antiquity, 38, 1, p. 266-278. 
